YOUTUBE AS AN EARLY CHILDHOOD MUSIC EDUCATION RESOURCE:

PARENTAL ATTITUDES, BELIEFS, USAGES, AND EXPERIENCES

A Dissertation presented to

the Faculty of the Graduate School at the University of Missouri-Columbia

In Partial Fulfillment

of the Requirements for the Degree

Doctor of Philosophy

by

MICHELLE Y. KO

Dr. Wendy L. Sims, Dissertation Supervisor

DECEMBER 2018 
(C) Copyright by Michelle Ko 2018

All Rights Reserved 
The undersigned, appointed by the dean of the Graduate School, have examined the dissertation entitled

\section{YOUTUBE AS AN EARLY CHILDHOOD MUSIC EDUCATION RESOURCE:}

\section{PARENTAL ATTITUDES, BELIEFS, USAGES, AND EXPERIENCES}

presented by Michelle Y. Ko, a candidate for the degree of doctor of philosophy, and hereby certify that, in their opinion, it is worthy of acceptance.

Professor Wendy L. Sims

Professor Brian A. Silvey

Professor Brandon Boyd

Professor Alice Dade

Professor Kathleen Unrath 
This work is dedicated to my biggest cheerleaders, Mia and Paul.

To my mom, because her overflowing love, support, and encouragement have sustained me throughout my life.

To my husband, for his devotion, patience, and unwavering support during the last five years.

"Do not go where the path may lead, go instead where there is no path and leave a trail." -Ralph Waldo Emerson 


\section{ACKNOWLEDGEMENTS}

First and foremost, I would like to thank Dr. Wendy Sims for believing in me. This work would not have been possible with her guidance and bottomless support during my doctoral studies. Thank you for being a fantastic mentor, teacher, inspiration, and shining example of a scholar.

I also want to express my appreciation to my committee members, Dr. Brian Silvey, Dr. Brandon Boyd, Dr. Kathleen Unrath, and Professor Alice Dade, whose expertise and enthusiasm fueled my curiosity during this dissertation process. Thank you for challenging me to expand my understanding of music education research and pushing my thinking as an artist, musician, teacher, and scholar.

To my graduate colleagues, especially Chris, Jordan, Cynthia, Aaron, and Laura. Thank you all for your friendship, encouragement, and pre-seminar coffee hangouts.

Sincere thanks to Dr. E. Michael Richards- thank you for taking me under your wing. You were instrumental in my career path and decision to pursue a doctorate.

Finally, I want to thank my family. My most heartfelt thanks to my parents, Richard and Mia Ko, who taught me to shoot for the stars, for making my dreams their dreams, for instilling a love of learning, and for faithfully supporting me ever since the day I was born. Also, thank you to my wonderful bonus parents, Yong and Byong Kim, and sister, Nancy, for their love and support in this process.

Most importantly, I wish to thank my loving and supportive husband, Paul, for going on this crazy journey with me. I truly could not have done this without you. Joey and Matty, thank you for always providing mommy with laughter, cuddles, and inspiration. You guys are my world and I hope I made you proud (:) 


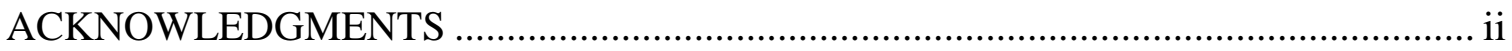

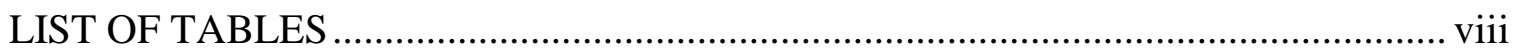

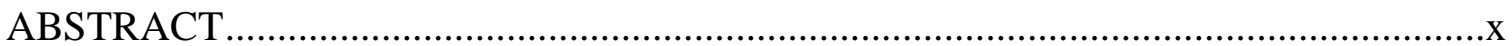

\section{Chapter}

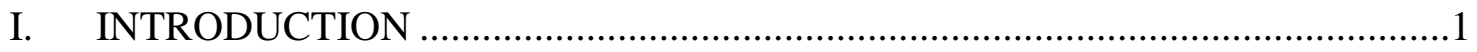

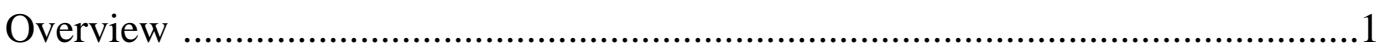

Music in the Home ……...................................................................................

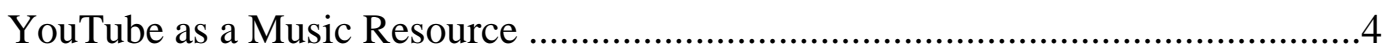

Statement of Purpose ………………….......................................................

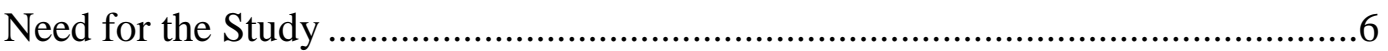

Conceptual and Theoretical Considerations …………......................................

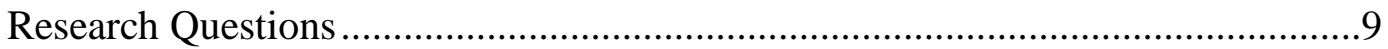

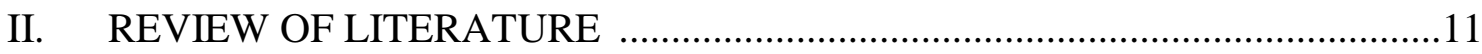

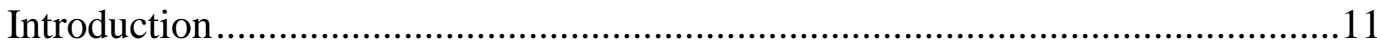

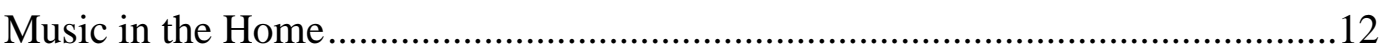

Describing the Early Childhood Home Music Environment ...................................13

Digital Home Music Environment ....................................................................15

Defining Digital Home Music Environment.......................................................16

Music Material Selection .............................................................................17

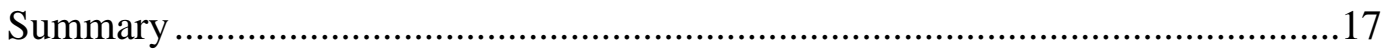

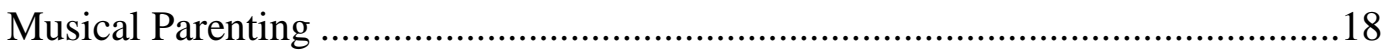

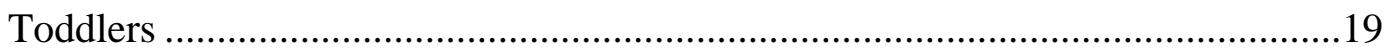




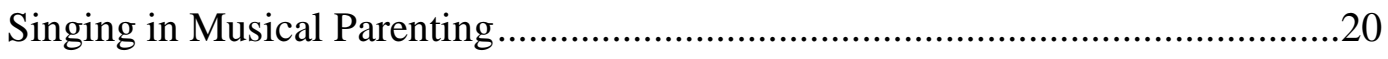

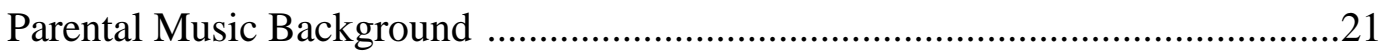

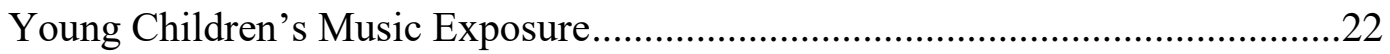

Digital Musical Parenting .............................................................................23

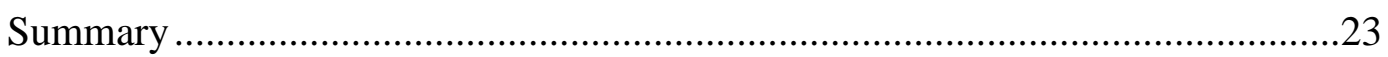

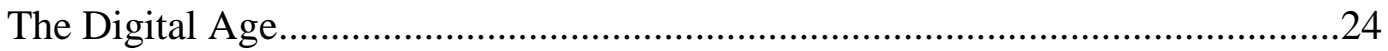

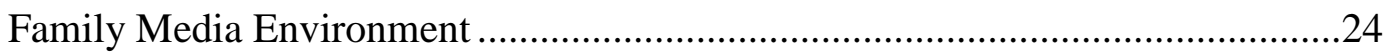

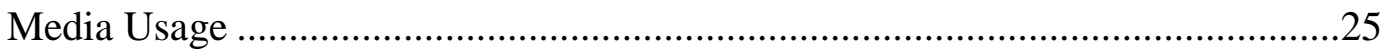

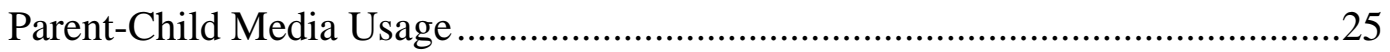

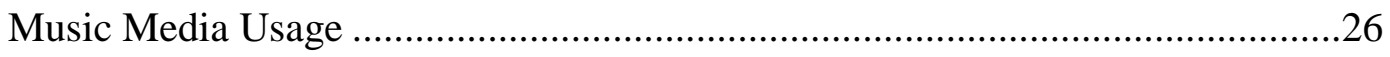

National Media Guidelines and Recommendations............................................27

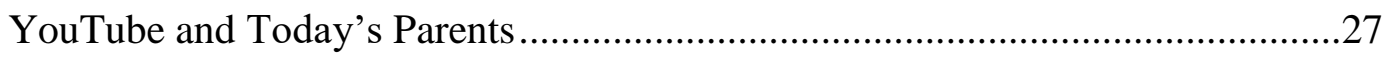

YouTube and Families ............................................................................28

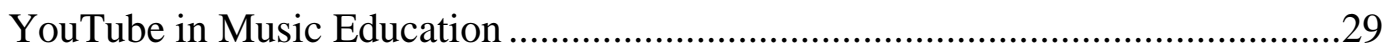

Parental Attitudes Towards Children's Media Usage..............................................30

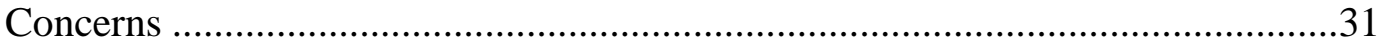

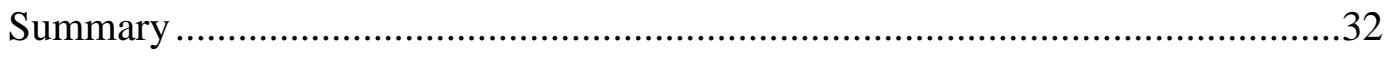

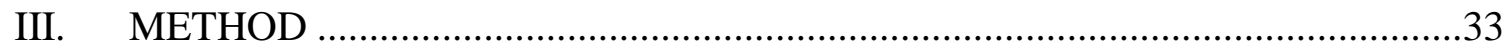

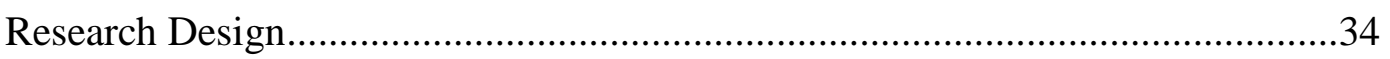

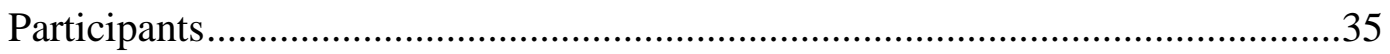

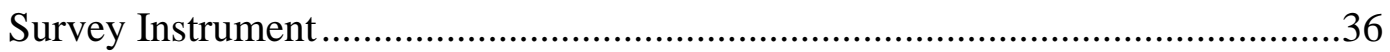

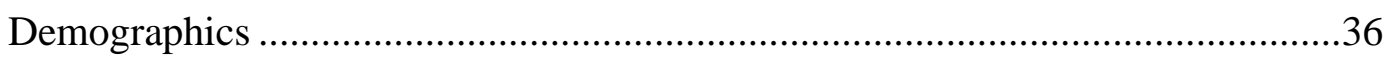

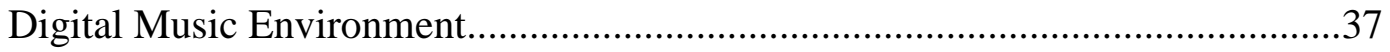




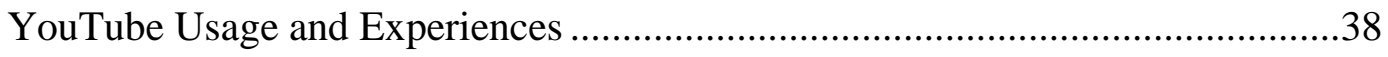

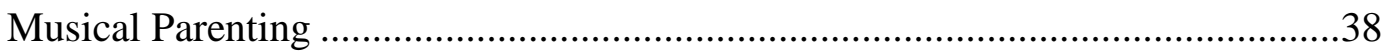

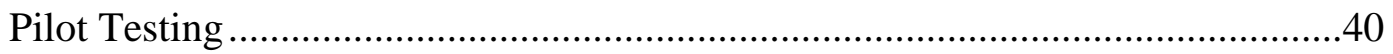

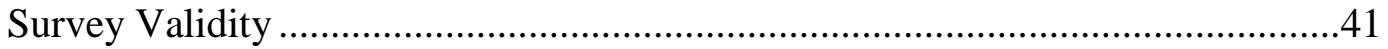

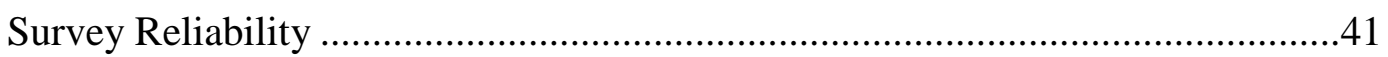

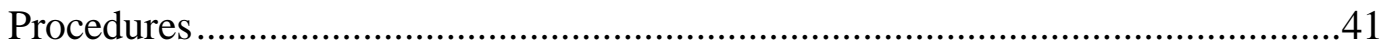

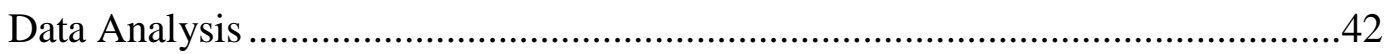

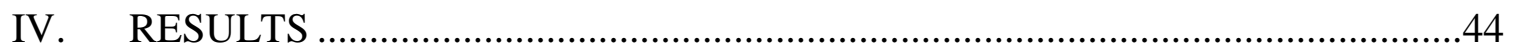

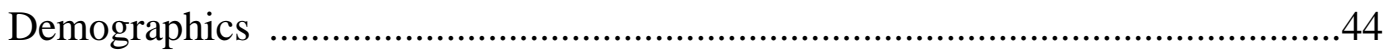

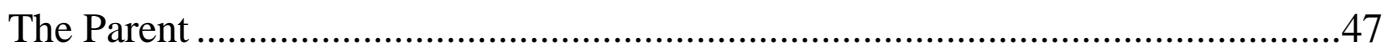

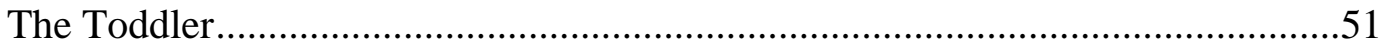

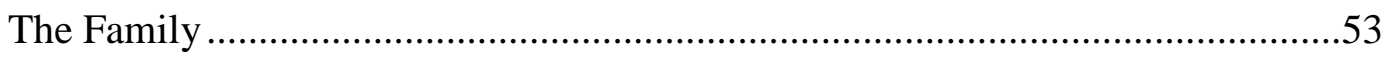

Music Backgrounds of Parents .....................................................................56

Digital Home Music Environment ...................................................................5

YouTube Music Usage and Purposes ................................................................62

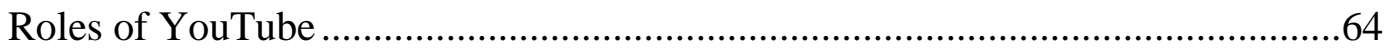

YouTube Music Experiences ........................................................................72

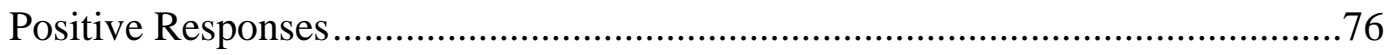

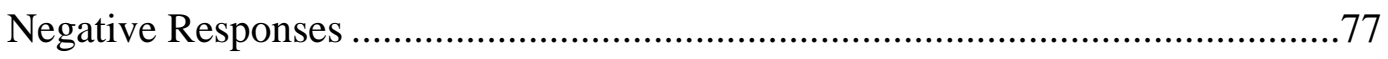

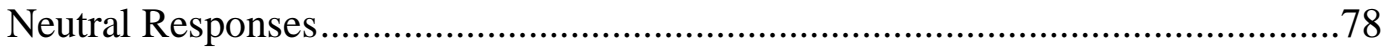

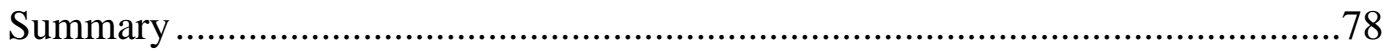

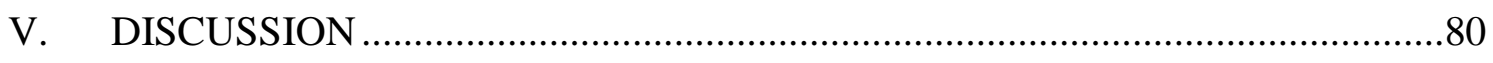

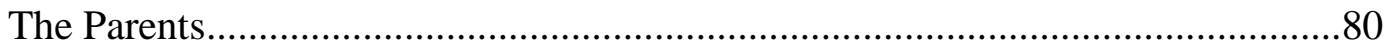




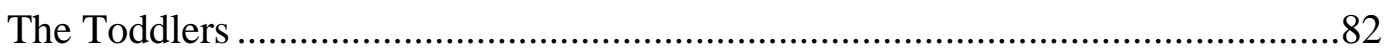

Characteristics of the Digital Home Music Environment.....................................82

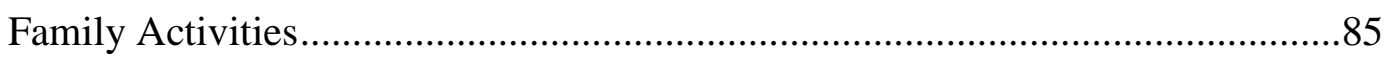

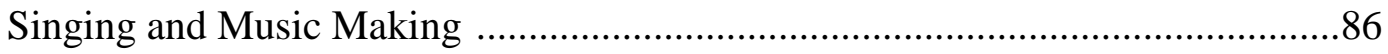

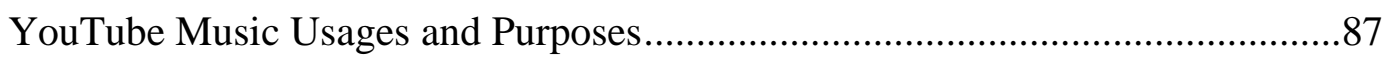

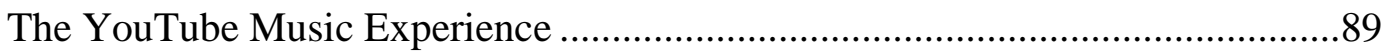

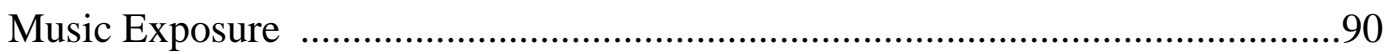

Characteristics of Digital Musical Parenting …………....................................91

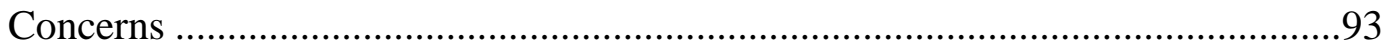

Musical Parenting Resources .......................................................................95

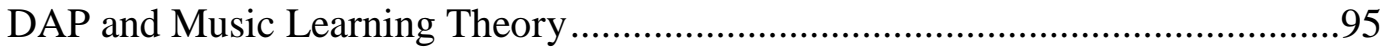

Gordon's Theory and YouTube Music Experiences .............................................97

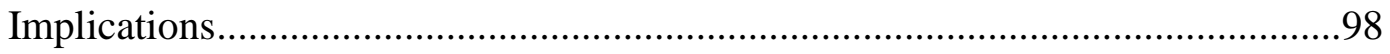

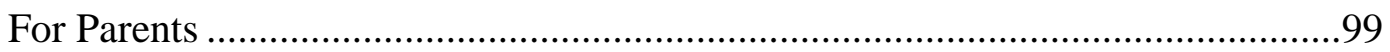

Establishing YouTube Guidelines ..................................................................99

Developmental Appropriateness ................................................................102

Limitations and Additional Suggestions for Research.........................................102

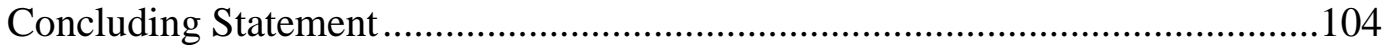

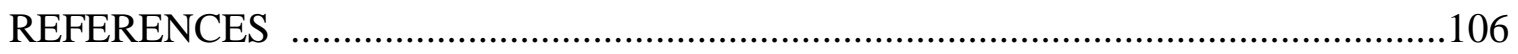

Appendix

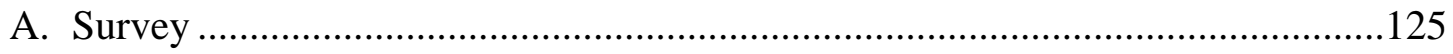

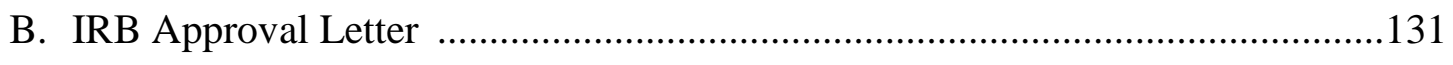

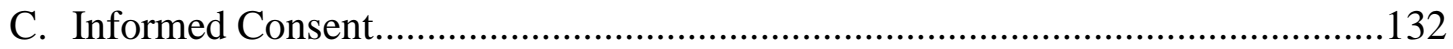


D. Recruitment Script

E. Social Media Recruitment Script

F. Purposes of YouTube Comments

G. Children's Response to YouTube Comments 136

H. Favorite YouTube Music Channels Comments ...................................................137

I. YouTube as a Music Education Resource Comments. 138

J. Response Percentages from a Previous National Survey and Comparison 141

K. Recruitment Post Comments

L. YouTube Guidelines and Suggestions

VITA 
Tables

\section{LIST OF TABLES}

1. Frequencies and Percentages of Respondents' States..........................................45

2. Frequencies and Percentages of Respondents' Ethnic Backgrounds.......................47

3. Frequencies and Percentages of Respondents' Marital Statuses .............................48

4. Frequencies and Percentages of Respondents' Highest Levels of Education..............49

5. Frequencies and Percentages of Spouse's Highest Level of Education .....................50

6. Frequencies and Percentages of Family Income Levels .......................................51

7. Frequencies and Percentages of Children's Ages .............................................52

8. Frequencies and Percentages of Children's Birth Orders ......................................53

9. Frequencies and Percentages of Family Childcare Arrangements ...........................54

10. Frequencies and Percentages of Parent-Reported Children's Characteristics .............55

11. Frequencies and Percentages of Parents' Perceived Music Ability............................56

12. Frequencies and Percentages of Parental Music Backgrounds ...............................57

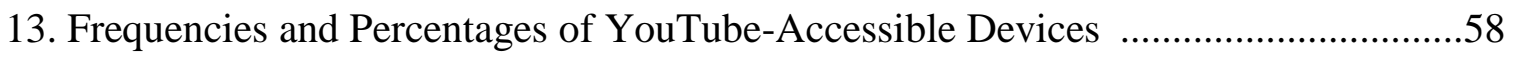

14. Frequencies and Percentages of Family Pastimes ...............................................60

15. Frequencies and Percentages of Family Music Making and Parental Music Background ...................................................................61

16. Frequencies and Percentages of Parents Accessing YouTube Music........................62

17. Family Income Level versus Frequency of YouTube Access ................................63

18. Frequencies and Percentages of YouTube Music Purposes ....................................64

19. Frequency and Percentage of Musical Parenting Statement ..................................65

20. Frequencies and Percentages of Musical Parenting Resource Usage ........................67

21. Frequencies and Percentages of Digital Musical Parenting Statements ...................69 
22. Frequencies and Percentages of Parental Beliefs and Attitudes Towards YouTube Music

23. Frequencies and Percentages of Perceived YouTube Effects on Development

24. Frequencies and Percentages of Selection Process .

25. Frequencies and Percentages of Children's Responses to YouTube Music Videos....74

26. Favorite YouTube Music Education Channels 


\title{
YOUTUBE AS AN EARLY CHILDHOOD MUSIC EDUCATION RESOURCE: PARENTAL ATTITUDES, BELIEFS, USAGES, AND EXPERIENCES
}

\author{
Michelle Y. Ko
}

Dr. Wendy Sims, Dissertation Supervisor

\begin{abstract}
This descriptive study was designed with two main purposes: (a) to provide researchers and educators with baseline information about current YouTube music usages and practices and (b) to examine parental attitudes and beliefs towards YouTube as a music education resource. One hundred ninety-two $(N=192)$ parents of toddler-age children (16-to-36 months old) participated in a researcher-constructed survey designed to examine the digital home music environment, digital musical parenting, and parentchild YouTube music experiences. Results indicated that parents accessed YouTube regularly, maintained positive attitudes towards YouTube, and considered YouTube to be an effective resource for children's overall learning and music skills. Data suggested that children engage with and respond to digital music in various ways, and parental beliefs about YouTube were multi-faceted. Findings suggested a need for accessible musical parenting guidelines and resources in this YouTube generation.
\end{abstract}




\section{CHAPTER 1}

\section{Introduction}

The first three years are critical to all aspects of a child's development. According to information provided by the National Association for the Education of Young Children (NAEYC, 2018), from birth to three years old, infants and toddlers seek security and opportunities to explore and learn about their identity. Gordon (2003) stated, "our potential to learn is never greater than at the moment of birth, and that after that it gradually decreases" (p. 1). The most crucial periods of neurological connections and synapses are believed to occur before and after birth, the peak learning time (p. 2). It is important to establish a strong foundation in the earliest years of life for future learning and development.

Advantages of an early introduction to language and the arts prompted an interest in young children's music education in recent decades. Some benefits, according to music education researchers include: language and reasoning development, memorization mastery, pattern recognition, higher standardized test scores, creative thinking skills, coordination, achievement and confidence, societal success, and spatial intelligence (NAfME, 2014). Supporting this notion, active music classes in infancy have been found to enhance musical, communicative and social development (Gerry, Unrau, \& Trainor, 2012).

\section{Overview}

Children should have plentiful music interactions, experiences, and opportunities in early childhood (NAfME, 2014). Researchers have proposed that music experiences begin as early as birth (Gordon, 2003), and perhaps even in utero (Parncut, 2009). 
Experiences include: singing, listening to music, responding to visual and verbal representations of music, moving, playing instruments, and creating music (NAfME, 2014). In the last three decades, the importance of music in early childhood has been a topic of particular scholarly interest (Andress, 1986). Ilari and Young (2016) stated, "musical engagement, learning, and development not only are by-products of human abilities to perceive and process musical sounds, but also are directly linked to issues of agency, identity, ethnicity, belief systems, and social and cultural values, to name a few" (p. 2). For centuries, music's value and purpose have been questioned and tested; however, empirical evidence has suggested that music education contributes to a pathway of lifelong musical engagement (Pitts, 2016).

Much of early childhood music education (ECME) research has explored areas such as: musical play (Berger \& Cooper, 2003; Niland, 2009); children's musical cultures (Campbell \& Wiggins, 2013), trends in ECME (Bond, 2013; Nardo et al., 2006; Persellin, 2007; Young, 2016); overall music development (Gembris \& Davidson, 2002; Gordon, 2003, 2013), music and movement (Levinowitz, 1998; Phillips-Silver \& Trainor, 2005; Sims, 1985), and music listening (Sims, 1986, 1993, 1995, 2001, 2005; Sims \& Nolker, 2002). More recently, an even broader range of topics have been explored, from music learning and cognitive skills (Costa-Giomi, 2015; Schellenberg, 2005; Trainor, 2005) to music experiences in the car (Koops, 2014).

Research on early childhood music in the classroom setting has offered great insight to and application for classroom teachers, administrators, legislators, parents, and scholars. One exploratory study (Bond, 2012) examined the representation of music in early childhood education journals in a comprehensive review of the literature. She 
organized thirty-eight researcher and practitioner articles thematically, which included: extra-musical benefits, music strategies, musical parenting, musical practices at home, musical lives of children, musical practices at school, and integration. Typically, the age range of children in this body of literature is 3 to 5 years old, or preschool, prekindergarten, and kindergarten children. A smaller body of early childhood music education research exists that has focused on infants and toddlers (birth to three).

Contemporary music education researchers have taken a stronger interest in the birth-to-three age range (Young, 2016). Infants, even in the first days of life, are fully capable, musical beings and responsive to their environments (Adachi \& Trehub, 2012; Trainor \& Hannon, 2013). Infants are naturally predisposed to music activities (Custodero, 2005; Custodero \& Green, 2003) and even show music preferences (Lamont, 2003). Infant music preferences are greatly influenced by the parent or caregiver's musical and cultural interests. Therefore, to examine very young children's engagement with music, it is necessary to take a closer look at the adults in the young children's lives. Authors of a position statement distributed by Zero to Three, a national early childhood organization, stated that young children learn through play, their environment, and most importantly, through interactions with significant adults in their lives (Zero To Three, 2018). Caregiver bonding has been closely linked to behavioral and emotional benefits for the child. The role of the caregiver has been emphasized by child development psychologists like John Dewey, Maria Montessori, Lee Vygotsky, Jean Piaget, and Erik Erikson. Their theories have stated the importance of children learning by doing, and engaging in positive interactions with others and their cultures, and emphasized that primary caregivers play major roles in facilitating these experiences. 
Parents, caregivers, early childhood educators, and the community influence young children's expectations about themselves and others (Copple \& Bredekamp, 2009).

\section{Music in the Home}

Home music environments set the tone for future musical growth and development (Sims \& Udtaisuk, 2008). Bond (2012) stressed the importance of an early introduction to music and quality musical environments. Rich music experiences do not require formal settings, but rather, can be integrated into the daily routine and play of children (NAfME, 2014). Previous studies have examined the music activities of infants and toddlers in their homes (Addessi, 2009; Custodero, Britto, \& Brooks-Gunn, 2003; De Vries, 2009; Kida \& Adachi, 2008) and parental involvement in music education (Berger \& Cooper, 2003; De Grätzer, 1999; Koutsoupidou, 2016). Opportunities to engage musically and play in all types of settings (home, school, community) allow children to learn about their worlds (Ilari, 2016). As children's first teachers, parents are often tasked with the responsibility of providing music experiences. Chapter 2 will examine musical parenting in depth.

\section{YouTube as a Music Resource}

YouTube videos have the potential to be an effective means of disseminating information on a global scale (Whitaker, Orman, \& Yarbrough, 2014). Recent studies have revealed that parents want to interact musically with children, but feel unprepared and uncomfortable in doing so (De Vries, 2009; Koops, 2011, 2012). "Families

worldwide are watching millions of videos on YouTube" (Google Official Blog, 2015). A YouTube search of "toddler music" results in a smorgasbord of lullabies, nursery 
rhymes, classical music, interactive music lessons, and early childhood music classes. Children watching YouTube is a new phenomenon that must be examined.

No previous studies have examined the role of YouTube in young children's music experiences and musical parenting. Today's two year olds can navigate a touch screen as naturally as they play with a new toy (Sharkins et al., 2016). Although there have been conflicting viewpoints on YouTube usage by young children, the National Association for the Education of Young Children (NAEYC) acknowledged the benefits of technology exposure and experiences for infants and toddlers (2018). Today's parents must navigate the world of digital musical parenting. Therefore, to fully understand young children's home music environments, it is necessary to find out how parents use young children's music videos on YouTube, and about their attitudes and beliefs towards YouTube as a musical parenting resource.

\section{Statement of Purpose}

The purpose of this study is to examine the nature of parent-toddler music experiences with YouTube. Parents have become increasingly interested and involved in approaches to support young children's development starting from birth (Zero To Three, 2017). Some may feel more comfortable streaming YouTube as the main source of home music experiences. Unique to today's parents, music resources like YouTube, Spotify, and GoNoodle are easily accessible and readily available on most electronic devices. Few studies have explored the influence of Internet resources on early childhood music education. Information about the nature of YouTube music experiences in a YouTube generation may help educators determine what type of music education resources and/or guidance parents need. 
These findings will be useful because very little is known about the nature of YouTube experiences with the youngest users. Not only will this study propel future research in early childhood music education, it will also be of assistance to scholars, school administrators, parents, and young children.

\section{Need for the Study}

Prior to beginning this study, I noticed that when parents found out I was a music educator specializing in early childhood, they would come up and ask me what they should be doing musically with their toddlers at home. According to the National Association for the Education of Young Children (NAEYC), toddlers are defined as children 16-to-36 months old. I would meet these parents when I was with my own children at local play-dates, playgroups, library story time, and local children's events. I would offer many suggestions, such as singing, short rhythmic games, and movement activities to encourage parent-child music interactions. One day, I took my son to our local library's weekly toddler music and movement program. Parents and children sat on one side of the room facing the screen that was projecting YouTube videos. The repertoire selection consisted of nursery rhymes, hip-hop alphabet songs, and interactive stretching activities. The majority of parents and children were actively engaged in the videos. I was a bit surprised that the entire session was based on YouTube videos, rather than having teacher-led songs, circle time and movement activities. This led to the realization that resources like YouTube are rapidly changing the face of parent-child music experiences.

What is known from the literature is that "media and technology use has become a family affair" (Wartella, Rideout, Lauricella, \& Connell, 2015, p. 30) and that nearly all 
parents have watched YouTube with their toddlers. However, very little is known to researchers and educators about what they are watching and what purpose YouTube serves for families. Children are increasingly exposed to digital technologies at younger ages, and it is crucial to equip parents with the resources to guide them in appropriate digital musical parenting. In 2008, when Sims \& Udtaisuk investigated music's representation in parenting magazines, those publications served as a primary resource for parents. Nowadays, with a multitude of media resources and videos to choose from, digital musical parenting is a new and challenging area to navigate. I am interested in seeing how parents feel about their young children's YouTube usage and how that might contribute to the musical experiences and education of their children. The results of this survey study will be valuable to early childhood music educators, as we seek to find ways to assist parents with providing quality musical experiences for their children.

\section{Conceptual and Theoretical Considerations}

The conceptual framework of this study was drawn upon two pedagogical approaches, Developmentally Appropriate Practice (DAP) (Copple \& Bredekamp, 2009) and Music Learning Theory for Newborn and Young Children (Gordon, 2003). These existing theories have influenced my own thinking and pedagogy, and served as the foundation upon which this research was constructed and analyzed.

Developmentally Appropriate Practice is "an approach to teaching grounded in the research on how young children develop and learn and in what is known about effective early education" (NAEYC, 2018). The guidelines are based on several child development theories and have been used to describe the developmental milestones of young children and the appropriate (and inappropriate) care and practices of early 
childhood practitioners (Bredekamp, 1986). The Position Statement issued by the National Association for the Education of Young Children (NAEYC) described policies to achieve DAP in early childhood programs. Three core considerations for DAP include: Knowing about child development and learning, knowing what is individually appropriate, and knowing what is culturally important (Copple \& Bredekamp, 2009). These considerations provided guidance in approaching the role(s) of YouTube in early childhood music education through the lens of DAP. This study's findings will provide information to help early childhood educators address these three considerations with respect to the use of technology with toddlers.

Edwin Gordon documented his theories about young children's music learning in his book, Music Learning Theory for Newborn and Young Children (2003, 2013). Stressing the difference between guidance and instruction, Gordon (2013) clarified that guidance is informal and instruction is formal. He identified types of guidance that lead to young children's music learning: unstructured and structured. Unstructured guidance involves no specific planning on the part of the parent or teacher; structured guidance includes the planning of specific lessons. "A distinguishing characteristic of both structured and unstructured informal guidance is neither imposes information and skills. Rather, children are exposed to their culture and encouraged to absorb it. Structured and unstructured informal guidance are based on and operate in consequence to natural sequential activities and responses of a child" (p. 3). Guidance is informal when specific musical responses are not expected or demanded from children. Once a parent plans and organizes what and how something will be taught, instruction becomes formal. Because 
this study examined YouTube music experiences, Gordon's theory offered some parameters to describe and analyze the role of the parent and the parent-child dynamic.

\section{Research Questions}

There were three overarching research questions examined in this descriptive survey study, each with several sub-questions:

1. What does the digital music home environment look like in young children's families?

a. How many YouTube/Internet accessible devices are in the home?

b. How often do parents access YouTube for young children's music videos?

c. Do families participate in singing and music making? What other activities are they doing together?

d. Is there a relationship between demographic variables and frequency of singing?

2. What roles does YouTube serve and what do digital music experiences look like?

a. For what purpose(s) are parents using YouTube?

b. Does previous music experience influence YouTube music usage and purposes?

c. What does a YouTube music experience look like?

3. What are parents' attitudes and beliefs towards YouTube as a means of digital musical parenting?

a. What are parental beliefs about YouTube children's music videos?

b. How do parents feel about YouTube music videos' effects on different areas of children's development? Are there concerns? 
c. Do parents consider YouTube to be an effective children's music education resource?

Researchers have determined that there is a need for stronger parent-focused music education resources (Ilari, 2005; Sims \& Udtaisuk, 2008; Youm, 2008), but first, we must gain a better understanding of how parents use existing music tools. Given the widespread use of YouTube as a source of musical material, in this study I will examine parental attitudes and beliefs towards young children's music experiences with YouTube, focusing on parents with toddlers (children 16-to-36 months). I will also attempt to gain a better understanding of the parent-child interactions and parental preferences for select children's YouTube videos. A substantial body of research exists regarding the musical parenting of preschool and school age children, but less is known about younger children. This study will help fill some of the gap in the literature regarding digital home musical experiences of toddlers. 


\section{CHAPTER TWO}

\section{Review of Literature}

This chapter includes a review of related literature organized into three sections: (a) home music environment, (b) musical parenting and digital musical parenting (c) The Digital Age and YouTube. These areas of study were selected because my research questions examine parents' attitudes toward, usage of, and experiences with YouTube early childhood music videos. With the ultimate goal of creating guidelines and strategies for YouTube as a music resource, baseline information must first be gathered on how YouTube is currently being utilized, what parental attitudes are towards the digital resource, and what parent-toddler YouTube music experiences look like.

\section{Introduction}

The importance of music in early childhood has been a topic of particular scholarly interest in the last thirty years (Andress, 1986; Berger \& Cooper, 2003; Bond, 2013; Campbell \& Wiggins, 2012; Gembris \& Davidson, 2002; Gordon, 2002, 2013; Levinowitz, 1998; Niland, 2009; Persellin, 2007; Sims, 1985, 1993, 1995, 2005). Music educators have realized that:

The most important time for learning is from birth (if not before) until eighteen months, the critical period during which a child learns through exploration and unstructured guidance by parents and other caretakers. Following is the sensitive period from eighteen months to three years, during which a child continues to receive such guidance. (Gordon, 2013, p. 1)

Before children enter preschool, it is crucial that they receive "such guidance" at home. Because children are capable of learning in their first days of life (Bond, 2013), there 
must be a strong focus on the home environment, where children spend most of their time (Ilari \& Young, 2016).

\section{Music in the Home}

Future musical growth and development is highly influenced by the home music environment (Sims \& Udtaisuk, 2008). Home music environments have been closely associated in the research with topics such as parental involvement, family musical background, socioeconomic status, music achievement, parenting style, and family music participation. A quality home music environment has been linked to stronger social, emotional, cognitive, and achievement outcomes in children-both musically and in overall development (Brand, 1986).

Extensive research has been conducted on home music environments (Brand, 1986; Custodero, Britto, \& Brooks-Gunn, 2003; Custodero, 2003, 2006; Dell et al., 2014; De Vries, 2007, 2009; Ilari, 2002; Ilari \& Young, 2016; Lum, 2008; Wills, 2011; Zdzinski, 2013). Authors have identified music-specific factors related to home music environment, which include: parents' attitudes towards music, resources in the home, music materials, musical home structure, and musical home environment (Brand, 1985; Wills, 2011; Zdzinski, 2013). Home music environment has been defined as:

...Frequency of musical interaction between child and parent, types of musical activities that occur in the home (i.e., singing, moving to, listening to, writing and playing music), musical materials that are present in the home, and frequency of attendance at musical events by family members. (Wills, 2011, p. 20)

For this literature review, a home music environment will be defined as the frequency of a child's music activity or interaction that occurs individually or with others, 
both formal and informal, inside the home. This also includes any musical materials found in the home (i.e. CD's, DVD's, homemade or real musical instruments, pots and pans, internet and media). Interactions include (but are not limited to): singing, listening to music, responding to visual and verbal representations of music, moving, playing instruments, and creating music (NAfME, 2014). There is a considerable amount of musical resources available for young children. When asked to estimate their consumption and uses of music-related goods, parents reported that resources like CDs, DVDs, music toys, and recorded music were the most prevalent (Ilari et al., 2011).

Describing the early childhood home music environment. Researchers have utilized different quantitative methods to describe the home music environment (Brand, 1986; Custodero, 2003, De Vries, 2009; Wills, 2011). An early researcher-designed scale, Home Musical Environmental Scale (HOMES), revealed significant relationships between home music environments and musical achievement (Brand, 1986). Researcherconstructed measures have been used to gather information on parental involvement related to home music environment (Dell et al., 2014), parental use of music with preschool students (Wills, 2011), and frequency of music interactions between parents and infants (Custodero, 2003). Grounded on his Parental-Involvement-Home Environment in Music measure (PIHEM; 2013), Zdzinski’s (2013) data revealed that home music environments had direct effects on participants' academic, musical, and psychosocial outcomes. Rich environments in music positively impacted students in many areas of their development, not just musically. Zdzinski's study also acknowledged the multifaceted structure of home music environments and different types of parental involvement in the home. 
Parental involvement, in the context of the home music environment, greatly influences children's musical development (Berger \& Cooper, 2003). Home learning environments "vary in their content and specificity but typically involve asking parents to report on the frequency particular activities occur, or in home observations" (Williams et al., 2015, p. 114). Frequency of specific activities, like singing or music making, has been utilized as a measure because it quantifies musical interactions. Whereas some studies revealed fairly high frequencies of musical interactions (Custodero, 2003; Wills, 2011), another study found frequencies of musical interactions to be quite low (De Vries, 2009). Furthermore, De Vries reported that some parents highlighted a lack of time to engage in music making with young children.

Two survey-based studies looked closely at the home music environments of children from birth to age five. Wills (2011) conducted a study on preschool children aged 3 to 5 years that were enrolled in an early childhood music class, and examined the effects of different factors such as demographic characteristics, parental musical experience, and early childhood music instruction on children's music interactions. Participants were surveyed using a researcher-constructed measure, Parents' Use of Music with Preschool Students (PUMPS), designed to gather information on participants' experiences and how music was used in the home. This is similar to the Parents' Use of Music with Infants Survey (PUMIS) by Custodero (2003) that examined parents' musical experiences and the frequency of music interactions in the home with 4- to 6-month olds. Wills' (2011) study revealed that families had a variety of musical materials in their homes, and participants reported frequent musical interactions. Both researchers, Custodero (2003) and Wills (2011), found that participants provided rich musical home 
environments for the children, and engaged in various types of musical interactions on a weekly basis. Interestingly, Wills' (2011) participants were found to not utilize the music class materials in their homes. Rather, participants were more likely to interact musically with other home materials. One study closely examined the in-school and out-of-school music experiences of older students (Tobias, 2015), and Wills' finding suggests that there may be a similar trend occurring for younger children.

Digital home music environment. Technological advancements have significantly influenced family home musical environments (Burroughs, 2017; Lum, 2008). Studies have recently focused on young children and digital technologies (Given et al., 2016; Oliemat, Ihmeideh, Alkhawaldeh, 2018; Palaiologou, 2014). There is a growing trend of very young children (birth to 3 years) using Internet-connected devices (Holloway, Green, \& Stevenson, 2015). One recent study aimed to investigate the types of digital technologies young children were using at home (Palaiologou, 2014). Utilizing a mixed methods approach, the project included focus groups, questionnaire, and followup interviews. Data revealed that children under five were heavy users of many different digital technologies at home.

One study examined the influence of media and technology on children's home musical environments (Lum, 2008). Lum examined the home musical environments of 28 Singaporean first-grade children and their families. The purpose was to capture the multifaceted musical lives and cultures of the children through in-depth ethnographic methods. Data collection over a four-month period included: observations of children's everyday activities at home, field notes, interviews, audio and video recordings, material artifacts, and other information gather from parents, siblings, and other family members 
(p. 104). Lum's findings revealed that the usage of media (television and radio programs), video/computer games, the Internet, CD's, and DVD's were prevalent in the home musical environment of most of the participants.

Defining digital home music environment. We must refine the previously defined, home music environment, to include the digital resources now prevalent in most families. Digital will refer to anything that utilizes a computer, tablet, smartphone or mobile device, and include usage of Internet-based resources, such as YouTube, Netflix, applications and games. The digital home music environment will be defined as the frequency of digital music activity or interaction that occurs individually or with others, both formal and informal, inside the home. This also includes any digital musical materials found in the home (i.e. CD's, DVD's, homemade or real musical instruments, internet and media). Interactions include (but are not limited to): singing, listening to music, responding to visual and verbal representations of music, moving, playing instruments, and creating music (NAfME, 2014).

Today's digital home music environment has been described to serve multiple purposes. In one study (Ilari et al., 2011), CDs and DVDs "were not only a common presence in the homes but also used in idiosyncratic ways by the interviewed mothers" (p. 61). They reported that at times, CDs, toys, and especially DVDs appeared to be used as 'temporary substitutes' for mother-child interactions. New methods available to families today make accessing and listening to music much easier than in previous years. These include: "phones, Bluetooth speakers, computers and television sets, and via downloads or stream services, in additional to CDs and radios" (Rideout, 2017, p. 34). 
This warrants a closer look at how prevalent these Internet-accessible resources are in the home music environment.

Music material selection. Studies have illustrated that parents are typically the gatekeepers to the child's music materials (Koutsoupidou, 2016; Lum, 2008).

Koutsoupidou (2016) stated, parents "decide which musical materials and resources will be provided to the child, and thus play a substantial role in forming and guiding children's musical experiences" (p. 81). Lum (2008) found nursery rhymes and children's songs to be a small part of the repertoire that the children were exposed to, but the majority of home music was associated with electronic and pop-influenced music, or popular culture and media. Hallam (2012) supported this finding in her discussion of children's exposure to music through different media like television, radio, and recordings. Exposing children to a variety of music is highly encouraged, however, it is equally important that the parents are equipped with the digital literacy necessary to select, use, integrate, and evaluate appropriate technology and interactive materials (NAEYC, 2012). This is influenced, in part, by parental backgrounds and experiences, which will be examined in a later section.

Summary. Researchers continually seek ways to enhance the quantity and quality of children's home music environments (Hamilton, 2014). There is much to be uncovered about today's digital home music environments, how new technologies are being used and for what purposes they serve, and what characterizes the experiences. The digital home environment should be conducive to limitless music learning, interactions, and experiences. 


\section{Musical Parenting}

Parents, with respect to the "parents are children's first teachers" mentality, have been the center of much early childhood education research. Because caregiver bonding has been linked to behavioral and emotional benefits for the child, the role of the caregiver has been strongly emphasized by child development psychologists such as John Dewey, Maria Montessori, Jean Piaget, Erik Erikson, and Lee Vygotsky. Parents and caregivers influence young children's expectations about themselves and others (Copple \& Bredekamp, 2009), the quality of their musical environment (Gibson, 2009) and early music experiences (McPherson, 2009).

Research has examined different areas of musical parenting, including infantparent musical communication (e.g. Adachi \& Trehub, 2012; De Vries, 2009; Trevarthen, Gratier, \& Osbourne, 2014), musical play (e.g. Berger \& Cooper, 2003), singing (e.g. Custodero et al., 2003; Custodero, 2006; Ilari, 2005; Gibson, 2009), parental beliefs and attitudes (Custodero \& Johnson-Green, 2008; Hamilton, 2014; McPherson, 2009; Pitt \& Hargreaves, 2017; Youm, 2008), and parental empowerment (Cutietta, 2001; Koops, 2011, 2011b, 2012). Musical parenting has been defined as musical engagement between parent and child (Custodero \& Johnson-Green, 2008) and can be characterized in different ways: singing, dancing, playing instruments, taking children to music concerts or classes, providing music resources or instruments, offering music toys and books, media forms like CDs, DVDs, and Internet (Gibson, 2009). As vital as the music resource offerings are for young children's earliest experiences, more important is parents creating the home environment to nourish music interests and development (Ilari, 2017). 
Toddlers. Much of the body of research has examined musical parenting either of very young babies (0-12 months) (Custodero et al., 2003; Custodero \& Johnson-Green, 2003, 2008; Ilari, 2005), or a wider range of birth to four years (Ilari, Moura, \&Bourscheidt, 2011; Gibson, 2009; Hamilton, 2014). The toddler-age group is the "middle child" of early childhood music education research. There are few studies that focus solely on the toddler age group. Noteworthy is the conflicting definitions of "toddler." Whereas the American Academy of Pediatrics (AAP) refers to toddlers as children 12-36 months of age, the National Association for the Education of Young Children (NAEYC) states that toddlerhood is from 16-36 months. This discrepancy may potentially lead to developmentally inappropriate activities and inaccurate implications, and therefore, a clearly defined age range should be addressed in early childhood research. For the purpose of this dissertation, we will define "toddler" as 16-36 months. We must seek to understand the nature of music experiences for this particular age group.

One particular study (Custodero et al., 2003) revealed that musical activities occurred more frequently with infants (0-23 months) than with toddlers (24-36 months). "The sharp decline of parental singing/playing music for children after 24 months suggests the appropriate timing for educational intervention" (p. 569). This is concerning, because many parents with poorer perceived music skills rely on daycares and preschools to provide music opportunities (De Vries, 2005), but many early childhood educators feel that they lack sufficient knowledge and training to support children's music development (Bolduc \& Evrard, 2017). Unknowing parents may be under the assumption that their toddlers are receiving quality music education from daycares and preschools. 
Parents and early childhood educators are opting for activities such as book reading rather than singing in the toddler years. Williams and her colleagues (2015) conducted a longitudinal study with 3031 Australian children and families on parentchild shared music activities. They acknowledged the abundance of research on the benefits of early-shared book reading between parents and children, and results suggested that parents feel more comfortable reading to their toddlers than singing to them. Similarly, participants from another study (Youm, 2008) revealed that some parents do not feel equipped to enhance their children's music learning. Based on Gordon's (2003) theory that birth to three years is the most important growth period of a child's life, toddlers are at an optimal age for musical development and should not be deprived of such experiences.

Singing in musical parenting. Singing is central to musical parenting, and was reported as the most frequent musical interaction between parents and young children (Ilari, 2017). Over $80 \%$ of participants in several studies reported singing to their children regularly (Custodero et al., 2003; Ilari, 2005; Ilari et al., 2011; Johnson-Green \& Custodero, 2002; Gibson, 2009). The parent-child dyad is greatly enhanced through singing in children's first years (Adachi \& Trehub, 2012), but what exactly are parents singing to their children? Most researchers noticed that lullabies and nursery rhymes emerged as the most popular style (for example, Ilari, 2005). Ilari and her colleagues discovered similar findings in a future study (Ilari et al., 2011) where Brazilian mothers mostly listened to traditional Brazilian lullabies and children's songs (48\%) and music from children's DVDs and television shows (39\%). Gibson's (2009) participants were found to be singing traditional songs such as "Twinkle Twinkle, Little Star," "Old 
MacDonald," and "Row Row Row Your Boat" (p. 78). Sixty-seven percent of the mothers reported singing "Twinkle Twinkle, Little Star," which parallels the findings of previous studies (Bergeson \& Trehub; 1999; Custodero \& Johnson-Green, 2003). In general, parental singing repertoire has included: "invented tunes, lullabies, play songs (Trehub \& Schellenberg, 1995), parodies, and a smorgasbord of familiar songs" (Ilari, 2017). This begs the question of how parents decide which songs to sing. Parents reported that they typically select existing and familiar repertoire—-songs they grew up listening to (Gibson, 2009). Similarly, Custodero's (2006) study revealed strong connections to past experiences for the participants. Music-evoked emotions and childhood memories may explain why the most popular children's songs, like Twinkle Twinkle, Little Star and The Alphabet Song haven't changed in the last century. They are the songs current parents grew up listening to, and their parents grew up with, and so forth. Singing is multifaceted in nature; parental practices are influenced by numerous factors, both past and present.

Parental music background. Evidence has suggested that there is a positive correlation between parents with more music experience and/or education and young children's music exposure. For example, Youm (2013) examined South Korean parents' understanding and desires for music education for their children. Utilizing purposeful sampling, she conducted in-depth interviews with 22 upper middle class parents with young children. The majority of participants, all mothers, had extensive musical backgrounds, which could have influenced their decision to enroll their children in music programs (p. 143). Typically, parents who enroll children in music programs or lessons tend to have higher socioeconomic status levels and can afford to pay for such activities 
(Corrigall \& Schellenberg, 2015). Previous studies also reported similar findings in which more musically experienced parents provided their children with more music opportunities (Atterbury \& Silcox, 1993; Custodero and Johnson-Green, 2003; Kelly \& Sutton-Smith, 1987). Another survey study revealed that more musically experienced parents were more likely to sing and play music with their infants than those without a music background (Custodero \& Johnson-Green, 2003). Whereas most studies (for example, Custodero et al., 2003) involving parents in a non-academic setting found similar results, results of a study of 68 mothers of young children indicated no significant differences between mothers' reported musical backgrounds and reported listening or singing with their infants (Ilari, 2002). According to Custodero, Britto, and Brooks-Gunn (2003), parent-child musical interactions are greatly influenced by demographic factors such as: age of child, gender of parent, and parental backgrounds.

Young children's music exposure. Children's exposure to a rich variety of music prepares them for formal music learning later in life (Gordon, 2003). According to Hallam (2012), "the greater the exposure to music, the more fully and speedily this [music] knowledge will be acquired" (p. 42). Parents are the best resource for offering music opportunities featuring a wide range of genres for their young children. An ethnographic study examined the musical parenting of young children (mostly toddlers) in a university-owned apartment complex (Gibson, 2009). Parent-participants, of which included at least one spouse pursuing a doctoral degree, felt strongly about their children being exposed to a variety of different music genres, instruments, and dance styles. When asked about parental beliefs on early music exposure, responses included: desire for 
children to pursue musical instrument training, music appreciation, developing a cultured ear, lifelong music participation.

Singing is the main musical interaction that occurs between parent and child, but not all singing is created equal. There is a clear distinction between singing directly to a child and singing along with music media, like CDs and DVDs, in the presence of a child (Ilari et al., 2011). What is unclear, however, is if and how the quality of the music experience is influenced.

Digital musical parenting. Digital technologies and electronic media are important parts of young children's musical lives, and are utilized by many parents today (Ilari et al., 2011; Marsh et al., 2005). Smartphones and tablets have become the "go-to" parenting tools (Wartella et al., 2014). However, only 29\% of parents reported that digital technologies make parenting easier. Whereas earlier digital music experiences focused on CD and DVD music usage (De Vries, 2005, 2007; Vestad, 2010; Young, 2012), more recent experiences include Internet-based resources and social media (Koops, 2012). Koops (2012) examined the use of an online social networking site by parents of young children enrolled in an early childhood music class. Based on online posts and exit interviews, she determined that the online resource fostered a deeper connection among participants and that the digital space afforded a place to reflect. Results also suggested that a barrier to full participation was a lack of time.

Summary. Parental attitudes play key roles in children's musical involvement (Koops, 2011). Parents with positive attitudes towards music are more inclined to take more interest in their children's musical development; negative attitudes towards music decrease the likelihood. Although active parental participation in young children's music 
experiences is highly emphasized by early childhood music educators, it is unknown to what extent new technologies are being used in parent-child music interactions. Research has suggested that digital music resources are sometimes being used as temporary parent substitutes. An analysis of digital music usage and the media experiences of parents and children is necessary to learn more about this aspect as related to children's early music experiences.

\section{The Digital Age}

Today's young children, including infants and toddlers, are growing up in digitally fluent home environments (Palaiologue, 2014). A 2011 national survey determined that approximately $38 \%$ of children under two had used a mobile device for media (Rideout, 2011). The number increased to $46 \%$ of children having used mobile media in 2017 replication (Rideout, 2017). Overall, children under 2 were found to spend an average of 42 minutes a day using screen media, 23 minutes a day listening to music, and 21 minutes a day reading or being read to (Rideout, 2017). Technology is now an "integral part of the soundscape of the home" (Koutsoupidou, 2016, p. 113). Favorite family pastimes and activities now include using a computer, tablet, or smartphone together (Rideout, 2017; Wartella et al., 2014).

Family media environment. Media and technology are interwoven in the daily lives of parents and children. There are three different types of family media environments that have been identified (Wartella et al., 2014). These include: mediacentric (39\%, consuming an average of 11 hours of screen media a day), media-moderate (45\%, under five hours), and media-light (16\%, less than two hours). The term Digitods describes children born after the introduction of the iPhone in 2007, the first population 
group to grow up with a range of digital technologies (Holloway et al., 2015). Parents of digitods have been described as experienced Internet users, and many are comfortable with their children's usage of digital technologies (Holloway et al., 2015). As a parent of a digitod myself, I can attest to digital technologies "making daily life easier and improving communication with family and friends, even during the high pressure parenting years of raising toddlers" (Holloway et al., 2015).

Media Usage. Similar to findings from a previous study (Ilari et al., 2011), the notion of "technology as a babysitter" was emphasized in a recent national media usage survey (Rideout, 2017). Parent participants $(N=2,326)$ revealed that usages included: keeping a child occupied, getting a child ready for bed, calming an upset child, rewarding or disciplining a child, and educating a child (2014). Notable findings were that $41 \%$ of parents of 2- to 5-year olds would give their children a mobile device in a restaurant to keep them occupied. Although parents shared that they did not find media to be the top educational activity for young children, they tended to turn to technology as a babysitter for the moments they needed to get things done.

Parent-child media usage. Before social media and digital technologies became largely accessible to the Western world, researchers published a report titled, "Digital Beginnings," exploring young children's usage of popular culture, media, and new technologies in the home (Marsh et al., 2005). Their survey study of 1,852 parents and caregivers examined: children's experiences with digital media, the nature of digital technology engagement, parental roles, media within education, popular culture, and professional development opportunities for uses of media and popular culture to promote learning. Results revealed that children's media engagement tended to be social, positive, 
and active. Parents were generally positive about the role of media in their young children's social, emotional, linguistic and cognitive development.

Parental reports of children's media usage can offer new perspectives into the influences of digital technologies. Two major large-scale, nationally representative studies (Rideout, 2017; Wartella et al., 2014) have examined and measured the media usage of children aged 8 and younger. Researchers at Northwestern University published a report titled, "Parenting in the Age of Digital Technology," about parent-child media usage, parental attitudes and concerns, and the impact of specific technologies on their children's development (Wartella et al., 2014). Researchers at Common Sense Media (2017) also conducted an online survey of 1,454 parents about parental perceptions of children's media usage. Parents reported time and frequency estimates of a randomly selected focal child in their household. To gather as precise and reliable estimates as possible, researchers asked parents to focus on their children's media usage the day prior to taking the survey, rather than asking about a "typical day" (p. 9).

Music media usage. Studies have indicated that children's media usage and exposure has increased, but how much of that usage includes music listening? One study indicated that babies younger than two averaged 23 minutes of music listening a day; 2to-4 year-olds averaged 21 minutes a day (Rideout, 2017, p. 34). Researchers asked parents to describe their usage of online music videos and found that $40 \%$ of parents with children under four watched these videos (p. 34). They also found that parents with higher family incomes watched fewer online music videos with their children than those with lower family incomes. 
National media guidelines and recommendations. Authors of a position statement for the National Association for the Education of Young Children offered recommendations for technology usage (NAEYC, 2012). They encouraged developmentally appropriate practices including: active engagement with technology as part of a balanced program or lifestyle, limiting any use of technology for children under two, limiting overall screen time, and prohibiting passive use of digital technologies. In 2016, officials at the American Academy of Pediatrics (AAP) released a new set of recommendations and resources for families, which included:

For children younger than 18 months, avoid use of screen media other than videochatting. Parents of children 18 to 24 months of age who want to introduce digital media should choose high quality programming, and watch it with their children to help them understand what they're seeing.

For children ages 2 to 5 years, limit screen use to 1 hour per day of high-quality programs. Parents should co-view media with children to help them understand what they are seeing and apply it to the world around them. (AAP, 2016)

There is scant research on parental awareness of guidelines centered on young children's screen media usage.

YouTube and today's parents. Parents live in a YouTube-based culture (Rudolph \& Frankel, 2009). YouTube launched in 2005 and has over a billion users, almost one-third of all people on the Internet (YouTube, 2018). YouTube is an accessible, web-based platform that allows people to upload, view, and share videos. It has radically changed the face of digital experiences in everyday life. The YouTube Generation, or Gen C, is a term that was coined to describe $80 \%$ of millennials as "people 
who care deeply about creation, curation, connection, and community" (Google, 2013). Some characteristics of Gen C include: connecting across all screens (mobile, tablet, television, computer), an urgency to engage with the world via community, uploading pictures, and viewing video content (Google, 2013). "I respect YouTube. I respect what it does. It puts this whole world of content out there that otherwise no one would have known existed. And that's really interesting" (Google, 2013). Today's parents grew up with some form media and technology and make up a large percentage of Gen C.

YouTube and families. YouTube usage by children and their families is exponentially increasing (Burroughs, 2017). A recent survey examining children's and parents' media use and attitudes found that $48 \%$ of 3- and 4-year olds used YouTube (Ofcom, 2017). With the rise of mobile parenting, young children have become a target demographic (Burroughs, 2017). YouTube launched the YouTube Kids application due to parental concerns regarding appropriateness of children's video content. With the sheer amount of content available at a user's fingertips, it can be challenging to ascertain the level of quality in videos. Interestingly, $83 \%$ of parents of children under age 2 were satisfied with the amount and quality of educational media available for their children (Rideout, 2017). According to survey results, media and technology resources such as YouTube are being used primarily for learning with young children, followed by developing creativity skills and the ability to focus. YouTube Kids was launched to "keep parents happy and ward off criticism that its content was unsafe and putting children in close proximity to adult entertainment" (Burroughs, 2017, p. 3). YouTube Kids' goals were to create a safe space for digital parenting problems and ease access with four browsing categories: Shows, Music, Learning, and Explore (Burroughs, 2017). 
Younger children are likely using YouTube to watch cartoons, animations, and songs (Ofcom, 2017). Among the most popular YouTube music channels is Little Baby Bum, with profits of 3.4 million dollars a year, with 270 million monthly viewers (Ferenstein, 2015). When typing "children's music" into the search bar, results include relaxation and meditation music, Little Baby Bum's playlist, Super Simple Songs, Disney lullabies, and a hodgepodge of soundtracks and advertisements. Data regarding the selection process of YouTube music by parents and young children currently does not exist.

YouTube in music education. There is a growing body of research on music education and YouTube. Areas of study have included: YouTube as an online music community (Waldron \& Veblen, 2008; Waldron, 2012, 2013), YouTube and music instruction (Kruse \& Veblen, 2012), and YouTube and culture/identity (Cayari, 2011; Marsh, 2013). A significant study by Whitaker, Orman, and Yarbrough (2014) analyzed the characteristics of music education videos on YouTube. Their two-level content analysis categorized 1,761 videos from a keyword search of "music education." Out of 1,352 relevant videos, the most observed categories were performance (36\%), teaching (28\%), public relations (27\%), and industry (10\%). "YouTube viewers represent nearly every demographic imaginable" (Rudolph \& Frankel, 2009, p. 2). There are even YouTube Music Education channels supported by professional organizations such as the MENC: The National Association for Music Education (now called NAfME), American Choral Directors Association (ACDA), The Midwest Clinic, Children's Music Workshop, among more (p. 2). 
Fewer studies have examined YouTube in early childhood music. One study (Hourcade, Mascher, Wu, \& Pantoja, 2015) analyzed YouTube videos watched by infants and toddlers using tablets. Music dominated as the most watched genre for the youngest age group (under 12 months), with educational videos being more popular with the 18 -to29 month olds. Young (2016) stated, "the impact of new technologies and new media on early childhood music, although profound and far-reaching, represents a new area of research activity, as yet in its infancy" (p. 13). Unique to today's parents, there is media pressure to be "Pinterest-perfect"; parents want to be socially desirable or "tend to answer questions in away that is correct, good, or expected" (Ilari, 2017, p. 6). Parents, who allow their children to watch YouTube music videos, but feel that society deems YouTube to be inappropriate, may not reveal their actual habits or daily usage in a questionnaire for the fear of being judged negatively.

Parental attitudes towards children's media usage. Scholarship has recently explored parental attitudes towards children's usage with new media and technologies. Sixty-nine percent of parents surveyed believed that digital devices provide educational content that teach their children important lessons (Wartella et al., 2014). Overall positive attitudes towards technology have included reasons such as: motor and cognitive skills, digital citizenship, and visual memory (Genc, 2014). One study explored parent and teacher perceptions on preschool children's media and technology use, and found a majority of caregivers to view children's interactions as positive (Sharkins et al., 2015). Parental attitudes are a bit more nuanced than initially assumed, however (Rideout, 2017). Data revealed that "parents do not see media as particularly "educational" for their children, but they certainly do not see most media as being particularly harmful to 
their children, either" (p. 30). YouTube music videos geared towards younger children tend to include bright animations that could encourage physical movement and developmental benefits. Survey responses suggested that mobile devices might have a positive effect on reading, math, and creativity (Wartella et al., 2014).

Concerns. With young children growing up in technology-saturated environments, there are many fears and concerns by early childhood experts and parents. Seventy-nine percent of parent responses to a survey agreed with the statement, "in general, the less time kids spend with screen media the better off they are" (Rideout, 2017, p. 2). Because little research attention has been given to young children's usage (Holloway et al., 2015), there is no longitudinal evidence whether children are actually better off. One fear is of digital technology overuse during this critical period of neurological development. Infants and toddlers need responsive interactions for cognitive development (NAEYC, 2012), which is why intentional, purposeful usage of digital technologies is stressed. Another concern is the impact of digital technologies on children's physical activity (Leopold, 2013). Parents in a national study attributed a negative effect to technology on its impact on lack of physical activity and sleep, although some did suggest a positive effect (Wartella et al., 2014). Passive screen time engagement has also been cited as a potential concern for young children's YouTube usage (NAEYC, 2017). Other concerns have included possible negative effects on children's social skills, and technology addiction (Wartella et al., 2014). Despite many concerns, however, most parents and caregivers were found to believe that children should not be excluded from new technologies that play major roles in everyday life (Holloway et al., 2015). 
Equipping parents with the digital tools they need for effective musical parenting is necessary in today's digital world. Filling this research gap can begin with an understanding of parental attitudes towards and usage of YouTube with their young children. Parent reports of YouTube usage for music education purposes will also offer a better understanding of the nature of digital musical parenting and the role that YouTube plays. Understanding parental beliefs and attitudes towards YouTube is the necessary starting point to create and offer musical parenting digital guidelines and resources. Music technology should be seen as an ally, rather than a threat to children's music experiences (Young, 2009). There are not sufficient data examining the current twentyfirst century music education resources, such as YouTube, that parents may very well be using.

Summary. Due to its accessibility and availability of music content, YouTube is attracting many millennial parents and young children. For some families, it may be the sole music resource in the digital home environment. Concerns and challenges have risen based on the amount of video content on YouTube. Special considerations must be given to the youngest viewers (NAEYC, 2017). These include questions about: access, appropriateness, quality, usage, and characteristics of parent-child interactions. Although there are large-scale media usage studies that provide a glimpse of how digital technologies like YouTube influence families, there is a scarcity of YouTube-specific research in early childhood music education. Before attempting to create more effective musical parenting resources, we must first acquire a comprehensive understanding of current parental attitudes and beliefs toward, and usage of, YouTube as a music education resource. 


\section{CHAPTER THREE}

\section{Method}

This study was designed to investigate the nature of parent-child music experiences in a YouTube generation. Previous research exists primarily in the areas of young children's home music environments, musical parenting of infants and toddlers, parental attitudes and beliefs towards early childhood music education, and large-scale media usage with young children. The present study is a necessary starting point intended to offer a representation of how parents from diverse community groups feel about YouTube, their own musical parenting, and how they use the digital resource in their home environments. My aim also is to inform educators, parents, scholars, and teachers about current parental practices of young children's music instruction.

The purpose of this study was to gather information to provide educators, scholars, and teachers with baseline data for this limited area of research. Because the majority of available studies addressing the roles of technology in early childhood music education have focused on the television, CD's and DVD's, and the Internet as a whole, an investigation of YouTube-specific usage by parents of toddlers seemed warranted.

This investigation targeted a very specific population, parents of toddlers. This is because toddlers are at a critical period of early childhood and musical development (Parlakian \& Lerner, 2016), and there is an overall lack of parental knowledge about music (Custodero, 2006). Because current parents are growing up with technology as a central part of their lives (Leopold, 2013), the roles of technology on musical parenting and parent-child music experiences must be explored. 


\section{Research Design}

This research study was descriptive, utilizing an author-designed survey based upon (a) similar surveys targeting parents and their children's media usage (Common Sense Media, 2017; Wartella et al., 2015), (b) reports of parental concerns regarding children's media usage found in the professional literature, (c) my own experiences as a parent of two children under three. Some questions were adopted directly from Northwestern University's "Parenting in the Age of Digital Technology" survey (Wartella et al., 2015) and Common Sense Media's Census of Children's Media Use (2017) and modified to specifically address the YouTube music experiences of young children.

Data were collected using an electronic web-based tool accessible through the University of Missouri (Qualtrics Lab, 2018). Online survey software was selected because of its convenience and accessibility for parent respondents. Qualtrics was used because of its distinct advantages over traditional postal or email data collection methods. Advantages include: cost-effectiveness, speed, and ease of analysis (McPeake, Bateson, \& O’Neill, 2014). Concerns about electronic surveys include potential selection bias and poorer response rates as compared with paper surveys (McPeake et al., 2014) The selection bias was addressed by the researcher by selecting social media groups that met three criteria: groups were publicly available (although both groups were invitation-only), diverse, and allowed me to post a short description of the study and survey link.

Due to the busy nature of parenting, the target population proves to be a difficult one to reach. According to Andrews, Nonnecke, \& Preece (2010), electronic surveys target "hard-to-reach" audiences. Because the majority of today's parents seek parenting 
advice through Facebook (Bartholomew et. al., 2012), I determined that social-media based recruitment would be the most appropriate for this particular study. Plus, of course, I was interested in recruiting parents who were active Internet users. However, one downside to recruiting participants through social media groups was the inability to quantify the exact response rate.

\section{Participants}

Participants were recruited through online social media groups focused on parenting-related interests. Selection was limited to parents of 16-to-36 month-old children-toddlers, as defined by the National Association for the Education of Young Children (NAEYC, 2014). I utilized purposeful sampling to target participants who met the criteria through social media, specifically, through two Facebook groups focused on the parenting of young children: one group with over 14,000 members [First Time Mommy Group] and a second group with approximately 2,000 members [Parents of Toddler-Age Children]. Prior to the study, I was a member of the larger group [First Time Mommy Group], however, I was required to submit a recruitment post request to the group moderators. This protocol exists to ascertain that members do not sell, promote, or monetize their businesses or names in any way. I requested to join the second group [Parents of Toddler-Age Children] because it was an active group focused on the target population. Also, it included both mothers and fathers, unlike the first group. Once admitted into the group as a member, I was required to go through the same process of receiving permission from a group moderator or administrator to post the recruitment script. 
From the total recorded survey responses $(N=201), 192$ usable surveys were returned. Nine respondents dropped out after the introductory page. It is impossible to know exactly how many people saw the survey link from social media-based distribution, or what percentage of group members met the participation requirements (parent of a 16to-36 month old child).

\section{Survey Instrument}

I used a survey to obtain descriptive information about the parents' musical practices and their usage of YouTube as a children's music education resource. All of the questions, minus the demographics, fell under one of three broader categories: Digital Music Environment, YouTube Usage and Experiences, or Musical Parenting, and included both closed and open-ended responses (see Appendix A for the complete survey).

Demographics. Participants completed a survey featuring a combination of Likert-type scale questions, questions with responses from which the parent chose the pertinent responses, and open-ended responses. Because this study targeted a very specific population of participants, survey items 1 through 4 were demographic questions that asked the parents to indicate their child's gender, birth date, their relationship to the child, and their marital status. Item 3 directly stated, "if you are not a parent, thank you for your interest, but only parents may participate in this survey." Additional demographic questions were included at the end of the survey (items 22-27) including: highest level of education completed, location of residence, ethnicity, and family income level. The more personal and sensitive items were placed at the end of the survey in an effort to decrease participant dropout rates. If respondents selected "married" in item 4, 
that prompted the system to ask for spouse's highest level of education in item 26, based on branching logic used in survey setup. Item 5 asked participants to rank their level of musical ability (as they perceive it) and item 6 briefly asked participants to discuss their music backgrounds. Studies have revealed that parents are uncomfortable interacting musically with their children (De Vries, 2009; Williams et al., 2015; Youm, 2008), so this item was included to examine this finding. Items 7 through 9 asked respondents a series of closed response questions to gather data pertaining to the children's backgrounds and lifestyles.

Digital music environment. Item 10 asked respondents to select the number of YouTube and Internet-accessible devices they have in their homes. Possible responses ranged from "none" to "more than six" responses. Item 11 included a series of family activities, including:

- Watching TV or movies

- Reading together

- Doing things outside together, like playing, taking a walk, or going to the park

- Doing indoor activities, like playing with toys, games, or art projects

- Playing or attending sports events

- Participating in clubs or other groups

- Singing songs or making music

- Cooking and eating meals

- Doing things on a computer, tablet, or smartphone 
Possible responses to each activity ranged from "A lot" to "Not at all." Survey items 9 and 11 were adopted directly from Wartella et al.'s (2014) media usage survey to better understand the family dynamic.

YouTube usage and experiences. Respondents were asked to indicate how often they access YouTube for young children's music videos (survey item 12). They were given a list of possible frequencies, from "never" to "frequently," and if they selected "Never," then they were automatically sent to the final survey block, which invited respondents to type comments in an open-ended writing area. Item 13 included closed/guided response options as well as an open-ended "Other" option to gather data regarding the purpose(s) that YouTube served in the respondents' homes.

Survey items 17 and 19 aimed to collect data that would illustrate the YouTube music experiences that occurred, including children's responses, the video selection process, and an open-ended question (19) asking parents to list their favorite YouTube children's music channels. Because I was interested in how parents navigate the millions of videos available on YouTube for their children, item 18 asked, "When navigating the millions of videos available on YouTube, how do you select videos for your child?" and included three closed/guided responses, as well as an open-ended "Other:"

- Type in "children's music" (or something similar) in the search bar

- Find the most popular/most viewed videos

- Select an existing playlist (i.e. Little Baby Bum)

- Other

Musical parenting. Items 14 through 16 were adopted from Common Sense Media's survey and modified to meet the focus of this study. Item 14 listed three 
YouTube usage statements in which parent respondents selected the most appropriate response ranging from "Strongly agree" to "Strongly disagree." These statements were adopted from Common Sense Media's survey sub-section aimed towards parents of children under 2:

- In general, the less time kids spend on YouTube, the better off they are.

- My child benefits from the YouTube music education videos he/she watches.

- YouTube has the potential to be an effective children's music education resource.

Item 15 addressed the musical parenting needs of parents in this digital age. Previous research has focused mainly on singing in the musical parenting of young children, but no study has looked at YouTube-based experiences, which may very well be the most common type of music experience between parent and child today. Statements, which were rated on the "Strongly agree" to "Strongly disagree" scale, included:

- I have all of the skills necessary to be an effective musical parent to my child.

- I am comfortable assessing the quality of music education videos on YouTube.

- I am satisfied with the quantity of educational music videos available on YouTube.

- I find YouTube to be easily accessible.

- Parents should always participate actively with their child while watching videos. 
- I feel comfortable leaving my child to watch specific YouTube music videos alone.

Responses to these statements were intended to help provide a baseline upon which future inquiries about YouTube music education might build.

The final musical parenting section (items 20-21) asked respondents to describe their likelihood of utilizing existing and non-existent resources (20), and an open-ended response section for respondents to share any additional thoughts regarding the use of YouTube as a music education resource (21). After the concluding demographic questions and their submission of the survey, respondents were able to access the musical parenting document, "YouTube Suggestions and Guidelines" created by the researcher (see Appendix L). This served as a "thank you" to parents for participating in the project and provided them with examples and suggestions for quality YouTube music education experiences.

\section{Pilot Testing}

Six music education professionals and parents of children outside of the target population group for this study piloted the survey instrument. Pilot participants had children under the age of fifteen-months or over the age of three. They were asked to report the length of time spent taking the survey and any additional comments regarding the content of the survey. Pilot participants' feedback included suggestions for slight wording changes and creating additional categories to select from. Modifications and revisions were made for the final survey instrument. 


\section{Survey Validity}

Content validity measures "whether the instrument adequately covers all the content that it should with respect to the variable" (Heale \& Twycross, 2016). For this study, content validity was established in two ways: (a) survey questions were directly based on the current bodies of literature, including previous national media usage surveys, and extant literature documenting parental attitudes towards young children's media usage; and (b) pilot study participants were parents of young children (outside of the target age group) and university music instructors or professors. Based on their experiences with this study's parenting topic, the feedback they provided about the structure and content of the survey helped to establish the survey instrument's validity.

\section{Survey Reliability}

Because this was an exploratory, baseline survey of experiences and attitudes, included various types of questions, and was completely anonymous, statistical assessments of reliability were not feasible. Given the participant anonymity and voluntary nature of the survey, it is reasonable to assume that parents were straightforward and honest with their responses.

\section{Procedures}

Prior to activating and distributing the survey, I submitted the participant recruitment script (see Appendix D), an informed consent letter (see Appendix B) and the survey instrument (Appendix A) to the university's Institutional Review Board (IRB) for approval (see Appendices A-E). In both the participant recruitment script and the informed consent letter, participants were ensured that their identities would remain anonymous and that all reported data would remain in the aggregate and confidential. 
The informed consent (see Appendix C) served as the opening introduction to the online survey. By clicking to enter the survey, respondents consented to participate in the study. Upon approval by the Facebook Group moderators, the survey was distributed in the form of two separate postings in each Facebook group. Because there are numerous rules and guidelines users must follow within groups, the researcher had requested and received approval to post from the group's moderators. The post included a description of the survey, the purpose of the research, the minimal risks involved, the anonymity and protection of personal information, the musical parenting resource survey-takers would receive at the end, and included a web link to access the online survey (see Appendix E). To maximize user response, each post also included a short header introducing the researcher as a "fellow sleepless parent to young children."

The online survey link remained available to participants for two weeks. One week after the initial post was published, a follow-up message was sent as a reminder to participate within the next seven days.

\section{Data Analysis}

The data of closed-response questions were analyzed using descriptive statistics. Qualtrics, the online survey program, provided the calculations for frequencies, means, percentages, and standard deviations. However, many of the items needed to be exported into Microsoft Excel to create more meaningful data summaries. Percentages were also calculated for Likert-type scale items. For open-ended items, as well as responses to "Other," text responses were categorized and coded thematically (Creswell, 2007) in order to illustrate the findings. To establish reliability, another doctoral candidate in music education reviewed responses to the two open-ended items. I 
provided this person with twenty percent of participant responses, as well as a list of codes that emerged from my initial analysis of each survey item; the doctoral candidate then assigned codes to the data using the provided list. Our percentage of agreements was $95 \%$ after comparing assigned codes. We then discussed code differences until we achieved $100 \%$ agreement.

For several of the survey items, tables were constructed to "to present a large amount of information efficiently and to make their data more comprehensible" (American Psychological Association, 2010, p. 125). 


\section{CHAPTER FOUR}

\section{Results}

The primary purpose of this study was to provide researchers, educators, and parents with information about parent-toddler music experiences in a YouTube generation. Because no other study has examined the current practices of YouTube in musical parenting and young children's home music experiences, I hoped that the data gathered would inform early childhood music educators and serve as a starting point for future studies. Parents of children between 16-to-36 months of age were invited on social media groups to participate in this study. Both the recruitment script and the introductory page stated the target age range for potential parent participants' children. One hundred ninety two parents of toddlers $(N=192)$ completed the survey, but the number of responses to individual items may range from 172-192, because all participants did not answer all items.

\section{Demographics of Parent Respondents and Toddlers}

The first and last sections of the survey were designed to gather demographic information about the parents, toddlers, and families in order provide data about the characteristics of this study's population.

Twenty-eight states were represented by the respondents $(N=172)$ : Alabama,

California, Colorado, Connecticut, Florida, Georgia, Hawaii, Illinois, Indiana, Kansas, Kentucky, Maryland, Massachusetts, Mississippi, Missouri, Nevada, New Jersey, New York, North Carolina, Ohio, Oklahoma, Oregon, Pennsylvania, Rhode Island, South Carolina, Texas, Utah, Virginia, and Washington (see Table 1). 
Table 1

Frequencies and Percentages of States (for US Participants Who Responded, $N=172$ )

\begin{tabular}{|c|c|c|}
\hline State & Response Frequency & $\%$ \\
\hline California & 45 & 26 \\
\hline Missouri & 38 & 22 \\
\hline Indiana & 12 & 7 \\
\hline Texas & 10 & 6 \\
\hline Washington & 8 & 4.5 \\
\hline New York & 7 & 4 \\
\hline New Jersey & 6 & 3.5 \\
\hline Ohio & 6 & 3.5 \\
\hline Pennsylvania & 5 & 3 \\
\hline Colorado & 4 & 2 \\
\hline North Carolina & 4 & 2 \\
\hline Maryland & 3 & $<2$ \\
\hline Virginia & 3 & $<2$ \\
\hline Florida & 2 & $<2$ \\
\hline Illinois & 2 & $<2$ \\
\hline Kansas & 2 & $<2$ \\
\hline Kentucky & 2 & $<2$ \\
\hline Alabama & 1 & $<1$ \\
\hline
\end{tabular}




\begin{tabular}{lcc}
\hline State & Response Frequency & $\%$ \\
\hline Connecticut & 1 & $<1$ \\
Georgia & 1 & $<1$ \\
Hawaii & 1 & $<1$ \\
Massachusetts & 1 & $<1$ \\
Mississippi & 1 & $<1$ \\
Nevada & 1 & $<1$ \\
Oklahoma & 1 & $<1$ \\
Oregon & 1 & $<1$ \\
Rhode Island & 1 & $<1$ \\
South Carolina & 1 & $<1$ \\
Utah & 1 & 100 \\
Total & 172 & \\
\hline
\end{tabular}

The majority of respondents were from California (26\%) and Missouri (22\%). If respondents lived outside of the United States, the survey prompted them to specify their country of residence. Three respondents represented the United Kingdom and Canada. There were 17 participants who did not respond to this question.

Seventy percent of respondents identified themselves as White/Caucasian $(n=$ 136; see Table 2), followed by respondents identifying themselves as Asian $(n=33$, 17.01\%). There were participants representing several additional ethnicities, each accounting for approximately $3 \%$ or less of the total sample, while $2 \%$ percent of respondents selected, "Prefer not to disclose." Two out of the 6 respondents that selected 
"Other," further specified in the text box: one identified as English and another identified as Indigenous Central American. Table 2 displays all of the ethnicities reported by respondents.

Table 2

Respondents' Ethnic Backgrounds

\begin{tabular}{lcc}
\hline Ethnicity & Response Frequency & $\%$ \\
\hline White & 136 & 70.10 \\
Asian & 33 & 3.09 \\
Black or African American & 6 & 2.06 \\
Hispanic or Latino & 4 & 1.55 \\
Hawaiian or Pacific Islander & 3 & 1.03 \\
American Indian or Alaskan & 2 & 3.09 \\
Other & 6 & 2.06 \\
Prefer not to disclose & 4 & 100 \\
Total & 194 & \\
\hline
\end{tabular}

NOTE: Participants were asked to select all that apply.

The parent. Respondents were predominantly mothers $(n=189,98.4 \%$; see Table 3); only three respondents (1.6\%) identified themselves as fathers. Out of 192 respondents, $182(94.79 \%)$ reported their marital status as "married." The remaining 10 respondents who participated in this question reported being "single" or "separated." Table 3 lists all frequencies and percentages of reported marital statuses. 
Table 3

Frequencies and Percentages of Respondents' Marital Statuses

\begin{tabular}{lcr}
\hline Marital Status & Response Frequency & $\%$ \\
\hline $\begin{array}{l}\text { Married or in a domestic } \\
\text { partnership }\end{array}$ & 182 & 94.79 \\
$\begin{array}{l}\text { Single (never married) } \\
\text { Separated }\end{array}$ & 7 & 3.65 \\
Divorced & 3 & 1.56 \\
Widowed & 0 & - \\
Prefer not to disclose & 0 & - \\
Total & 0 & 100 \\
\hline
\end{tabular}

The largest group of respondents reported a Bachelor's Degree as their highest level of education completed or in progress $(n=65,38.5 \%$; see Table 4$)$, followed by a Master's Degree $(n=51,29.3 \%)$. Forty-one respondents reported a High School Diploma or Associate's Degree to be their highest level of education completed or in progress $(n=41,23.6 \%)$. Doctorate/Professional degree holders or students made up $8.6 \%$ of the respondent population. Table 4 lists the frequencies and percentages of all respondents' educational backgrounds. 
Table 4

Frequencies and Percentages of Parents' Highest Levels of Education

\begin{tabular}{lcc}
\hline Highest Level of Education & Response Frequency & $\%$ \\
\hline High School Diploma & 21 & 12.1 \\
Associate's Degree & 20 & 11.5 \\
Bachelor's Degree & 65 & 38.5 \\
Master's Degree & 51 & 29.3 \\
Doctorate/Professional Degree & 15 & 8.6 \\
Total & 172 & 100 \\
\hline
\end{tabular}

If respondents had selected "Married," "Separated," "Widowed," or "Divorced," in response to the question about marital status (item 4; see Table 3), the online survey prompted them with Item 23, "What is your spouse's highest level of education completed (or in progress)?" Table 5 lists the frequencies and percentages of the spouse's highest level of education. A general comparison of the educational backgrounds between these mothers and fathers revealed that mothers (37.9\%) tended to hold more graduate, professional, and doctoral degrees than fathers (31.5\%). 
Table 5

Frequencies and Percentages of Spouse's Highest Level of Education

\begin{tabular}{lcr}
\hline Education & Response Frequency & $\%$ \\
\hline High School Diploma & 27 & 16.4 \\
Associate's Degree & 27 & 16.4 \\
Bachelor's Degree & 59 & 35.7 \\
Master's Degree & 42 & 25.4 \\
Doctorate/Professional Degree & 10 & 6.1 \\
Total & 165 & 100 \\
\hline
\end{tabular}

There was representation of all family income levels, from "Less than $\$ 20,000$ " to "More than 120,000." One-third of the survey respondents reported a family income level of "More than $\$ 120,000 "(n=59,33.9 \%$; see Table 6,$)$. Less than $1 \%$ of respondents reported a family income level of "Less than $\$ 20,000$." Ten respondents selected, "Prefer not to disclose" (5.75\%). Table 6 lists the frequencies and percentages of all reported family income levels. 
Table 6

Frequencies and Percentages of Family Income Levels

\begin{tabular}{lcr}
\hline Income Level & Response Frequency & $\%$ \\
\hline Less than $\$ 20,000$ & 2 & 1.1 \\
$\$ 20,000-\$ 39,999$ & 12 & 6.9 \\
$\$ 40,000-\$ 59,999$ & 29 & 16.7 \\
$\$ 60,000-\$ 89,999$ & 28 & 16.1 \\
$\$ 90,000-\$ 119,999$ & 34 & 33.9 \\
More than $\$ 120,000$ & 59 & 5.8 \\
Prefer not to disclose & 10 & 100 \\
Total & 174 & \\
\hline
\end{tabular}

The toddler. Items 1 and 2 asked respondents about the child's gender and child's birth month and year, to confirm that the target population of respondents met the criteria (parent of a 16-to-36 month old child). The gender breakdown was as follows:

$53.13 \%(n=102)$ male and $46.35 \%(n=89)$ female. One respondent selected the option, "Prefer not to disclose." The average age of the toddler reported by 172 parent respondents was almost 2 years old $\left(\mathrm{M}_{\text {months }}=23.94, S D=6.4\right.$; see Table 7$)$. Table 7 lists the frequencies and percentages of all reported children's ages. 
Table 7

Frequencies and Percentages of Children's Ages in Months

\begin{tabular}{|c|c|c|}
\hline Age & Response Frequency & $\%$ \\
\hline$\overline{16}$ & 19 & 11.05 \\
\hline 17 & 16 & 9.30 \\
\hline 18 & 9 & 5.23 \\
\hline 19 & 10 & 5.81 \\
\hline 20 & 10 & 5.81 \\
\hline 21 & 6 & 3.49 \\
\hline 22 & 15 & 8.72 \\
\hline 23 & 11 & 6.40 \\
\hline 24 & 7 & 4.07 \\
\hline 25 & 5 & 2.91 \\
\hline 26 & 4 & 2.33 \\
\hline 27 & 9 & 5.23 \\
\hline 28 & 1 & .58 \\
\hline 29 & 5 & 2.91 \\
\hline 30 & 7 & 4.07 \\
\hline 31 & 8 & 4.65 \\
\hline 32 & 9 & 5.23 \\
\hline 33 & 4 & 2.33 \\
\hline 34 & 10 & 5.81 \\
\hline 35 & 2 & 1.16 \\
\hline 36 & 5 & 2.91 \\
\hline Total & 172 & 100 \\
\hline
\end{tabular}


Item 7 asked parents to share their children's birth order. The majority of parents reported their toddler to be "an only child" ( $n=88,48.62 \%$; see Table 8$)$, followed by "the youngest child" ( $n=49,27.07 \%)$. Table 8 lists the frequencies and percentages of all reported children's birth orders.

Table 8

Frequencies and Percentages of Children's Birth Orders

Birth Order Response Frequency

An only child

The youngest child

The oldest child

A middle child

88

7
48.62

27.07

20.44

3.87

The family. Item 8 asked respondents to describe the family's childcare arrangements. Because families often arrange multiple forms of childcare, participants were asked to select all responses that applied. Data revealed that roughly one-third of families included a stay-at-home parent $(n=77,32.6 \%$; see Table 9), followed by fulltime daycare $(n=54,22.88 \%)$ and relatives (approximately 20\%). Four respondents selected "Other" and reported different childcare arrangements. Table 9 lists the frequencies and percentages of all responses regarding childcare arrangements. 
Table 9

Frequencies and Percentages of Family Childcare Arrangements

Childcare Arrangement $\quad$ Response Frequency

Stay-at-home parent 77

Full-time daycare/preschool

Relatives

Part-time daycare

Nanny/Babysitter

Other

Mother's Day Out

Full time preschool

Full time caregiver- "I bring the children to work with me"

"Full time daycare up to 29 months"

Total

236

100

NOTE: Participants selected all responses that applied.

In Item 9, to help describe their child, parents responded on a scale from "a lot" to “not at all” to a listing of children's characteristics (adopted from Wartella et al.'s survey). A large majority of parents described their toddlers to be "active and energetic" ( $n=148,81.3 \%$; see Table 10$)$ and not very "easily overwhelmed or over-stimulated" $(53 \%)$. Table 8 lists the characteristics, in order of frequency (based on the category "a lot”), as reported by 182 (except for the statement, "Easily overwhelmed or overstimulated," which received 181 responses) parent-respondents. 
Table 10

Frequencies and Percentages of Parent-Reported Children's Characteristics

\begin{tabular}{|c|c|c|c|c|c|c|}
\hline Statements & A lot & Somewhat & Not much & Not at all & Not sure & $N$ \\
\hline \multirow[t]{2}{*}{ Active and energetic } & 148 & 33 & 1 & 0 & 0 & 182 \\
\hline & $(81.32 \%)$ & $(18.13 \%)$ & $(0.55 \%)$ & $(0 \%)$ & $(0 \%)$ & \\
\hline \multirow[t]{2}{*}{ Easy and adaptable } & 72 & 90 & 14 & 5 & 1 & 182 \\
\hline & $(39.56 \%)$ & $(49.45 \%)$ & $(7.69 \%)$ & $(2.75 \%)$ & $(0.55 \%)$ & \\
\hline \multirow{2}{*}{$\begin{array}{l}\text { Fidgets and squirms } \\
\text { frequently }\end{array}$} & 28 & 60 & 77 & 17 & 0 & 182 \\
\hline & $(15.38 \%)$ & $(32.97 \%)$ & $(42.31 \%)$ & $(9.34 \%)$ & & \\
\hline \multirow{2}{*}{$\begin{array}{l}\text { Easily overwhelmed or } \\
\text { over-stimulated }\end{array}$} & 8 & 34 & 96 & 41 & 2 & 181 \\
\hline & $(4.42 \%)$ & $(18.78 \%)$ & $(53.04 \%)$ & $(22.65 \%)$ & $(1.10 \%)$ & \\
\hline \multirow[t]{2}{*}{ Has difficulty focusing } & 6 & 40 & 100 & 29 & 7 & 182 \\
\hline & $(3.30 \%)$ & $(21.98 \%)$ & $(54.95 \%)$ & $(15.93 \%)$ & $(3.85 \%)$ & \\
\hline
\end{tabular}

NOTE: Characteristics were adopted from item 6 in the "Parenting in the Age of Digital Technology" Survey (Wartella et al., 2014). The most frequent response to each statement appears in bold type. 


\section{Music Backgrounds of Parents}

Parents were asked to rank their level of musical ability (item 5) on a scale of 0 (no knowledge) to 10 (professional/expertise). One hundred eighty-two participants responded to this item, ranging from 0 (no general music knowledge) to 10 (professional musician/expertise $)(M=4.05, S D=2.47$; See Table 11). The most frequent response was $5(n=26,14.29 \%)$. Eleven respondents $(n=11,6.04 \%)$ reported have no music ability, rating themselves with a " 0 ", and 3 respondents $(n=3,1.65 \%)$ reported professional music expertise or " 10 ." Approximately $30 \%$ of respondents $(n=55)$ reported that they had above average musical ability. The majority of respondents $(n=$ $101,55.5 \%$ ) reported below average musical ability.

Table 11

Frequencies and Percentages of Parents' Perceived Music Ability

\begin{tabular}{lcr}
\hline General Music Skills & Response Frequency & $\%$ \\
\hline 0 (no music ability) & 11 & 6.04 \\
1 & 25 & 13.74 \\
2 & 20 & 10.99 \\
3 & 24 & 13.19 \\
4 & 21 & 11.54 \\
5 & 26 & 14.29 \\
6 & 22 & 12.09 \\
7 & 18 & 9.89 \\
8 & 9 & 4.95 \\
9 & 3 & 1.65 \\
10 (professional) & 3 & 1.65 \\
Total & 182 & 100 \\
\hline
\end{tabular}


To gain a better understanding of parents' previous music backgrounds, item 6 gathered information on past and current formal and informal experiences. This may have included band, orchestra, choir, garage bands, church or community ensembles, and so forth. Almost $60 \%(n=111$; see Table 12$)$ of respondents had high school music experiences; less than half of those respondents $(n=42,24 \%)$ had college music experiences; $12.6 \%(n=21)$ experienced music post-college; only 10 respondents $(n=$ $10,6.1 \%$ ) reported that they were currently participating in musical experiences. Table 12 lists the frequencies and percentages of respondents' previous music experiences.

Table 12

Frequencies and Percentages of Parental Music Backgrounds

\begin{tabular}{lccc}
\hline Music Experience & Yes & No & $N$ \\
\hline In High School & 111 & 79 & 190 \\
In College & $(58.42 \%)$ & $(41.58 \%)$ & 172 \\
& 42 & 130 & 167 \\
Post College & $(24.42 \%)$ & $(75.58 \%)$ & 164 \\
Currently & 21 & 146 & \\
& $(12.57 \%)$ & $(87.43 \%)$ & \\
\hline
\end{tabular}

NOTE: Participants selected all responses that applied.

\section{Digital Home Music Environment}

This section of the survey was designed to collect information regarding the digital home music environment in order to answer Research Question 1: "What does the digital home music environment look like?" Sub-questions pertaining to family activities and YouTube usage included: (a) how many YouTube/Internet accessible devices are in the home?" (b) "How often do parents access YouTube for young children's music 
education videos?" (c) "Do families participate in singing and music-making? What other activities are they doing together?" and (d) "Is there a relationship between demographic variables and the frequency of singing?"

Items 10 through 13 served to gather data on the digital home music environments of today's families, specifically those including young children. Regarding the number of YouTube and Internet-accessible devices in the home (i.e. smartphones, tablets, smart televisions), $36.8 \%$ of respondents ( $n=67$; see Table 12) reported to have "more than six." Out of 182 respondents, only two $(n=1.1 \%)$ reported having just two Internetaccessible devices in the home. Approximately $62 \%$ reported having three to six devices.

Table 13

Frequencies and Percentages of YouTube/Internet-Accessible Devices in the Home

\begin{tabular}{lcr}
\hline \multicolumn{1}{c}{ Number of Devices } & Response Frequency \\
\hline More than six & $\mathbf{6 7}$ & 36.81 \\
Five & 35 & 19.23 \\
Four & 33 & 18.13 \\
Six & 24 & 13.19 \\
Three & 21 & 11.54 \\
Two & 2 & 1.10 \\
One & 0 & - \\
None & 0 & - \\
Total & 182 & $100 \%$ \\
\hline
\end{tabular}


To gain a better understanding of the families in the home environment, respondents were asked to describe how their families spend time together, capturing frequencies of specific pastimes (item 11; see Table 14). Statements included common family activities, adopted from the Common Sense Media Survey (2017) such as: watching TV, reading together, singing songs, cooking, doing things indoors and outdoors, and using media devices. Based on 182 responses, the most popular family pastime was "doing things outside together" $(68.13 \%)$, followed closely by "cooking and eating meals" (46.7\%). For statement seven, "singing songs or making music," 63 respondents (34.6\%) selected "A lot," and 80 respondents (46.7\%) selected "somewhat." Thirty respondents (16.5\%) stated that they rarely participate in music activities at home; four respondents $(2.2 \%)$ selected "Never." Statement nine was "Doing things on a computer, tablet, or smartphone." Interestingly, the breakdown of technology-centered family activity was split exactly 50:50. Half of the 182 respondents to this item $(n=91)$ selected "A lot" or "Somewhat"; the other 91 respondents selected "Not much" or "Never." Other media activities such as, "Watching television or movies," was reported to be enjoyed "Somewhat" by $50 \%$ of the respondents. Forty-nine respondents $(n=49$, $26.92 \%$ ) reported enjoying "A lot" of television or movie watching in their families. Table 14 lists the frequencies and percentages of all family pastimes in the home environment. 
Table 14

Frequencies and Percentages of Family Pastimes in the Home Environment

\begin{tabular}{|c|c|c|c|c|c|c|c|c|c|}
\hline \multirow[t]{2}{*}{ Type of Activity } & \multicolumn{2}{|c|}{ A lot } & \multicolumn{2}{|c|}{ Somewhat } & \multicolumn{2}{|c|}{ Not much } & \multicolumn{2}{|c|}{ Not at all } & \multirow{2}{*}{$\begin{array}{r}N \\
182\end{array}$} \\
\hline & Frequency & $\%$ & Frequency & $\%$ & Frequency & $\%$ & Frequency & $\%$ & \\
\hline $\begin{array}{l}\text { Doing things } \\
\text { outside together }\end{array}$ & 124 & $68.13 \%$ & 51 & $28.02 \%$ & 7 & $3.85 \%$ & 0 & - & 182 \\
\hline Reading together & 96 & $52.75 \%$ & 73 & $40.11 \%$ & 12 & $6.59 \%$ & 1 & $.55 \%$ & 182 \\
\hline $\begin{array}{l}\text { Doing indoor } \\
\text { activities together }\end{array}$ & 89 & $48.90 \%$ & 81 & $44.51 \%$ & 12 & $6.59 \%$ & 0 & - & 182 \\
\hline $\begin{array}{l}\text { Cooking and eating } \\
\text { Meals }\end{array}$ & 85 & $46.70 \%$ & 80 & $43.96 \%$ & 16 & $8.79 \%$ & 1 & $.55 \%$ & 182 \\
\hline $\begin{array}{l}\text { Singing songs or } \\
\text { music making }\end{array}$ & 63 & $34.62 \%$ & 85 & $46.70 \%$ & 30 & $16.48 \%$ & 4 & $2.20 \%$ & 182 \\
\hline $\begin{array}{l}\text { Watching TV or } \\
\text { Movies }\end{array}$ & 49 & $26.92 \%$ & 91 & $50 \%$ & 37 & $20.33 \%$ & 5 & $2.75 \%$ & 182 \\
\hline $\begin{array}{l}\text { Doing things on a } \\
\text { device }\end{array}$ & 17 & $9.34 \%$ & 74 & $40.66 \%$ & 77 & $42.31 \%$ & 14 & $7.69 \%$ & 182 \\
\hline $\begin{array}{l}\text { Participate in clubs } \\
\text { or other groups }\end{array}$ & 15 & $8.24 \%$ & 48 & $26.37 \%$ & 76 & $41.76 \%$ & 43 & $23.63 \%$ & 182 \\
\hline $\begin{array}{l}\text { Playing or attending } \\
\text { sports events }\end{array}$ & 12 & $6.59 \%$ & 46 & $25.27 \%$ & 71 & $39.01 \%$ & 53 & $29.12 \%$ & 182 \\
\hline
\end{tabular}

NOTE: The most frequent response to each statement appears in bold type. 
To examine whether relationships existed between parental music backgrounds and frequency of singing and music making in the home (Research Question 1d), Table 15 compared the results of the two variables.

Table 15

Frequencies and Percentages of Family Music Making and Parental Music Backgrounds

\begin{tabular}{lcccccc}
\hline Experiences & A lot & Somewhat & $\begin{array}{c}\text { Not } \\
\text { much }\end{array}$ & Not at all & $n$ & $\%$ \\
\hline High School & 48 & 44 & 13 & 3 & 108 & 44.44 \\
College & 23 & 16 & 3 & 0 & 42 & 54.76 \\
Post College & 15 & 51 & 1 & 0 & 21 & 71.43 \\
Currently & 10 & 0 & 0 & 0 & 10 & 100 \\
\hline
\end{tabular}

NOTE: \% Column presents percentage of respondents reporting "A lot" of singing songs or music making based on the number reporting each education level $(n)$

Table 15 displays the frequencies and percentages of responses to the item "Singing songs and music making," one of the Family Pastimes item statements, by the parents' previous music backgrounds. Over $44 \%$ of the parents with high school music experiences reported "a lot" of "singing songs and music making." The percentage responding "a lot" increased to over half $(54.76 \%)$ of the 42 respondents with college music experiences, and $71.43 \%$ of those with post-college music experiences selected "a lot". All parents currently experiencing music indicated that they spend a lot of time engaged in singing or music making with their children $100 \%(N=10)$. 


\section{YouTube Music Usage and Purposes}

The breakdown of YouTube access and usage was relatively even across the response levels: approximately 55\% of respondents reported accessing YouTube children's music videos occasionally (1-2 times per week) or regularly (1-2 times per day) $(n=57,31.32 \%$; see Table 16). The smallest percentage of the respondents $(6.59 \%)$ reported frequent ( 3 or more times per day) YouTube usage for children's music videos. The 24 respondents (13.2\%) that selected "Never" were automatically skipped to the end of the block (item 26), to the remaining musical parenting questions and closing demographics section. The rest of the participants continued the survey with the items related to their YouTube usage.

Table 16

Frequencies and Percentages of Parents Accessing YouTube Children's Music

\begin{tabular}{lcc}
\hline YouTube Access & Response Frequency & $\%$ \\
\hline Occasionally (1-2 times/week) & 57 & 31.32 \\
Rarely (1-2 times/month) & 45 & 24.73 \\
Regularly (1-2 times/day) & 44 & 24.18 \\
Never & 24 & 13.19 \\
Frequently (3 or more times/ day) & 12 & 6.59 \\
Total & 182 & 100 \\
\hline
\end{tabular}

With most of this study's participants having higher-than-average family income levels, I was interested in examining whether relationships existed between family income levels and frequency of YouTube access. According to the breakdown of family 
income levels, the highest frequency of YouTube music access occurred in respondents reporting a family income level of $\$ 20,000$ to $\$ 39,999(M=3.25, S D=1.23)$, followed by respondents reporting a family income level of $\$ 40,000$ to $\$ 59,999(M=3.17, S D=$ 0.75). Respondents who reported a family income level of over $\$ 120,000$ were the third highest population of parents accessing YouTube music education videos $(M=3.03, S D$ $=1.22)$. Participants reporting the lowest family income level, less than $\$ 20,000$, revealed that they have never used YouTube with their children.

Table 17

Family Income Level and Frequency of YouTube Access

\begin{tabular}{lccc}
\hline Income & $M$ & SD & $N$ \\
\hline$\$ 20,000-\$ 39,999$ & 3.25 & 1.23 & 12 \\
$\$ 40,000-\$ 59,999$ & 3.17 & 0.75 & 29 \\
More than $\$ 120,000$ & 3.03 & 1.22 & 60 \\
$\$ 60,000-\$ 89,999$ & 2.64 & 1.08 & 28 \\
Prefer not to disclose & 2.60 & 1.02 & 10 \\
$\$ 90,000-119,000$ & 2.53 & 1.06 & 34 \\
Less than $\$ 20,000$ & 1.00 & - & 2 \\
Total & & & 175 \\
\hline
\end{tabular}

NOTE: Means were calculated with the following scale: $1=$ Never, $2=$ Rarely $(1$ to 2 times per month), 3 = Occasionally ( 1 to 2 times per week), $4=$ Regularly (1 to 2 times per day), $5=$ Frequently $(3$ or more times per day) 


\section{Roles of YouTube}

Table 18 illustrates the frequencies and percentages of purposes for using YouTube. Item 13 asked respondents to describe what purpose(s) YouTube serves in their homes (Research Question 2a), in order to gain perspective on why and for what reason parents are utilizing YouTube. The top purpose for YouTube usage was "Entertainment" ( $n=111,34.7 \%$; see Table 14), followed by "Music Resource" $(n=99$, 30.9\%). Respondents were able to select more than one response for this survey item, so entertainment and music could serve equal purposes for some families. Based on these data, families are more inclined to utilize Internet-based resources to access and play songs in lieu of CDs, DVDs, and radio. One-fourth of the respondents reported that they used YouTube for "Learning" ( $n=78,24.4 \%)$. In "Other," all six respondents specified "Distraction" to be another usage for YouTube. For example, at a restaurant or a grocery store, YouTube music videos would keep the toddlers occupied.

Table 18

Frequency and Percentages of Purposes for using YouTube

\begin{tabular}{lcc}
\hline Purpose & Frequency & $\%$ \\
\hline Entertainment & 111 & 34.69 \\
Music Resource & 99 & 30.94 \\
Learning & 78 & 24.38 \\
Daytime/Nighttime Routine & 26 & 8.13 \\
Other (please specify) & & 1.88 \\
$\quad$ Distraction & 6 & 100 \\
TOTAL & 320 & \\
\hline
\end{tabular}

NOTE: Participants selected all responses that applied. 
Items 14 and 15 included Likert-type scale statements centered on musical parenting. Respondents indicated the extent of their agreement on a 7-point scale: from Strongly Agree (1) to Strongly Disagree (7). Although 36.36\% of respondents selected "strongly agree," "agree" or "somewhat agree" with the statement, "I have all of the skills necessary to be an effective musical parent" (see Table 19), 48.7\% disagreed with the statement, and $14.94 \%$ neither agreed nor disagreed.

Table 19

Frequency and Percentage of Musical Parenting Statement

\begin{tabular}{lccccccc}
\hline & 1 & 2 & 3 & 4 & 5 & 6 & 7 \\
\hline $\begin{array}{c}\text { I have all of the skills } \\
\text { necessary to be an } \\
\text { effective musical } \\
\text { parent to my child. }\end{array}$ & 9 & 21 & 26 & 23 & $\mathbf{3 8}$ & 28 & 9 \\
\end{tabular}

NOTE: The scale ranged from $1=$ Strongly Agree to 7 = Strongly Disagree

To examine whether a relationship exists between parents' perceived music skills (see Table 11) and musical parenting beliefs (see Table 19), I calculated the means and standard deviations for the two variables. On scale of 0 (no music knowledge) through 10 (professional music knowledge), parents who perceived their own music skills to be 6 or higher reported a stronger level of agreement in the musical parenting belief statement [I have the skills necessary to be an effective musical parent] $(M=2.78)$. Respondents whose perceived music skill was less than or equal to 5 reported lower levels of agreement with the statement $(M=4.7)$.

Respondents indicated the extent of their likelihood of participating in specific music education resources by responding to a 5-point Likert-type scale (see Table 20): Completely likely (5) to Not at all likely (1). Out of 175 respondents, almost $20 \%$ stated 
that they would definitely enroll their children in a music class. Another $45 \%$ of respondents reported being "moderately likely" or "very likely" to enroll their children in a music class. Almost $11 \%$ stated that they would not enroll their children at all. Community music programs were found to be the most popular option for parents as a music education resource ("very likely" plus "completely likely" = 114 responses; $65.2 \%)$. In response to the statement regarding usage of internet-based information/resources, a total of 63 respondents (36\%) reported that they were not likely or slightly likely to search or read the Internet for information about music for children, while $64 \%$ of respondents $(n=112)$ were at least somewhat likely to do so.

Table 20 lists the frequencies and percentages of all activities and responses. 
Table 20

Frequencies and Percentages of Musical Parenting Resource Usage

\begin{tabular}{|c|c|c|c|c|c|c|}
\hline Activity & $\begin{array}{l}\text { Not at all } \\
\text { likely }\end{array}$ & $\begin{array}{l}\text { Slightly } \\
\text { likely }\end{array}$ & $\begin{array}{l}\text { Moderately } \\
\text { likely }\end{array}$ & Very likely & $\begin{array}{l}\text { Completely } \\
\text { likely }\end{array}$ & $\mathrm{N}$ \\
\hline $\begin{array}{l}\text { Attend music } \\
\text { education workshops }\end{array}$ & $\begin{array}{c}64 \\
(36.78 \%)\end{array}$ & $\begin{array}{c}41 \\
(23.56 \%)\end{array}$ & $\begin{array}{c}34 \\
(19.54 \%)\end{array}$ & $\begin{array}{c}26 \\
(14.94 \%)\end{array}$ & $\begin{array}{c}9 \\
(5.17 \%)\end{array}$ & 174 \\
\hline $\begin{array}{l}\text { Take private music } \\
\text { lessons }\end{array}$ & $\begin{array}{c}33 \\
(18.97 \%)\end{array}$ & $\begin{array}{c}39 \\
(22.41 \%)\end{array}$ & $\begin{array}{c}38 \\
(21.84 \%)\end{array}$ & $\begin{array}{c}39 \\
(22.41 \%)\end{array}$ & $\begin{array}{c}25 \\
(14.37 \%)\end{array}$ & 174 \\
\hline $\begin{array}{l}\text { Search/read the Internet } \\
\text { for information about } \\
\text { music for children }\end{array}$ & $\begin{array}{c}26 \\
(14.86 \%)\end{array}$ & $\begin{array}{c}37 \\
(21.14 \%)\end{array}$ & $\begin{array}{c}51 \\
(29.14 \%)\end{array}$ & $\begin{array}{c}35 \\
(20 \%)\end{array}$ & $\begin{array}{c}26 \\
(14.86 \%)\end{array}$ & 175 \\
\hline $\begin{array}{l}\text { Enroll your child in a } \\
\text { music class }\end{array}$ & $\begin{array}{c}19 \\
(10.86 \%)\end{array}$ & $\begin{array}{c}44 \\
(25.14 \%)\end{array}$ & $\begin{array}{c}43 \\
(24.57 \%)\end{array}$ & $\begin{array}{c}35 \\
(20 \%)\end{array}$ & $\begin{array}{c}34 \\
(19.43 \%)\end{array}$ & 175 \\
\hline $\begin{array}{l}\text { Take your child to } \\
\text { children's music } \\
\text { concerts }\end{array}$ & $\begin{array}{c}18 \\
(10.29 \%)\end{array}$ & $\begin{array}{c}34 \\
(19.43 \%)\end{array}$ & $\begin{array}{c}39 \\
(22.29 \%)\end{array}$ & $\begin{array}{c}56 \\
(32 \%)\end{array}$ & $\begin{array}{c}28 \\
(16 \%)\end{array}$ & 175 \\
\hline $\begin{array}{l}\text { Take your child to } \\
\text { community music } \\
\text { programs }\end{array}$ & $\begin{array}{c}7 \\
(4 \%)\end{array}$ & $\begin{array}{c}20 \\
(11.43 \%)\end{array}$ & $\begin{array}{c}34 \\
(19.43 \%)\end{array}$ & $\begin{array}{c}60 \\
(34.29 \%)\end{array}$ & $\begin{array}{c}54 \\
(30.86 \%)\end{array}$ & 175 \\
\hline
\end{tabular}

NOTE: The most frequent response to each statement appears in bold type. 
Participants responded to a block of statements pertaining to parental attitudes and beliefs towards YouTube related to Research Question 3: "What are parental attitudes and beliefs towards YouTube as a means of digital musical parenting?" Sub-questions included: (a) "What are parental beliefs about YouTube children's music videos” (b) “How do parents feel about YouTube music videos' effects on different areas of children's development?" (c) “Do parents consider YouTube to be an effective children's music education resource?"

Over $65 \%$ of respondents reported feeling comfortable assessing the quality of YouTube music education videos (see Table 21). Regarding their satisfaction with the quantity of children's music videos available on YouTube, the majority of respondents (39\%) reported neither agreeing nor disagreeing with the statement. Because access is a common hurdle in early childhood music resources, responses were solicited to the statement, "I find YouTube to be easily accessible." Although five respondents reported that YouTube is not easily accessible, a total of over $95 \%$ of the respondents $(n=145)$ agreed with the statement. Most respondents also felt strongly that "parents should always participate actively with their child when watching YouTube." Over 50\% of respondents selected "strongly agree" and another 40\% selected "agree" or "somewhat agree" in response to that statement. Two respondents disagreed with the statement $(n=$ 2; see Table 15) and five respondents were indifferent, selecting "neither agree nor disagree." The final statement was "I feel comfortable leaving my child to watch specific YouTube music videos or channels alone," and the responses were evenly distributed across the various responses. Table 21 lists the frequencies and percentages of all responses to survey item 15 . 
Table 21

Frequencies and Percentages of Digital Musical Parenting Statements

\begin{tabular}{|c|c|c|c|c|c|c|c|c|}
\hline Statements & $\begin{array}{c}1 \\
\text { Strongly } \\
\text { Agree }\end{array}$ & $\begin{array}{c}2 \\
\text { Agree }\end{array}$ & $\begin{array}{c}3 \\
\text { Somewhat } \\
\text { Agree }\end{array}$ & $\begin{array}{c}4 \\
\text { Neither agree } \\
\text { nor disagree }\end{array}$ & $\begin{array}{c}5 \\
\text { Somewhat } \\
\text { disagree }\end{array}$ & $\begin{array}{c}6 \\
\text { Disagree }\end{array}$ & \begin{tabular}{c}
\multicolumn{1}{c}{7} \\
Strongly \\
Disagree
\end{tabular} & $\mathrm{N}$ \\
\hline $\begin{array}{l}\text { I have all of the skills } \\
\text { necessary to be an } \\
\text { effective musical parent } \\
\text { to my child. }\end{array}$ & $\begin{array}{c}9 \\
(5.84 \%)\end{array}$ & $\begin{array}{c}21 \\
(13.64 \%)\end{array}$ & $\begin{array}{c}26 \\
(16.88 \%)\end{array}$ & $\begin{array}{c}23 \\
(14.94 \%)\end{array}$ & $\begin{array}{c}38 \\
(24.68 \%)\end{array}$ & $\begin{array}{c}28 \\
(18.18 \%)\end{array}$ & $\begin{array}{c}9 \\
(5.84 \%)\end{array}$ & 154 \\
\hline $\begin{array}{l}\text { I am comfortable } \\
\text { assessing the quality of } \\
\text { music education videos } \\
\text { on YouTube. }\end{array}$ & $\begin{array}{c}16 \\
(10.39 \%)\end{array}$ & $\begin{array}{c}47 \\
(30.52 \%)\end{array}$ & $\begin{array}{c}39 \\
(25.32 \%)\end{array}$ & $\begin{array}{c}22 \\
(14.29 \%)\end{array}$ & $\begin{array}{c}15 \\
(9.74 \%)\end{array}$ & $\begin{array}{c}12 \\
(7.79 \%)\end{array}$ & $\begin{array}{c}3 \\
(1.95 \%)\end{array}$ & 154 \\
\hline $\begin{array}{l}\text { I am satisfied with the } \\
\text { quantity of education } \\
\text { YouTube music videos } \\
\text { available for my child. }\end{array}$ & $\begin{array}{c}10 \\
(6.49 \%)\end{array}$ & $\begin{array}{c}30 \\
(19.48 \%)\end{array}$ & $\begin{array}{c}33 \\
(21.43 \%)\end{array}$ & $\begin{array}{c}60 \\
(38.96 \%)\end{array}$ & $\begin{array}{c}10 \\
(6.49 \%)\end{array}$ & $\begin{array}{c}8 \\
(5.19 \%)\end{array}$ & $\begin{array}{c}3 \\
(1.95 \%)\end{array}$ & 154 \\
\hline $\begin{array}{l}\text { I find YouTube to be } \\
\text { easily accessible. }\end{array}$ & $\begin{array}{c}68 \\
(44.74 \%)\end{array}$ & $\begin{array}{c}61 \\
(40.13 \%)\end{array}$ & $\begin{array}{c}16 \\
(10.53 \%)\end{array}$ & $\begin{array}{c}2 \\
(1.32 \%)\end{array}$ & $\begin{array}{c}3 \\
(1.97 \%)\end{array}$ & $\begin{array}{c}1 \\
(.66 \%)\end{array}$ & $\begin{array}{c}1 \\
(.66 \%)\end{array}$ & 152 \\
\hline $\begin{array}{l}\text { Parents should always } \\
\text { participate actively } \\
\text { with their child while } \\
\text { watching YouTube. }\end{array}$ & $\begin{array}{c}84 \\
(54.90 \%)\end{array}$ & $\begin{array}{c}39 \\
(25.49 \%)\end{array}$ & $\begin{array}{c}23 \\
(15.03 \%)\end{array}$ & $\begin{array}{c}5 \\
(3.27 \%)\end{array}$ & $\begin{array}{c}1 \\
(.65 \%)\end{array}$ & $\begin{array}{c}1 \\
(.65 \%)\end{array}$ & $\begin{array}{c}0 \\
(0 \%)\end{array}$ & 153 \\
\hline $\begin{array}{l}\text { I feel comfortable leaving } \\
\text { my child to watch } \\
\text { specific YouTube } \\
\text { music videos or } \\
\text { channels. }\end{array}$ & $\begin{array}{c}16 \\
(10.39 \%)\end{array}$ & $\begin{array}{c}39 \\
(25.32 \%)\end{array}$ & $\begin{array}{c}36 \\
(23.38 \%)\end{array}$ & $\begin{array}{c}7 \\
(4.55 \%)\end{array}$ & $\begin{array}{c}20 \\
(12.99 \%)\end{array}$ & $\begin{array}{c}17 \\
(11.04 \%)\end{array}$ & $\begin{array}{c}19 \\
(12.34 \%)\end{array}$ & 154 \\
\hline
\end{tabular}

NOTE: The most frequent response to each statement appears in bold type. 
Item 14 included three statements that aimed to develop a general understanding of current parental attitudes and beliefs towards YouTube. Of the 154 respondents, 103 (66.8\%) selected either "strongly agree," "agree," or "somewhat agree" for the statement, "In general, the less time kids spend on YouTube, the better." One respondent selected "strongly disagree."

To determine if differences exist between parents of "first born" and/or "only children" and parents with more than one child, regarding usage and perspectives of YouTube music, I compared the demographic variable (child's birth order) with the following statement [In general, the less time kids spend on YouTube, the better off they are]. Thirty-nine respondents $(37.5 \%)$ with children identified as "an only child" or a "first born child" selected "Strongly agree" or "Agree," compared to the $31.3 \%(n=15)$ of parents with multiple children (toddler identified as "the youngest child" or "a middle child") More parents with one child (or with their first born child) believed that less time spent on YouTube was beneficial.

Although 14 respondents disagreed with the statement, "my child benefits from the YouTube music education videos he/she watches," 122 respondents $(80 \%)$ indicated some degree of agreement (strongly agree, agree, or somewhat agree). For the statement, "YouTube has the potential to be an effective children's music education resource," 26 respondents (16.88\%) strongly agreed, 70 respondents (45.45\%) agreed, and 41 respondents (26.62\%) somewhat agreed. Even though four respondents disagreed, the vast majority of respondents also reported that YouTube has the potential to be an effective children's music education resource $(n=137,89 \%$; see Table 22$)$. Thirteen respondents selected "neither agree nor disagree." 
Table 22

Frequencies and Percentages of Parental Beliefs and Attitudes Towards YouTube Music

\begin{tabular}{|c|c|c|c|c|c|c|c|c|}
\hline Statements & $\begin{array}{c}1 \\
\text { Strongly } \\
\text { Agree }\end{array}$ & $\begin{array}{c}2 \\
\text { Agree }\end{array}$ & $\begin{array}{c}3 \\
\text { Somewhat } \\
\text { Agree }\end{array}$ & $\begin{array}{c}4 \\
\text { Neither } \\
\text { agree nor } \\
\text { disagree }\end{array}$ & $\begin{array}{c}5 \\
\text { Somewhat } \\
\text { disagree }\end{array}$ & $\begin{array}{c}6 \\
\text { Disagree }\end{array}$ & $\begin{array}{c}7 \\
\text { Strongly } \\
\text { Disagree }\end{array}$ & $\mathrm{N}$ \\
\hline $\begin{array}{l}\text { In general, the less } \\
\text { time kids spend } \\
\text { on YouTube, the } \\
\text { better off they are. }\end{array}$ & $\begin{array}{c}27 \\
(17.53 \%)\end{array}$ & $\begin{array}{c}28 \\
(18.18 \%)\end{array}$ & $\begin{array}{c}48 \\
(31.17 \%)\end{array}$ & $\begin{array}{c}33 \\
(21.43 \%)\end{array}$ & $\begin{array}{c}11 \\
(7.14 \%)\end{array}$ & $\begin{array}{c}6 \\
(3.90 \%)\end{array}$ & $\begin{array}{c}1 \\
(0.65 \%)\end{array}$ & 154 \\
\hline $\begin{array}{l}\text { My child benefits } \\
\text { from the } \\
\text { YouTube music } \\
\text { education videos } \\
\text { he/she watches. }\end{array}$ & $\begin{array}{c}15 \\
(9.74 \%)\end{array}$ & $\begin{array}{c}51 \\
(33.12 \%)\end{array}$ & $\begin{array}{c}56 \\
(36.36 \%)\end{array}$ & $\begin{array}{c}18 \\
(11.69 \%)\end{array}$ & $\begin{array}{c}6 \\
(3.90 \%)\end{array}$ & $\begin{array}{c}6 \\
(3.90 \%)\end{array}$ & $\begin{array}{c}2 \\
(1.30 \%)\end{array}$ & 154 \\
\hline $\begin{array}{l}\text { YouTube has the } \\
\text { potential to be an } \\
\text { effective } \\
\text { children's music } \\
\text { education resource. }\end{array}$ & $\begin{array}{c}26 \\
(16.88 \%)\end{array}$ & $\begin{array}{c}70 \\
(45.45 \%)\end{array}$ & $\begin{array}{c}41 \\
(26.62 \%)\end{array}$ & $\begin{array}{c}13 \\
(8.44 \%)\end{array}$ & $\begin{array}{c}2 \\
(1.30 \%)\end{array}$ & $\begin{array}{c}1 \\
(0.65 \%)\end{array}$ & $\begin{array}{c}1 \\
(0.65 \%)\end{array}$ & 154 \\
\hline
\end{tabular}

To further examine parental attitudes and beliefs towards YouTube as a music education resource, item 16 aimed to gauge the perceived effects of YouTube on children's development. Although one respondent stated that YouTube does more harm than good, a majority of respondents $(n=103,68.2 \%$; see Table 23$)$ indicated that YouTube helps children's music skills. Over $70 \%$ of respondents attributed YouTube to helping with children's overall learning. Table 23 lists the frequencies and percentages of responses to all areas of development. 
Table 23

Frequencies and Percentages of Perceived YouTube Effects on Development

\begin{tabular}{lccccc}
\hline Area & Helps & Hurts & $\begin{array}{c}\text { Makes No } \\
\text { Difference }\end{array}$ & Not Sure & N \\
\hline Learning & $\mathbf{1 0 7}$ & 5 & 29 & 10 & 151 \\
& $\mathbf{( 7 0 . 8 6 \% )}$ & $(3.31 \%)$ & $(19.21 \%)$ & $(6.62 \%)$ & \\
Music Skills & $\mathbf{1 0 3}$ & 1 & 25 & 22 & 151 \\
& $(\mathbf{6 8 . 2 1} \%)$ & $(0.66 \%)$ & $(16.56 \%)$ & $(14.57 \%)$ & \\
Creativity & $\mathbf{6 4}$ & 19 & 38 & 29 & 150 \\
& $(\mathbf{4 2 . 6 7 \%})$ & $(12.67 \%)$ & $(25.33 \%)$ & $(19.33 \%)$ & \\
Ability to Focus & 46 & 28 & $\mathbf{4 7}$ & 30 & 151 \\
& $(30.46 \%)$ & $(18.54 \%)$ & $\mathbf{( 3 1 . 1 3 \% )}$ & $(19.87 \%)$ & \\
Social Skills & 22 & 31 & $\mathbf{7 8}$ & 19 & 150 \\
& $(14.67 \%)$ & $(20.67 \%)$ & $\mathbf{( 5 2 \% )}$ & $(12.67 \%)$ & \\
Behavior & 18 & 38 & $\mathbf{6 8}$ & 27 & 151 \\
& $(11.92 \%)$ & $(25.17 \%)$ & $\mathbf{( 4 5 . 0 3 \% )}$ & $(17.88 \%)$ & \\
Physical Activity & 16 & $\mathbf{7 0}$ & 58 & 7 & 151 \\
& $(10.60 \%)$ & $\mathbf{( 4 6 . 3 6 \% )}$ & $(38.41 \%)$ & $(4.64 \%)$ & \\
\hline
\end{tabular}

NOTE: The most frequent response to each statement appears in bold type.

\section{YouTube Music Experiences}

Because little is known about how parents select videos for use with children, item 18 was designed to gain knowledge about this [Research Question 2c]. Most respondents reported typing in "children's music" or "something similar" in YouTube's search bar ( $n=93,42.3 \%$; see Table 20$)$, followed by selecting an existing playlist $(32.7 \%)$. Out of 25 respondents, 24 provided additional text information about their process, which were categorized into 7 processes, included in Table 24. The process most frequently reported by parents to be part of their YouTube video selection was "searching for a specific song" $(n=14)$. Table 24 lists the frequencies and percentages of all reported processes. 
Table 24

Frequencies and Percentages of How Parents select YouTube Music Education Videos

\begin{tabular}{|c|c|c|}
\hline Process & Frequency & $\%$ \\
\hline Type in "children's music" & 93 & 42.27 \\
\hline Select an existing playlist & 72 & 32.73 \\
\hline $\begin{array}{l}\text { Find the most popular/viewed } \\
\text { songs }\end{array}$ & 30 & 13.64 \\
\hline Other* & 25 & 11.36 \\
\hline $\begin{array}{l}\text { Search for specific } \\
\text { song }\end{array}$ & 14 & \\
\hline Request from child & 4 & \\
\hline $\begin{array}{l}\text { YouTube } \\
\text { suggestions }\end{array}$ & 2 & \\
\hline $\begin{array}{l}\text { Other } \\
\text { parents/caregivers' } \\
\text { suggestions }\end{array}$ & 2 & \\
\hline $\begin{array}{l}\text { From favorite } \\
\text { movies }\end{array}$ & 1 & \\
\hline $\begin{array}{l}\text { Parents' music } \\
\text { preference }\end{array}$ & 1 & \\
\hline $\begin{array}{l}\text { Create individual } \\
\text { playlist }\end{array}$ & 1 & \\
\hline Total & 220 & 100 \\
\hline
\end{tabular}

*Only 24 out of the 25 respondents who selected "Other" provided additional details NOTE: Participants selected all responses that applied.

Item 17 was designed to depict a typical YouTube music experience. It asked respondents to describe how their child responded to YouTube music and movement videos. The most popular response was "Move/Dance" ( $n=119 ; 36.1 \%$; see Table 25), followed closely by "Sing/Chant Along” (35.5\%). Eighty-seven respondents reported 
children listening quietly. Out of the 25 respondents that selected "Other," only 6 provided additional information in the text box (see full list in Appendix G). Two respondents reported active engagement and participation (for example, "asks me questions, points things out"). Two mentioned passive engagement by their toddlersone described the child to be "mesmerized by the visuals," and another discussed how the child "goes into a zombie-like coma unless she is familiar with the characters." Two other parents reported that their child does not watch YouTube, but listens. Table 25 lists the frequencies and percentages of all reported responses.

Table 25

Frequencies and Percentages of Children's Responses to YouTube Music Videos

\begin{tabular}{lcr}
\hline Response & Frequency & $\%$ \\
\hline Move/Dance & 119 & 36.06 \\
Sing/Chant Along & 117 & 35.45 \\
Listen Quietly & 87 & 26.36 \\
Other & 7 & 2.12 \\
Total & 330 & 100 \\
\hline
\end{tabular}

NOTE: Participants selected all responses that applied.

Additional questions were asked in the form of open-ended short response sections (items 19 and 21). Item 19 asked respondents to share their favorite YouTube children's music channels. Eighty-one respondents participated in this question and shared 116 YouTube playlists/channels. Table 26 lists the most frequently shared channels. 
Table 26

Favorite YouTube Music Education Channels

\begin{tabular}{lcr}
\hline Playlist & Frequency & $\%$ \\
\hline Little Baby Bum & 34 & 29.31 \\
Super Simple Songs & 19 & 16.38 \\
None & 10 & 8.62 \\
ABC Kid TV & 8 & 6.90 \\
\hline
\end{tabular}

Note: Percentages were calculated out of the total of 116 responses.

The most frequently reported responses included, "Little Baby Bum," "Super Simple Songs," and "ABC Kid TV" (see Appendix H for the full list). Ten respondents $(n=10)$ wrote, "none."

To conclude the survey, I designed item 21 to ask all respondents, including those that reported never having used YouTube with their toddler, to provide additional details about their YouTube usage. The question stated, "Is there anything else that you would like to share about the use of YouTube as a music education resource?" I assigned codes to the twenty-four responses provided for this open-ended question (see Appendix I for all responses). Based on the codes that were identified, I grouped the coded data into one of three categories: (1) positive $(n=14)$, (2) negative $(n=4)$, (3) neutral $(n=4)$. From those categories, themes that emerged in the responses included: appropriateness, educational value, parental music backgrounds, and music exposure. 


\section{Positive Responses}

There were 14 positive responses provided by the parents. Two reported being teachers or university music professors. One shared:

I use music from YouTube in my classroom as well as at home for my children (ages 1-3). I think it can be used as a valuable resource as long as it is used with moderation and is included with parent participation!

Another educator who identified as a university music professor stated, "My

daughter is in charge of choosing what she watches. I do have some music instrument apps that she plays with as well. I am also a music education professor with an elementary focus." He or she did not delve more into the YouTube music video selection process.

YouTube's educational value was mentioned in five comments. For example, “In our house we think it is important to expose her to more than just children's songs. We use YouTube mostly to play all different genres of music and have her instruments to play along with." Here is another respondent's opinion on YouTube as an educational resource:

We use YouTube as an entry point for our son to learn rhymes, music, sight words, etc. Throughout the day, we leave Spotify on (Super Simple Songs Playlist) and our son recognizes the beat or beginning of a song . . . overall, YouTube can be a music education resource and parents shouldn't fear it unless they are completely dependent on it to serve as a babysitting service. 
Parents and caregivers discussed their digital resource habits to provide music opportunities. One respondent said:

Since my child is not in preschool ... YouTube helps me to share the songs I learned as a child as well as interact with him in a way I couldn't without the use of YouTube. I am really glad that music is on YouTube for this reason.

\section{Negative Responses}

There were four respondents who shared negative views towards YouTube. For example, here is one respondent's opinion:

I actively discourage my children from spending time looking at screens and even my 9 year old is prohibited from using it unattended because it is too easy to end up watching highly inappropriate videos. As a mother and a teacher (M.Ed) I work to minimize how much exposure my children have to screens and especially advertising.

Some mentioned the appropriateness (or lack thereof) of YouTube. A few respondents mentioned using YouTube to search for lyrics or learning new songs, but not allowing their children to watch. Here is a sample of these responses: "I've used YouTube to look up the words/tune for some children's songs but I don't allow my son to watch the videos."

Another parent stated that she would be more inclined to use YouTube if the videos wouldn't veer off into other non-music videos. Parental concerns regarding young children's YouTube usage were clarified in this response:

I think it could be an excellent resource but it is so easy for toddlers (who are smart and industrious with tech) to navigate away from parent-approved content 
to weird and borderline unsavory content within the YouTube platform. We used to let our son watch LBB [Little Baby Bum] while preparing dinner or some activity he didn't need to be a part of then would find him watching some obscure video he'd navigated to, likely unintentionally. We have since really limited its use in our house.

\section{Neutral Responses}

Four responses were neither in favor of nor against YouTube. One parent said, "I don't know if I find it appropriate for toddlers." Another said, "We don’t use YouTube, but I do often put on the Wiggles or Little Baby Bum from Netflix. My daughter loves to sing and dance along!" Some parents delved into their backgrounds in the neutral responses:

I'm not musical, so I don't really know where to begin to find instructional children's videos. I have just enough knowledge to understand a music scale and sight-read music enough to approximate a melody and sing reasonably well. So we just pick videos that have lovely melodies or catchy educational lyrics and roll with it.

Another respondent stated, “...I wouldn't know how to judge a good from ineffective music education video.”

\section{Summary}

Results of this study indicated that most parents are using YouTube $(n=113$, $62.09 \%$ ) at least occasionally (1 to 2 times per week) with their toddlers. The largest percentage of parents $(n=67,36.8 \%)$ reported having more than six YouTube accessible devices in their home environments. Purposes for using YouTube included: for 
entertainment, using it as a music resource (in lieu of CDs, DVDs, etc.), for learning, and as a part of daily routines. Although the majority of parents had at least high school music experiences, there was an overall below average self-perceived ability regarding general music skills and musical parenting. Data revealed a high level of agreement regarding YouTube as an effective music resource. YouTube was perceived as beneficial to children's development in the areas of overall learning, music skills, and creativity, but reported to make no difference on children's social skills, ability to focus, and behavior. 


\section{CHAPTER FIVE}

\section{Discussion}

In this study, I sought to provide researchers, educators, and parents/caregivers with information about the usage of YouTube for early childhood music education experiences. Parents of toddler-age children (16-to-36 months) were invited via three social media groups to participate in a survey, which was used to collect demographic information about the families and their YouTube usage, beliefs, and experiences. I also intended to determine how current parents perceive YouTube as a music education resource.

\section{Demographics}

The parents. This study's respondents were predominately married females who were identified as mothers $(n=189)$, with at least a Bachelor's degree. Because studies have acknowledged mothers to be more involved in their children's music education than fathers (McPherson \& Davidson, 2002), it was not surprising that only three fathers participated in this study. Fathers may very well play active or single-parent roles in children's lives, especially those engaged on social media groups focused on parenting, and thus, their responses were included in this study. Researchers have illustrated the indirect, but equally important role that fathers play in children's education (Youm, 2008). For example, Youm's participants, mainly upper-middle class mothers of young children, attributed the support of fathers to be the second-most important factor to contribute to children's music activities (p. 145). However, because mothers and fathers have been found to interact differently with children (Craig, 2006), the fathers that participated in this study may have provided unique paternal viewpoints that might 
indicate potential gender differences that exist regarding YouTube music usage and beliefs, although the number was too few to analyze. Future research addressing fathers' musical interactions with young children could help provide a more complete picture of the home musical environment.

Nearly half of the participants (48\%) emanated from two states - California and Missouri. This could be explained by several reasons. Perhaps the recruitment notice stating that this research was being completed under the auspices of the University of Missouri attracted group members from that state. Another reason could relate to the construction of the social media networks. If the majority of moderators reside in the same state, and they invite friends within their separate social networks to join, that could increase the likelihood of including a large number of group members from the same state. Also, survey respondents were encouraged to invite other potential participants that met the criteria to take the survey. Due to the nature of self-selection, survey respondents from Missouri could have sent the survey link to their own networks or tagged friends to participate in the study. The volume of respondents from California may have skewed the demographic variable, family income level, to be less nationally representative (see Appendix I). As one participant noted, "we live in California Bay area, so the amount of income is different than the rest of the country." However, other demographics of the California respondents, such as ethnicity and education level, appeared more consistent with national norms.

Research has suggested that parents with higher education backgrounds and higher income levels tend be more involved in children's academic and extracurricular activities (Corrigall \& Schellenberg, 2015; Livingstone, Mascheroni, Dreier, Chadron, \& 
Lagae, 2015). In this study, participants' education levels ranged from high school diplomas to doctoral or professional degrees, with the majority of parents reporting at least a Bachelor's Degree as their highest level of education. Over one-third of the participants had graduate degrees completed, or in progress.

The toddlers. First-born children spend their early years as an only child (Hanushek, 1992), and, of course, some first-born children remain the only child in the family. The majority of respondents identified their children as an only child. A study by Price (2008) revealed that a first-born child received 20-30 more minutes of quality time each day with his or her parent, followed by the youngest child, who received the secondmost amount of time. In this study, data suggested that parents with multiple children viewed YouTube more positively than parents with one child or parents of first-born children. One explanation could be that the larger the family, the less time a parent may spend with each child, similar to Price's (2008) findings. Family pastimes including YouTube or Internet-based music could be viewed as parent-child quality time. Another consideration is that young children spend much of their time watching and emulating their parents and siblings at home, including media usage and habits (Lauricella, Wartella, \& Rideout, 2015). Studies have found that older children spend considerably more time using digital media than younger children (Wartella et al., 2014), so it is likely that family activities may include screen-based activities, and include the youngest children.

\section{Characteristics of the Digital Home Music Environment}

Young children are growing up in homes with multiple media technologies (Lauricella et al., 2015). Research Question 1 addressed the digital home music 
environment of young children's families. Data revealed that all families, regardless of family income level, had at least two YouTube/Internet accessible devices in the home. Bluetooth, Internet, and stream services have made music listening accessible across all demographic areas (Common Sense Media, 2017), so it was not surprising that $37 \%$ of this study's respondents had "more than six" YouTube-accessible devices.

According to the majority of this survey's participants, YouTube music was accessed occasionally (1-2 times per week) in the home music environments. The number of respondents reporting "rare" (1-2 times per month) and "regular" (1-2 times per day) access to YouTube music followed closely behind "occasional" access. One factor that future studies should consider is a more precise measurement of YouTube music usage; quantifying children's YouTube music usage would provide a better understanding of the amount of time being spent in this activity. Lum's (2008) study of children's home music environments indicated a high frequency of usage of media devices by parents and children, so these results of occasional usage were a bit surprising and begged the question of whether a relationship existed between income level, or some other variable(s), and frequency of YouTube access.

There was no relationship found between family income level and frequency of YouTube music access; however, there were some interesting findings. Parents indicating the lowest family income level (Less than $\$ 20,000$ ) also reported lower levels of education (High School Diploma or Associate's Degree) and revealed that they never used YouTube with their child. This finding is consistent with a previous study that found parents restricting media usage was more common in lower income, less educated families (Livingstone et al., 2015). Those authors reported that higher income, more 
educated families were associated with a wide range of parental practices including digital device usage and restrictions, as well as efforts to promote non-digital activities for children. Higher income parents with higher education levels also tend to structure their young children's digital home environments with the newest forms of technology, as compared to lower-educated parents with lower incomes (Nikken \& Schols, 2015). The same might be concluded regarding the music resources in the home music environment.

Although family income level did not appear to influence the frequency of YouTube access by parents and children, one facet of this finding can be explained by parental attitudes being shaped by cultural norms (Hollingworth et al., 2011). For example, if a parent-participant deems 'good parenting' to look a certain way (i.e. less screen time), then those beliefs may influence their attitudes and habits. Because of the negative stigma attached to parents who utilize screen time, parents who have used (or regularly use) YouTube may not disclose actual usage or habits. Digital parenting "has become another area where they [parents] fear possible criticism and in which their parental practices risk negative evaluation by others" (Holloway et al., 2015). This could influence the responses of parents when asked about anything parenting-related. It may be worthwhile to explore parental perceptions on 'good' parenting related to YouTube music usage with young children. Another factor may be the ideology of "intensive mothering," which has been associated with low income, single mothers (Elliott, Powell, Brenton, 2013). This is the notion that good mothers should invest a great deal of time, money, energy, and emotional labor in mothering children. In this study, seven respondents reported their marital status as Single (Never Married). If any of those 
respondents identified their parenting as "intensive mothering" (Elliott et al., 2013) then their responses would reflect the mindset.

Family activities. Family pastimes, or activities shared by parents and young children, greatly influence the home environment and children's overall development (Sobkin \& Skobeltsina, 2015). I adopted items about family pastimes from Wartella et al.'s 2014 study for the purpose of comparison. Whereas the favorite family activity in the 2014 study was "cooking and eating together," (66\% said they enjoy that "a lot"), the participants in this study reported, "doing things outside together" as the top favorite family activity (68\%). "Cooking and eating together" was the fourth most frequent family activity among the current parent participants (46.7\%). Sobkin and Skobeltsina (2015) examined the favorite pastimes of Russian parents and children, and found reading together to be the preferred shared activity $(53.9 \%)$ followed by taking walks (44.5\%). Corresponding with their findings, participants from this study reported "doing things outside together" and "reading together" as the top two favorite family pastimes.

An interesting facet of Sobkin and Skobeltsina's (2015) study was that mothers more often preferred walks and reading, whereas the fathers preferred media based activities such as watching television and playing video games (p. 54). This warranted a closer look at the paternal responses in the current study $(N=3)$, which revealed "a lot" of watching TV or movies and media activities. Mothers tend to be more proactive and involved in young children's activities (Sobkin \& Skobeltsina, 2015). Because of the small percentage of fathers $(1.6 \%)$ who participated in this study, it is not possible to generalize this finding, but future studies may wish to examine a larger population of 
fathers to see if differences exist between parent gender/roles and preferred parent-child activities.

Despite recommendations by the American Academy of Pediatrics, young children and families are spending more time than the one hour per day recommended with screen media (Lauricella, Wartella, \& Rideout, 2015). Concerning the family pastime, "doing things on a computer, tablet, or smartphone together," there was a resemblance between Wartella et al.'s (2014) study (16\% said they enjoyed it "a lot;" $35 \%$ said they enjoy it "somewhat") and this study (10\% said they enjoyed it "a lot;" $40 \%$ said they enjoyed it "somewhat;" see Appendix J). A nationally representative sample of over 2300 parents of children ages 0 to 8 examined different factors that influence the screen media habits of young children and families (Lauricella et al., 2015). Based on linear regression analyses of children's time spent with television, computers, smartphones, and tablets, the researchers identified parents' own screen time to be the strongest indicator of children's screen time. They also found that children's screen time use was highly influenced by parental attitudes.

Singing and music making. This survey data indicated that families are somewhat likely to participate in singing songs and making music in the home environment. Although there was indication of some respondents' families not singing at all, over one-third of respondents reported "a lot" of family music making. A comparison of Wartella et al.'s (2014) survey results for the family pastime statements (see Appendix J) and the results of this study (see Table 14) revealed a higher frequency of singing songs and music making by the 2018 respondents. This is in line with previous studies (Custodero et al., 2002; Ilari, 2005; Ilari et al., 2011; Johnson-Green \& Custodero, 2002; 
Gibson, 2009), which reported a high percentage of parents indicating that they sing to their children. Given that the parent-reported average age of child was 23 months old in the current study, this is consistent with Custodero et al.'s (2003) findings in that musical activities occurred more frequently with 0 - to 23 -month-olds than with 24- to 36-montholds.

There was a positive correlation between parents' previous music experiences and frequency of singing and music making in the home. Parental music backgrounds have been found to influence the quantity or quality of their young children's music experiences (Atterbury \& Silcox, 1993; Corrigall \& Schellenberg, 2015; Custodero \& Johnson-Green, 2003; Kelly \& Sutton-Smith, 1987; Youm, 2008). Respondents with post-college and current music experiences reported more frequent singing and music making with their children than those with high school and college music experiences.

\section{YouTube Music Usage and Experiences}

Data from this study suggested that parents find YouTube very helpful to children's learning and music skills. This finding is consistent with previous research that found beliefs about media as educational (National Association for the Education of Young Children, 2012; Rideout, 2014). Rideout (2014) emphasized that parents' views on media as a source of children's learning were consistent across socioeconomic groups. This was supported by one of the current respondents who shared, "We use YouTube as an entry point for our son to learn rhymes, music, sight words, etc.” According to participants' responses, daily routines and bedtime routines were enhanced with YouTube music (see Appendix I). For example, one mother stated, "my guy loves watching The Wiggles on YouTube! Also the Elmo Brushy Brush song plays every night 
at 6:30 pm for bedtime routine! He won't brush his teeth without it” (see Appendix K). Establishing and maintaining traditions, and making routine activities special, are musical parenting practices that families can adopt (Custodero, 2006).

Several studies have indicated the usage of digital media as a parenting tool, specifically as a distraction, discipline tool, or reward (Genc, 2014; Rideout, 2017; Wartella et al., 2014). Forty-four percent of parents in Wartella et al.'s (2014) study said they were likely to let their child use a smartphone or mobile device as a reward, which corresponded with participant statements from this study. One mother noted using YouTube music videos as a reward for good behavior. Open response statements also revealed that participants offered their children mobile phones and digital devices to watch YouTube music videos while the parents run errands or do household chores. In Wartella et al.'s study, $58 \%$ of respondents stated that they were "very likely" to give their young children (under-2-year-old- 17\%; 2-to-5-year old- 41\%) media to keep them occupied while getting things done around the house (p. 16). Likewise, one of the survey respondents in this study referred to media as a "quick distraction for public meltdowns" (p. 21). Additional open-ended responses supported YouTube as a distraction at various places like: the doctor's office, during vaccinations, and during meals (See Appendix F). One of the main findings of the study is that YouTube plays an important role in the music experiences of current families. Its uses and purposes varied from family to family, but parents indicated that they mainly seek YouTube for young children's entertainment, learning, and as a music resource. A previous study that explored parents' perceptions about preschool aged children's mobile technology usage also revealed that 
the primary purpose of smartphone use was for entertainment, but not for educational purposes (Genc, 2014).

A key factor to consider for future studies is the notion of music entertainment versus music education. Regarding purposes for using YouTube, parents with higher levels of music knowledge (rated themselves as 6 or greater) reported that YouTube served primarily as a music resource, whereas parents with lower levels of music knowledge (rating themselves as less than or equal to 5) reported that YouTube served as a form of music entertainment.

Open-response statements shared by participants offered more insight into this paradigm:

My kids and I love to sing, and most of what we view on YouTube is music, but it is Disney or other catchy songs about animals or the solar system. It is fun to sing along, but there is no music education involved, and I wouldn't know how to judge a good from ineffective music education video.

Participants with lower perceived music abilities tended to view YouTube as entertainment, and participants with higher perceived music abilities tended to view it as a music resource. Future studies should consider examining this unique facet of parental music backgrounds that appears to influence perceptions of YouTube music.

The YouTube music experience. Parent-child music experiences can be an ideal time to bond and enjoy music together. Participants in the current study described their children as very active and energetic and somewhat easy and adaptable, which are characteristics of toddlers (NAEYC, 2018). One purpose of this study was to investigate 
the typical YouTube music experience of families with young children, from the selection process of videos, to children's responses to the videos.

Music exposure. Exposure to a variety of different music is highly beneficial to children's music development (Hallam, 2010). One theme that emerged in the participant responses was the usage of YouTube for music exposure. Similar to the participants in Gibson's (2009) study, this study's parents felt very strongly about their children being exposed to a variety of different music genres, cultural dances, and instruments. One participant stated, "We use YouTube mostly to play all different genres of music and have her instruments to play along with" (see Appendix I). Another participant mentioned using YouTube "more for exposure, in particular with dancing and ethnic music." An additional respondent replied, "In our house, we think it is important to expose her to more than just children's songs." Gordon (2003) stated the importance of children being exposed to a rich variety of music for future formal learning. Much like Gibson's participants who reported strong beliefs about early music exposure for their children, these responses suggested a high level of appreciation as well.

According to participant responses, the most common way to find YouTube music education videos for children was to type in "children's music" into the search bar. As a parent of a toddler and an infant, I know that I have felt overwhelmed by the sheer quantity of search results. Other ways to find children's music, as reported by parents in this survey, included: finding the most popular/viewed songs or searching for specific songs based on recommendations or suggestions. One participant shared, "YouTube helps me to share the songs I learned as a child as well as interact with him in a way I couldn't without the use of YouTube" (see Appendix I). In both Gibson's (2009) and 
Custodero's (2006) studies, parents typically reported selecting familiar repertoiresongs they grew up listening to- - to sing with their children.

Survey respondents reported the top children's response to YouTube music education videos to be moving and dancing, followed closely by singing and chanting along. Gordon (2003) stated that music learning through exploration and unstructured guidance is key for young children. Moving, dancing, singing, and chanting are developmentally appropriate and musical responses, suggesting that YouTube music experiences have the potential to be creative and active.

\section{Characteristics of Digital Musical Parenting}

Research Question 3 focused on musical parenting with YouTube. Because studies have found that more musically experienced parents are more likely to provide music experiences for their children (Atterbury \& Silcox, 1993; Custodero and JohnsonGreen, 2003; Ilari, 2005; Kelly \& Sutton-Smith, 1987), I examined this relationship between two variables: parents' perceived music abilities and parental beliefs on musical parenting ("I have all of the skills necessary to be an effective musical parent"). There was a positive correlation between perceptions of parental music skills and of effective musical parenting. Parents who perceived their music skills to be higher were more likely to believe that they possessed the necessary skills for providing music experiences for their children.

Supporting previous claims that parental perceptions and beliefs impact children's home music experiences and development (Custodero, 2006; Ilari, 2005; Koops, 2011), it was not surprising that there was both a generally positive attitude towards YouTube held by parents, as well as an overall positive belief that YouTube is 
beneficial for their young children's development in the areas of learning, music, and creativity. Parental attitudes and beliefs were overall very positive towards YouTube as a music education resource. Although commercial music programs are more common in upper-middle class and affluent families (Corrigall \& Schellenberg, 2015), they are inaccessible for some families. Respondents across all demographic areas were optimistic about YouTube being easily accessible and affording music opportunities for everyone. YouTube also provides access to cultural music and various genres that may be otherwise unavailable.

As reported in previous studies (De Vries, 2009; Youm, 2008) and found in this current study, there was a perceived lack of music knowledge. Studies have suggested a positive correlation between parental perceptions of music ability and young children's music experiences (Atterbury \& Silcox, 1993; Custodero and Johnson-Green, 2003; Gibson, 2009; Kelly \& Sutton-Smith, 1987). In a study examining parents' goals for their children's music education in South Korea (Youm, 2008), several participants' responses shared a common theme: their own lack of perceived music knowledge or ability. The below average perceived music ability reported by this study's respondents supported this general lack of music confidence by parents. Parents' perceived music skills were positively correlated with the statement about effective musical parenting ("I have all of the necessary skills to be an effective musical parent"). Parents who reported higher general music skills held more positive beliefs about their ability to provide music experiences to their children.

Musical parenting in the digital age involves selecting appropriate, quality music for optimal experiences. Although $66 \%$ of parents felt they had the knowledge and skills 
to determine whether or not a particular video was appropriate, the lack of confidence was evident in this parent-response:

I'm not musical, so I don't really know where to begin to find instructional children's videos. I have just enough knowledge to understand a music scale and sight-read music enough to approximate a melody and sing reasonably well. So we just pick videos that have lovely melodies or catchy educational lyrics and roll with it.

If parents are unsure about the quality of music education videos, their children may be watching developmentally inappropriate content. Furthermore, parents who believe their children are watching YouTube music videos for entertainment, rather than for learning, may be missing out on educational opportunities.

Concerns. Despite national guidelines encouraging active participation during parent-child technology experiences (NAEYC, 2012), there were participants in this study who reported feeling comfortable leaving their toddlers alone in front of YouTube (over $50 \%$ of respondents agreed at least somewhat with the following statement: "I feel comfortable leaving my child to watch specific YouTube music videos or channels." Positive parental attitudes towards television content have been associated with higher television watching by children (Beyens \& Eggermont, 2014). Alarmingly, nearly half of the parents in a previous study stated benefits of using television as a babysitter (Evans et al., 2011). Although this study did not aim to measure children's actual time spent watching YouTube music videos, music educators should be concerned about the possibility of children spending longer and longer periods of time in front of YouTube alone. In line with previous studies (Rideout, 2017; Wartella et al., 2014), some of this 
study's parents felt that YouTube was harmful to their children's physical activity. Sedentary usage of technologies such as television, computers, and video games have been cited to be dangerous for young children (Plowman, Stevenson, Stephen, \& McPake, 2012), and the same concerns may stand for children's YouTube usage. Contrary to parental concerns about children's lack of physical activity while watching YouTube, data revealed that most children respond to videos by moving and dancing, followed closely by singing or chanting. Authors of a 2018 position statement by the National Association for Music Education (NAfME) stressed the importance of children's musicking to foster their learning and development; findings suggested that YouTube, unlike other media activities such as television watching or video games, may actually encourage active responses, and therefore, have potential in being utilized as an effective resource.

Another concern by parents was YouTube's inappropriate content. Parent responses indicated strong concerns over the "weird and borderline unsavory" (participant response) videos that YouTube search results tended to lead viewers to. These have been referred to as "Elsagate" videos, which refers to videos that are extremely low-budget, low-effort, and populated with unlicensed Disney characters behaving oddly to nursery rhymes tunes (Di Placido, 2017). Parents could potentially be selecting an "Elsagate" video that begins with a common children's song, and step away to tend to other responsibilities, assuming the content being viewed is safe and appropriate.

Earlier this year, YouTube Kids acknowledged this concern by publishing more guidelines and increasing parental controls such as blocking content and limiting access 
to only approved searches (YouTube, 2018). Regardless of increased parental controls, children could still potentially find inappropriate content, which necessitates the shared media use and parent participation in all YouTube music experiences. One of the respondents who attributed YouTube to be a positive, educational music resource stated, “...parents shouldn't fear it unless they are completely dependent on it to serve as a babysitting service" (see Appendix J).

Musical parenting resources. Previous research and the results of this study have pointed us to a need for parent-focused music education and guidance (Nardo et al., 2006, Sims \& Udtaisuk, 2008; Tarnowski \& Barrett, 1997; Youm, 2008). Parents were found to "lack confidence with music yet desired to learn how to interact musically with their children" (Youm, 2008, p. 186). Corresponding with Youm's findings, data from this study revealed a need for musical parenting resources. In an interview study, Koops (2011) found that several parents desired more information about children's music development and teaching methods. Although parents have been found to seek parenting advice from other people (i.e. spouse, mother, pediatrician), websites, blogs, and social networking sites were also utilized as sources for parenting advice (Wartella et al., 2014). According to this study, $65 \%$ of parents reported being "moderately likely," "very likely," or "completely likely" to search, or read, the Internet for musical parenting information. This indicates a potential channel for music educators and parents to be able to share relevant information regarding digital music experiences for children.

\section{Developmentally Appropriate Practice and Music Learning Theory}

Copple and Bredekamp (2009) described core considerations for developmentally appropriate practice (DAP), including: knowing about child development and learning, 
knowing what is individually appropriate, and knowing what is culturally important. A basic understanding of child development and learning is important for parents to offer their children developmentally appropriate activities. There are many cognitive, social, and emotional benefits to children learning through play at home. Parents reported a great amount of family time, including indoor and outdoor play, reading together, playing games, and sharing meals. Results indicated that families are providing diverse home experiences to their young children, which could suggest some DAP awareness. However, not all family time is created equal; it is unknown exactly how rich this family time is. It is crucial to provide a "rich variety of materials, challenges, and ideas that are worthy of children's attention" (p. 18). Creating a rich learning environment by providing children with opportunities to develop and practice newly acquired skills is a DAP that parents should aim to achieve.

Parental awareness of well-rounded activities for young children was evident in survey responses. This survey did not directly ask parents questions related to their implementation or understanding of DAP; I feared that parents might feel judged and drop out of the survey. Therefore, questions were strategically aimed towards the children, media usages, and previous and current music experiences.

Educators should consider the developmental needs and age of the child when planning music and overall learning goals. Naturally, music activities would look different for younger toddlers versus older toddlers. "Given the enormous variation among children of the same chronological age, a child's age is only a crude index of developmental ability and interests" (p. 11). If a child has special learning needs or 
abilities, then the learning environment must be modified to help them develop and thrive.

The DAP principle of "knowing what is individually important" was evident by some of the study's respondents. "All children have their own strengths, needs, and interests...decisions about curriculum, teaching, and interactions should be as individualized as possible" (p. 11-12). Some parental responses indicated high levels of involvement, engagement, and awareness of children's individual learning needs. DAP was evidenced in responses that described the usage of YouTube music as a starting point for new concepts, or as a music resource to reinforce learning.

Culture refers to the societal beliefs and patterns of behavior, including social, religious, and ethnic influences. Although culture is typically discussed in the context of diversity and minority groups, "all of us are members of cultures and are powerfully influenced by them. Every culture structures and interprets children's behavior and development in its own way" (p. 13). "Knowing what is culturally important," refers to the need for understand how one's own cultural experience shapes their perspective, and that "multiple perspectives, not just their own, must be considered in decisions about children's development and learning" (p. 13). Some of the parental responses reflected DAP; for example, one respondent mentioned using YouTube to introduce and integrate ethnic dance music into the home music environment.

\section{Gordon's Theory and YouTube Experiences}

Based on Gordon's Music Learning Theory for Infants and Young Children, (2003, 2013), YouTube music experience descriptions as reported by parents were primarily unstructured. Parents did not plan specific lessons for the YouTube music 
videos. Rather, children were exposed to their culture and encouraged to absorb it (2013, p. 3). Some parents shared their fondness for YouTube because it provided access to cultural music and dances otherwise inaccessible or unavailable to them locally. The majority of parents tended to participate in YouTube music experiences to an extentsome parents revealed that they ask children prompting questions about YouTube videos. Depending on whether or not those parents entered the experience with questions planned, some of the guidance may have been structured. A few parents also reported looking for specific songs or videos on YouTube. It is possible that those parents may have had specific music learning goals planned for their children, and searched for a YouTube video to meet those goals, in which guidance becomes formal instruction. Some open response statements suggested that YouTube was used as a starting point for further music and non-music learning. Although parents' use of YouTube would primarily be categorized as informal unstructured guidance, the multi-session usage of YouTube music by some parents suggests that guidance may be more nuanced than just "structured" versus "unstructured." A replication of this study could also include additional questions to better understand the goals and expectations of parents.

\section{Implications}

The findings of this study may help to provide parents with guidelines and suggestions for YouTube music experiences with their young children. They may also offer music educators information that would be helpful for creating musical parenting resources. These findings may be transferable to other areas of research, such as early childhood education, digital education, media, and technology. 
For parents. Parents play key roles in children's music experiences and development. YouTube music experiences are influenced by factors including: parental music background, parents' perceived music abilities, parental attitudes towards YouTube, and demographic characteristics such as education level and family income level. Because toddlers are at a critical period of development, and given that parents are often the primary caregivers, parents should prioritize the developmental needs of their young children. As reported in the literature reviewed, and shared by this study's respondents, not all parents feel equipped to engage with their children during YouTube music experiences. Findings from this study indicated that parents are not very likely to search for information on music for children on the Internet, but parents and their children would benefit from learning about early childhood music education.

Based on previous research and this study's findings, that children as young as two-years old are being left alone with YouTube videos, parents may be unaware of the existence of guidelines issued by public health organizations and national groups that have stressed the importance of parental supervision and engagement with technology. Because children's screen time is highly associated with parent screen time (Lauricella et al., 2015), parents should consider their own YouTube usage and digital technology habits. Given that parental values and beliefs play influential roles on children's musical development, we must take a closer look at the role(s) of YouTube in musical parenting practices and parent-child music experiences. In addition, establishing and distributing guidelines for the YouTube music experiences is a necessary next step.

Establishing YouTube guidelines. There has yet to exist an established set of guidelines specific to YouTube usage for educational music experiences. The following 
considerations serve as baseline guidelines to promote positive and educational YouTube music education experiences. They are based on the principles of the American Academy of Pediatrics, the National Association for the Education of Young Children, the National Association for Music Education, previous nationally representative survey results, and the open and closed-responses of this study. While the aim was to provide musical parenting guidelines and suggestions for parents of young children, they may also be beneficial for early childhood scholars, teachers, and administrators.

Shared media use. YouTube experiences should include both parent (or caregiver) and child. Data have revealed that technology usage has "become a family affair," (Google Official Blog, 2015), however, previous studies (Rideout, 2017; Wartella et al., 2014) and this current study have revealed that children as young as 2 are watching online videos alone. Adults must play the role of mediator and co-player in children's digital experiences (NAEYC, 2012). Regarding infants and toddlers, "if technology is used, it must be in the context of conversation and interactions with an adult" (p. 1). Guidelines issued by the American Academy of Pediatrics (AAP, 2016) also stated the importance of parents co-viewing, co-playing, and co-engaging with children.

Active engagement and interactions. Children and parents/caregivers are encouraged to play and interact while watching music education videos on YouTube. However, survey results illustrated a lack of parental engagement during children's YouTube usage, with less than $40 \%$ of parents reporting actively engaging with their children. One major concern highlighted by some parents was the "zombie-like coma" that certain YouTube videos can elicit; they should avoid passive responses by actively participating with children. Findings from this study revealed that children responded to 
YouTube music by moving and dancing, singing or chanting along, or listening. We can promote children's fine and gross motor development through YouTube music activities. Parents are encouraged to take their children's lead and offer abundant opportunities for spontaneous and creative responses.

Reteach the content. A key finding from this study was that YouTube has the potential to be a highly effective music education resource. Several parents from this study reported that YouTube is used as an "entry point" for their children to learn. After watching videos together, music experiences should go beyond the screen and into daily life and routines. This may include new vocabulary words, concepts, rhymes, and songs. Based on national age-appropriate guidelines, YouTube can be used to "help them [children] understand what they are seeing and apply it to the world around them" (AAP, 2016).

Time limit. Setting time limits on children's YouTube usage and experiences is highly beneficial to overall development. Although this study did not ask parents to specify actual time spent on YouTube, previous studies have indicated young children's digital media usage exceeded limits set forth by public health organizations (Beyens \& Eggermont, 2014; Genc, 2014; Lauricella et al., 2015) Guidelines set by the American Academy of Pediatrics (AAP, 2016) have suggested that screen time should be limited to one hour of high-quality programs for children ages 2 through 5 years; the National Association for the Education of Young Children (NAEYC) issued guidelines suggesting a screen-time limit of two hours (2012). This study's participants reported limiting their children's YouTube time, mentioning aspects of quality and appropriateness. However, it is still unknown whether parents are aware of media usage guidelines. 
Developmental appropriateness. Research in general and early childhood music education about YouTube is sparse. More information is needed to better understand how parents, children, and educators are using YouTube music videos and what they are watching. Music educators should be concerned about these children's music videos that are being watched frequently by young children, including infants and toddlers. Future research might be undertaken to analyze the musical qualities of the most viewed/popular YouTube children's music videos. Findings from the present study revealed that the most common ways for parents to find music on YouTube was to search for "children's music" or simply view the top playlists for children. The creators of the top playlists do not appear to have been concerned with developmentally appropriate practices in early childhood music. This is disturbing, given that some of the playlists have been viewed over one billion times. As a parent and early childhood music educator, I have viewed many of these children's music playlists, and have concerns about most of them. An online space for dialogue, possibly on social media or YouTube, where parents, educators, and researchers could interact and share ideas, would be very helpful.

\section{Limitations and Additional Suggestions for Research}

There were several limitations of this study that provide guidance for future studies using quantitative methods. The recruitment process limited the population surveyed; therefore, results were less generalizable to the U.S. population. Participant recruitment, especially one that narrows into the sub-population of parents, parents of toddler-age children, can be logistically challenging. Parents are more inclined to participate if the study could possibly benefit them in some way (Houle, Besnard, Bérubé, \& Dagenais, 2018). It is possible that parents who responded were open to 
participating in this YouTube-focused study because it validated certain parenting habits they may have been exercising.

Another limitation was the inability to determine an exact response rate. Social media recruitment was conducted in parenting-centered groups because respondents already had ascertained their interest in aspects of parenting. There is no way of quantifying the exact number of people who (a) saw the post, (b) met the qualifications (parent of a toddler) for the study, and (c) clicked on the online survey link.

Data from this study were reliant on parental reports of children's YouTube use, and the parents' attitudes towards YouTube. I did not expect parents to over-report their children's usage or under-report their own attitudes towards YouTube due to social desirability; however, I could not exclude the fact that some parents may have done so. Despite these limitations, the results provide a useful indication of how parents and toddlers may currently be using YouTube as a music education resource.

Because research in this area is still in its infancy, future studies should seek to understand YouTube music usage in a variety of settings such as the home, early childhood settings such as daycares or preschools, or community settings. Future studies should examine the top children's music channels and playlists reported in this study, for various elements such as music quality and appropriateness. The results of this investigation led to new questions about parental perceptions on quality. What are the components of a YouTube music education video deemed as good "quality" versus those deemed as poor quality? This study examined the current state and nature of YouTube usage for music education experiences. Future studies should delve into parental beliefs and perspectives about the quality in order to better understand how and why parents 
select certain music education videos for their children. Examining how early childhood music educators define quality music videos would help inform these discussions. These would be the necessary next steps to create effective musical parenting resources.

Examining parent-child YouTube music experiences using different quantitative and qualitative methods (such as interviews, recordings, and observations) would provide new perspectives on this global phenomenon. A replication of this study could also benefit from the inclusion of more fathers or a wider range of ages and locations in the population. Because this study focused on parents of toddlers, it would be interesting to replicate the study with parents of preschoolers, or children birth through five.

\section{Concluding Statement}

This study provides valuable baseline data and insights into the use of YouTube music education videos by parents and young children. Key findings included: a wide range of YouTube accessible devices in the home, and regular YouTube access by parents and young children for the purposes of learning, entertainment, and serving as a music resource. Parental attitudes towards and beliefs about YouTube shape their children's YouTube music education experiences. Parents want to offer their children quality music experiences, but some lack the music background or knowledge to provide them. There is a need for musical parenting resources, particularly related to YouTube and digital music usage. Current parents must raise their children to be digitally literate (Palaiologou, 2014), so equipping parents with music guidelines and tools should be prioritized. YouTube can be an effective music education resource for parents to offer children music experiences. I hope that the information provided here will encourage 
researchers to conduct similar studies and further examine YouTube in early childhood and general music education. 


\section{References}

Adachi, M., \& Trehub, S. E. (2012). Musical lives of infants. In G. McPherson \& G. Welch (Eds.), Music learning and teaching in infancy, childhood, and adolescence (pp. 5-25). New York, NY: Oxford University Press.

Addessi, A. R. (2009). The musical dimension of daily routines with under-four children during diaper change, bedtime and free-play. Early Child Development and Care, 179, 747-768. doi: 10.1080/03004430902944122

American Academy of Pediatrics. (2016). American Academy of Pediatrics announces new recommendations for children's media use. Retrieved from https://www.aap.org/en-us/about-the-aap/aap-press-room/Pages/AmericanAcademy-of-Pediatrics-Announces-New-Recommendations-for-ChildrensMedia-Use.aspx

Andress, B. (1986). Toward an integrated developmental theory for early childhood music education. Bulletin of the Council for Research in Music Education, 86, 1017.

Andrews, D., Nonnecke, B., \& Preece, J. (2010). Electronic survey methodology: A case study in reaching hard-to-involve Internet users. International Journal of HumanComputer Interaction, 16, 185-210. doi: 10.1207/S15327590IJHC1602_04

Andrews, E. L. (2014). Eric Bettinger: Why stay-at-home parents are good for older children. Stanford Business. Retrieved from https://www.gsb.stanford.edu/insights/eric-bettinger-why-stay-home-parents-aregood-older-children 
Atterbury, B. W., \& Silcox, L. (1993). A comparison of home musical environment and musical aptitude in kindergarten students. Update: Applications of Research in Music Education, 11(2), 18-22. doi: 10.1177/875512339301100205

Berger, A. A., \& Cooper, S. (2003). Musical play: A case study of preschool children and parents. Journal of Research in Music Education, 51, 151-165. doi: $10.2307 / 3345848$

Bergeson, T. R., \& Trehub, S. E. (1999). Mothers' singing to infants and preschool children. Infant Behavior and Development, 22(1), 51-64. doi: 10.1016/S0163-6383(99)80005-8

Beyens, I., \& Eggermont, S. (2014). Putting young children in front of the television: Antecedents and outcomes of parents' use of television as a babysitter. Communication Quarterly, 62, 57-74. doi: 10.1080/01463373.2013.860904

Bolduc, J., \& Evrard, M. (2017). Music education from birth to five: An examination of early childhood educators' music teaching practices. Research and Issues in Music Education, 13(1), 3.

Bond, V. L. (2013). Follow and facilitate: What music educators can learn from the Reggio Emilia approach. General Music Today, 27, 24-28. doi: $10.1177 / 1048371313480798$

Brand, M. (1985). Research in music teacher effectiveness. Update: Applications of Research in Music Education, 3(2), 13-16. doi:10.1177/875512338500300204

Brand, M. (1986). Relationship between home musical environment and selected musical attributes of second-grade children. Journal of Research in Music Education, 34, 111-120. doi:10.2307/3344739 
Bredekamp, S. (1986). Developmentally appropriate practice. Washington, DC: National Association for the Education of Young Children.

Cabus, S. J. \& Aries, R. J. (2017). What do parents teach their children? The effects of parental involvement on student performance in Dutch compulsory education. Educational Review, 69, 285-302. doi:10.1080/00131911.2016.1208148

Campbell, P. S., \& Wiggins, T. (Eds.). (2012). The Oxford handbook of children's musical cultures. New York, NY: Oxford University Press.

Cayari, C. (2011). The YouTube effect: How YouTube has provided news ways to create, consume, and share music, International Journal of Education and the Arts, 12(6), 1-30.

Copple, C., \& Bredekamp, S. (2009). Developmentally appropriate practice in early childhood programs serving children from birth through age 8. Washington, DC: National Association for the Education of Young Children.

Corrigall, K. A. \& Schellenberg, E. G. (2015). Predicting who takes music lessons: Parent and child characteristics. Frontiers in Psychology, 6, 1-8. doi: 10.3389/fpsyg.2015.00282

Costa-Giomi, E. (2015). The long-term effects of childhood music instruction on intelligence and general cognitive abilities. Update: Applications of Research in Music Education, 33(2), 20-26. doi: 10.1177/8755123314540661

Custodero, L. A. (2005). Observable indicators of flow experience: A developmental perspective on musical engagement in young children from infancy to school age. Music Education Research, 7, 185-209. doi: 10.1080/14613800500169431 
Custodero, L. A. (2006). Singing practices in 10 families with young children. Journal of Research in Music Education, 54, 37-56. doi:10.1177/002242940605400104

Custodero, L. A., \& Johnson-Green, E. A. (2003). Passing the cultural torch: Musical experience and musical parenting of infants. Journal of Research in Music Education, 51, 102-114. doi: 10.2307/3345844

Custodero, L. A., \& Johnson-Green, E. A. (2008). Caregiving in counterpoint: Reciprocal influences in the musical parenting of younger and older infants. Early Child Development and Care, 178, 15-39. doi: 10.1080/03004430600601115

Custodero, L., Britto, P., \& Xin, T. (2002). From Mozart to motown, lullabies to love songs: A preliminary report on parents' use of music with infants survey (PUMIS). Zero to Three, 23(1), 41-46.

Custodero, L. A., Britto, P. R., \& Brooks-Gunn, J. (2003). Musical lives: A collective portrait of American parents and their young children. Journal of Applied Developmental Psychology, 24, 553-572. doi: 10.1016/j.appdev.2003.08.005

Cutietta, R. A. (2001). Raising musical kids: A guide for parents. New York: Oxford University Press.

De Grätzer, D. P. D. (1999). Can music help to improve parent-child communication? Learning music with parents-an Argentine experience. International Journal of Music Education, 34(1), 47-56. doi: 10.1177/025576149903400105

Dell, C., Rinnert, N., Yap, C. C., Keith, T., Zdzinski, S., Gumm, A., \& Russell, B. (2014). Musical home environment, family background, and parenting style on success in school music and in school. Contributions to Music Education, 41(1), 71-89. 
De Vries, P. (2005). Lessons from home: Scaffolding vocal improvisation and song acquisition with a 2-year-old. Early Childhood Education Journal, 32, 307312. doi: $10.1007 / \mathrm{s} 10643-004-0962-2$

De Vries, P. (2007). The use of music CDs and DVDs in the home with the under-fives: what the parents say. Australian Journal of Early Childhood, 32(4), 18. doi: $10.1080 / 03004430802691914$

De Vries, P. (2009). Music at home with the under fives: What is happening? Early Child Development and Care, 179, 395-405. doi: 10.1080/03004430802691914

Di Placido, D. (2017). YouTube's "Elsagate" illuminates the horrors of the digital age. Retrieved from https://www.forbes.com/sites/danidiplacido/2017/11/28/youtubeselsagate-illuminates-the-unintended-horrors-of-the-digital-age/\#6bfed9f56ba7

Donahue, C. \& Schomburg, R. (2017). Technology and interactive media in early childhood programs: What we've learned from five years of research policy, and practice. Young Children, 72(4). Retrieved from https://www.naeyc.org/resources/pubs/yc/sep2017/technology-and-interactivemedia

Elliott, S., Powell, R., \& Brenton, J. (2015). Being a good mom: Low-income, black single mothers negotiate intensive mothering. Journal of Family Issues, 36, 351370. doi: 10.1177/0192513X13490279

Genc, Z. (2014). Parents' perceptions about the mobile technology use of preschool aged children. Procedia-Social and Behavioral Sciences, 146, 55- 60. doi: 10.1016/j.sbspro.2014.08.086 
Gerry, D., Unrau, A., \& Trainor, L. J. (2012). Active music classes in infancy enhance musical, communicative and social development. Developmental Science, 15, 398-407. https://doi.org/10.1111/j.1467-7687.2012.01142.x

Gembris, H., \& Davidson, J. W. (2002). Environmental influences. In G. McPherson \& R. Parncutt (Eds.), The science and psychology of music performance (pp.17-30). New York, NY: Oxford University Press.

Gibson, R. E. (2009). Musical parenting: An ethnographic account of musical interactions of parents and young children. University of Washington. Retrieved from ProQuest Dissertations and Theses Global. (AAT 3377340)

Given, L. M., Winkler, D. C., Willson, R., Davidson, C., Danby, S., \& Thorpe, K. (2016). Watching young children "play" with information technology: Everyday life information seeking in the home. Library \& Information Science Research, 38, 344-352. doi: 10.1016/j.lisr.2016.11.007

Google. (2013, May 1). Meet gen c: The YouTube generation. Retrieved from google.com/think

Google Official Blog. (2015, February 23). Our first building block in tech for tykes: YouTube Kids. Retrieved from https://googleblog.blogspot.com/2015/02/youtube-kids.html

Gordon, E. (2002). Rating scales and their uses for measuring and evaluating achievement in music performance. Chicago, IL: GIA Publications.

Gordon, E. (2003). A music learning theory for newborn and young children. Chicago, IL: GIA Publications. 
Gordon, E. (2013). Listening: The critical component for understanding music. Audea, 18(1), 5-8.

The Gordon Institute for Music Learning. (2018). Early childhood. Retrieved from https://giml.org/mlt/earlychildhood/

Hallam, S. (2010). The power of music: Its impact on the intellectual, social and personal development of children and young people. International Journal of Music Education, 28, 269-289. doi: 10.1177/0255761410370658

Hamilton, L. (2014). Home listening practices of parents, infants, and toddlers: A survey of parents enrolled in early childhood music education classes. Texas Music Education Research, 19-22.

Hanushek, E. A. (1992). The trade-off between child quantity and quality. Journal of Political Economy, 100, 84-117.

Heale, R. \& Twycross, A. (2015). Validity and reliability in quantitative studies. Evidence-Based Nursing, 18(3), 66-67. doi: 10.1136/eb-2015-102129

Holloway, D. J., Green, L., \& Stevenson, K. J. (2015). Digitods: Toddlers, touch screens and Australian family life. M/C Journal, 18(5), 1-7.

Houle, A. A., Besnard, T., Bérubé, A., \& Dagenais, C. (2018). Factors that influence parent recruitment into prevention programs in early childhood: A concept map of parents', practitioners', and administrators' points of view. Children and Youth Services Review, 85, 127-136. 
Hourcade, J. P., Mascher, S. L., Wu, D., \& Pantoja, L. (2015, April). Look, my baby is using an iPad! An analysis of YouTube videos of infants and toddlers using tablets. In Proceedings of The 33rd Annual ACM Conference on Human Factors in Computing Systems (pp. 1915-1924). ACM.

Ilari, B. S. (2002). Music perception and cognition in the first year of life. Early Child Development and Care, 172, 311-322.

Ilari, B. (2005). On musical parenting of young children: Musical beliefs and behaviors of mothers and infants. Early Childhood Development and Care, 175, 647660.

Ilari, B., Moura, A., \& Bourscheidt, L. (2011). Between interactions and commodities: Musical parenting of infants and toddlers in Brazil. Music Education Research, 13(1), 51-67. doi: 10.1080/14613808.2011.553277.

Ilari, B., \& Young, S. (2016). MyPlace, MyMusic: Home musical experiences of children across the world. In B. Ilari \& S. Young (Eds.), Children's home musical experiences across the world. Bloomington, IN: Indiana University Press.

Ilari, B. (2016). Music in the early years: Pathways into the social world. Research Studies in Music Education, 38, 23-39. doi: 10.1177/1321103X16642631

Ilari, B. (2017). Children's ethnic identity, cultural diversity and music education. In R. MacDonald, D. Hargreaves, and D. Miell (Eds.), The handbook of musical identities. Oxford, UK: Oxford University Press.

Johnson-Green, E., \& Custodero, L. (2002). The toddler top 40: Musical preferences of babies, toddlers, and their parents. Zero to Three, 23(1), 47-48. 
Kelley, L., \& Sutton-Smith, B. (1987). A study of infant musical productivity. In J. Peery, I. Peery, \& T. Draper (Eds.), Music and child development (pp. 35-53). New York, NY: Springer.

Kida, I., \& Adachi, M. (2008). The role of musical environment at home in the infant's development (Part 2): Exploring effects of early musical experiences on the infant's physical and motor development during the first 2 years. In K. Miyazaki, Y. Hiraga, M. Adachi, Y. Nakajima \& M. Tsuzaki (Eds.), Proceedings from The 10th International Conference on Music Perception and Cognition (pp. 722-728). Sapporo, Japan: Hokkaido University.

Koops, L. H. (2011). Music play zone: An online social network site connecting parents and teacher in an early childhood music class. In S. L. Burton \& C. C. Taggart, Learning from young children: Research in early childhood music (pp. 181-212). Lanham, MD: Rowman \& Littlefield Education.

Koops, L. H. (2011b). Parental perceptions of current and desired involvement in early childhood music instruction. Visions of Research in Music Education, 17. Retrieved from http://www-usr.rider.edu/\%7Evrme/v17n1/

Koops, L. H. (2012). Music Play Zone II: Deepening parental empowerment as music guides for their young children. Early Childhood Education Journal, 40, 333341. doi: 10.1007/s10643-012-0513-1

Koops, L. H. (2014). Songs from the car seat: Exploring the early childhood musicmaking place of the family vehicle. Journal of Research in Music Education, 62, 52-65. doi: 10.1177/0022429413520007. 
Koutsoupidou, T. (2016). Nurturing MyMUSICal Child: Parental Perspectives and Influences. In B. Ilari \& S. Young (Eds), Children's home musical experiences across the world. Bloomington, IN: Indiana University Press.

Kruse, N. B., \& Veblen, K. K. (2012). Music teaching and learning online: Considering YouTube instructional videos. Journal of Music, Technology \& Education, 5, 77-87. doi: 10.1386/jmte.5.1.77_1

Lamont, A. (2003). Toddlers' musical preferences: musical preference and musical memory in the early years. Annals of the New York Academy of Sciences, 999, $518-519$

Lauricella, A. R., Wartella, E., \& Rideout, V. J. (2015). Young children's screen time: The complex role of parent and child factors. Journal of Applied Developmental Psychology, 36, 11-17. doi: 10.1016/j.appdev.2014.12.001.

Leopold, W. (2013). Study finds parents drive children's media use. Northwestern Now. Retrieved from https://news.northwestern.edu/stories/2013/06/study-findsparents-not-young-kids-drive-childrens-media-use

Levinowitz, L. M. (1998). The importance of music in early childhood. General Music Today, 12(1), 4-7. doi: 10.1177/104837139801200103

Livingstone, S., Mascheroni, G., Dreier, M., Chaudron, S., \& Lagae, K. (2015). How parents of young children manage digital devices at home: The role of income, education and parental style [EU Kids Online Report]. Retrieved from http://eprints.1se.ac.uk/63378/ 
Lum, C. H. (2008). Home musical environment of children in Singapore: On globalization, technology, and media. Journal of Research in Music Education, 56, 101-117. doi: 10.1177/0022429408317517

Marsh, J., Brooks, G., Hughes, J., Ritchie, L., Roberts, S., \& Wright, K. (2005). Digital beginnings: Young children's use of popular culture, media and new technologies. Sheffield: University of Sheffield. Retrieved from http://www.digitalbeginnings.shef.ac.uk/

McPeake, J., Bateson, M., \& O’Neill, A. (2014). Electronic surveys: How to maximize success. Nurse Researcher, 21(3), 24. doi: 10.7748/nr2014.01.21.3.24.e1205

McPherson, G. E. (2009). The role of parents in children's musical development. Psychology of Music, 37, 91-110. doi: 10.1177/0305735607086049

Mooney, C. G. (2013). Theories of Childhood: An Introduction to Dewey, Montessori, Erikson, Piaget \& Vygotsky. St. Paul, MN: Redleaf Press.

Nardo, R., Custodero, L. A., Persellin, D. C., \& Fox, D. B. (2006). Looking back, looking forward: A report on early childhood music education in accredited American preschools. Journal of Research in Music Education, 54, 278-292. doi: $10.1177 / 002242940605400402$

National Association for the Education of Young Children. (2009). Developmentally appropriate practice in early childhood programs serving children from birth through age 8 [Policy statement]. Retrieved from https://www.naeyc.org/sites/default/files/globallyshared/downloads/PDFs/resourc es/position-statements/PSDAP.pdf 
National Association for the Education of Young Children. (2012). Technology and interactive media as tools in early childhood programs serving children from birth through age 8 . Retrieved from https://www.naeyc.org/sites/default/files/globallyshared/downloads/PDFs/resourc es/topics/PS_technology_WEB.pdf

National Association for the Education of Young Children (2012). Selected examples of effective classroom practice involving technology tools and interactive media. Retrieved from https://www.naeyc.org/sites/default/files/globallyshared/downloads/PDFs/resources/topics/PS_technology_Examples.pdf.

National Association for Music Education. (2014). Early childhood education [Position statement]. Retrieved from https://nafme.org/about/position-statements/earlychildhood-education-position-statement/early-childhood-education/

National Association for Music Education. (2018). Early childhood music education [Updated position statement]. Retrieved from https://nafme.org/about/positionstatements/early-childhood-education-position-statement/early-childhoodeducation/

Niland, A. (2009). The power of musical play: The value of play-based, child-centered curriculum in early childhood music education. General Music Today, 23, 1721. doi: $10.1177 / 1048371309335625$

OFCOM. (2017). Children and Parents: Media use and attitudes report. Retrieved from https://www.ofcom.org.uk/_data/assets/pdf_file/0020/108182/children-parents media-use-attitudes-2017.pdf 
Oliemat, E., Ihmeideh, F., \& Alkhawaldeh, M. (2018). The use of touch-screen tablets in early childhood: Children's knowledge, skills, and attitudes towards tablet technology. Children and Youth Services Review, 88, 591-597. doi: 10.1016/j.childyouth.2018.03.028

Palaiologou, I. (2014). Children under five and digital technologies: Implications for early years pedagogy. European Early Childhood Education Research Journal, 24, 5-24. https://doi.org/10.1080/1350293X.2014.929876

Parlakian, R. \& Lerner, C. (2010). Beyond twinkle, twinkle: Using music with infants and toddlers. Young Children, 65(2), 14-19.

Parncutt, R. (2009). Prenatal and infant conditioning, the mother schema, and the origins of music and religion. Musicae Scientiae, 13, 119-150. doi: $10.1177 / 1029864917738130$

Papousek, M. (1996). Intuitive parenting: A hidden source of musical stimulation in infancy. In I. Deliege \& John Sloboda (Eds.), Musical beginnings: Origins and development of musical competence (pp. 88-112). Oxford, UK: Oxford University Press.

Persellin, D. C. (2007). Policies, practices, and promises: Challenges to early childhood music education in the United States. Arts Education Policy Review, 109(2), 5461. doi: 10.3200/AEPR.109.2.54-64

Pitt, J., \& Hargreaves, D. J. (2017). Attitudes towards and perceptions of the rationale for parent-child group music making with young children. Music Education Research, 19, 292-308. doi: 10.1080/14613808.2016.1145644. 
Pitts, S. E. (2016). Music, language and learning: Investigating the impact of a music workshop project in four English early years settings. International Journal of Education \& the Arts, 17(20), 1-26.

Phillips-Silver, J., \& Trainor, L. J. (2005). Feeling the beat: movement influences infant rhythm perception. Science, 308(5727), 1430-1430. doi: 10.1126/science.1110922

Plowman, L. (2015). Researching young children's everyday uses of technology in the family home. Interacting with Computers, 27, 36-46. doi: 10.1093/iwc/iwu031

Plowman, L., Stevenson, O., Stephen, C., \& McPake, J. (2012). Preschool children's learning with technology at home. Computers \& Education, 59, 30-37. doi: 10.1016/j.compedu.2011.11.014

Price, J. (2008). Parent-child quality time. Does birth order matter? The Journal of Human Resources, 43, 240-265. doi: 10.3368/jhr.43.1.240

Richert, R. A., Robb, M. B., Fender, J. G., \& Wartella, E. (2010). Word learning from baby videos. Archives of Pediatrics \& Adolescent Medicine, 164, 432-437.

Rideout, V. (2011). Zero to eight: Children's media use in America. Common Sense Media Research. Retrieved from http://static1.1.sqspcdn.com/static/f/1083077/14791820/1319492585427/ZerotoEi ghtFINAL2011.pdf?token=t9qgj5sB99Md5mtSIWxGhf9p\%2F7I\%3D

Rideout, V. (2013). Zero to eight: Children's media use in America 2013. Retrieved from http://www.commonsensemedia.org/file/zero-to-eight-2013pdf-0/download. 
Rideout, V. (2017). The Common sense media census: Media use by kids age zero to eight. Retrieved from http://static1.1.sqspcdn.com/static/f/1083077/27723826/1508433603540/CSM_Ze roToEight_Full+Report.FINAL.2017.1.pdf?token=6XzqNxlxaFwyzQ3IB\%2BSU eFKimk8\%3D

Rudolph, T. E. \& Frankel, J. (2009). YouTube in music education. Milwaukee, WI: Hal Leonard Publishing Corporation.

Schellenberg, E. G. (2005). Music and cognitive abilities. Current Directions in Psychological Science, 14, 317-320.

Sharkins, K. A., Newton, A. B., Albaiz, N. E. A., \& Ernest, J. M. (2016). Preschool children's exposure to media, technology, and screen time: Perspectives of caregivers from three early childcare settings. Early Childhood Education Journal, 44, 437-444. doi: 10.1007/s10643-015-0732-3

Sims, W. L. (1985). Young children's creative movement to music: Categories of movement, rhythmic characteristics, and reactions to changes. Contributions to Music Education, 12, 42-50.

Sims, W. L. (1986). The effect of high versus low teacher affect and passive versus active student activity during music listening on preschool children's attention, piece preference, time spent listening, and piece recognition. Journal of Research in Music Education, 34, 173-191. doi:10.2307/3344747

Sims, W. L. (1995). Children's ability to demonstrate music concept discriminations in listening and singing. Journal of Research in Music Education, 43, 204-221. doi: $10.2307 / 3345636$ 
Sims, W. L. (2001). Characteristics of preschool children's individual music listening during free choice time. Bulletin of the Council for Research in Music Education, 149, 53-63.

Sims, W. L. (2005). Effects of free versus directed listening on duration of individual music listening by prekindergarten children. Journal of Research in Music Education, 53, 78-86. doi:10.1177/002242940505300107

Sims, W. L., \& Nolker, D. B. (2002). Individual differences in music listening responses of kindergarten children. Journal of Research in Music Education, 50, 292300. doi: $10.2307 / 3345356$

Sims, W. L., \& Udtaisuk, D. B. (2008). Music's representation in parenting magazines: A content analysis. Update: Applications of Research in Music Education, 26(2), 17-26. doi: $10.1177 / 8755123308317682$

Sobkin, V. S., \& Skobeltsina, K. N. (2015). Shared activities of parents with their preschool children during family pastime. Psychology in Russia, 8(2), 52. doi: 10.11621/pir.2015.0205

Tarnowski, S. M., \& Barrett, J. R. (1997). The beginnings of music for a lifetime: Survey of musical practices in Wisconsin preschools. Update: Applications of Research in Music Education, 15(2), 3-7. doi: 10.1177/875512339701500202

Tobias, E. S. (2015). Crossfading music education: Connections between secondary students' in-and out-of-school music experience. International Journal of Music Education, 33, 18-35. doi: 10.1177/0255761413515809 
Trainor, L. J., \& Corrigall, K. A. (2010). Music acquisition and effects of musical Experience. In M. Jones, R. Fay, \& A. Popper (Eds.), Music Perception (pp. 89127). New York, NY: Springer. doi: 10.1007/978-1-4419-6114-3_4

Trainor, L. J., \& Hannon, E. E. (2013). Musical development. In D. Deutsch (Ed.), The Psychology of Music (pp. 423-497). San Diego, CA: Elsevier Academic Press.

Trevarthen, C., Gratier, M., \& Osborne, N. (2014). The human nature of culture and education. Wiley Interdisciplinary Reviews: Cognitive Science, 5, 173-192. doi: $10.1002 /$ wcs. 1276

Vestad, I. L. (2010). To play a soundtrack: How children use recorded music in their everyday lives. Music Education Research, 12, 243-255. doi: 10.1080/14613808.2010.504811

Waldron, J. L., \& Veblen, K. K. (2008). The medium is the message: Cyberspace, community, and music learning in the Irish traditional music virtual community. Journal of Music, Technology \& Education, 1, 99-111. doi: 10.1386/jmte.1.2and3.99_1

Waldron, J. (2012). Conceptual frameworks, theoretical models and the role of YouTube: Investigating informal music learning and teaching in online music community. Journal of Music, Technology \& Education, 4, 189-200. doi: 10.1386/jmte.4.2-3.189_1

Waldron, J. (2013). User-generated content, YouTube and participatory culture on the Web: Music learning and teaching in two contrasting online communities. Music Education Research, 15, 257-274. doi: 10.1080/14613808.2013.772131 
Wartella, E., Rideout, V., Lauricella, A. R., \& Connell, S. L. (2014). Parenting in the age of digital technology. Retrieved from https://cmhd.northwestern.edu/wpcontent/uploads/2015/06/ParentingAgeDigitalTechnology.REVISED.FINAL_.20 14.pdf

Whitaker, J. A., Orman, E. K., \& Yarbrough, C. (2014). Characteristics of "music education" videos posted on YouTube. Update: Applications of Research in Music Education, 33(1), 49-56. doi: 10.1177/87455123314540662

Williams, K. E., Barrett, M. S., Welch, G. F., Abad, V., \& Broughton, M. (2015). Associations between early shared music activities in the home and later child outcomes: Findings from the Longitudinal Study of Australian Children. Early Childhood Research Quarterly, 31, 113-124. doi: 10.1016/j.ecresq.2015.01.004

Wills, A. M. (2011). Relationships among musical home environment, parental involvement, demographic characteristics, and early childhood music participation. Retrieved from The University of Miami Scholarly Repository Open Access Theses (243)

Youm, H. K. (2008). South Korean parents' goals, knowledge, practices, and needs regarding music education for young children. Retrieved from ProQuest Dissertations and Theses Global (AAT 3484001)

Young, S. (2009). Towards constructions of musical childhoods: Diversity and digital technologies. Early Child Development and Care, 179, 695-705. doi: $10.1080 / 03004430902944908$ 
Young, S. (2012). Theorizing musical childhoods with illustrations from a study of girls' karaoke use at home. Research Studies in Music Education, 14, 113-128.

Young, S. (2016). Early childhood music education research: An overview. Research Studies in Music Education, 38, 9-21. doi: 10.1177/1321103X16640106

Young, S., \& Ilari, B. (2018). Musical participation from birth to three: Toward a global perspective. In G. E.McPherson \& G. F. Welch (Eds.), Music learning and teaching in infancy, childhood, and adolescence: An Oxford handbook of music education. New York, NY: Oxford University Press.

YouTube. (2018). YouTube Kids Parental Guide. Retrieved from https://support.google.com/youtubekids/answer/6130561?hl=en\&ref_topic=61305 04

Zdzinski, S. (2013). The underlying structure of parental involvement-home environment in music. Bulletin of the Council for Research in Music Education, 198, 69-88. doi: 10.5406/bulcouresmusedu.198.0069

Zero to Three. (2018). Early learning. Retrieved from https://www.zerotothree.org/earlylearning 


\section{APPENDIX A}

Survey

1. What is your child's gender?
- Male
- Female
- Prefer not to disclose

2. What is your child's birth date (month and year)?

3. What is your relationship to the child?

If you are not a parent, thank you for your interest, but only parents may participate in this study.
○ Mother
- Father

4. What is your marital status?

Display logic for married: Display What is your spouse's highest level of education completed (or in progress)?

- Single (never married)

- Married or in a domestic partnership

- Widowed

- Divorced

- Separated

- Prefer not to disclose

5. Please rank your level of musical ability (as you perceive it):

\begin{tabular}{|l|l|l|l|l|l|l|l|l|l|l|}
\hline \multicolumn{1}{|l|}{ No Knowledge } & \multicolumn{11}{c|}{ Professional Knowledge } \\
\hline 0 & 1 & 2 & 3 & 4 & 5 & 6 & 7 & 8 & 9 & 10 \\
\hline
\end{tabular}

6. Have your played in a band, orchestra, or sung in a choir in any setting, formal or informal (school, community, religious, "garage band" with friends, etc.)?

\begin{tabular}{|c|c|c|}
\hline & Yes & No \\
\hline In High School & & \\
\hline In College & & \\
\hline Post College & & \\
\hline Currently & & \\
\hline
\end{tabular}


Taken from the "Parenting in the Age of Technology" Survey:

7. Please mark the box that best describes where your child fits in your family.

○ An only child

$\circ$ The youngest child

- A middle child

- The oldest child

8. Which of the following childcare arrangements does your family have?
- Stay at home parent
- Relative
- Nanny/babysitter
- Part-time daycare
- Full-time daycare
O Other

9. Compared to other children your child's age, how well do the following statements describe him/her: A lot, somewhat, not too much, or not at all

- Easy and adaptable

- Active and energetic

- Easily overwhelmed or over-stimulated

- Fidgets and squirms frequently

- Has difficulty focusing

10. How many YouTube/Internet accessible devices do you have in your home (this includes smartphones, smart tv's, tablets, laptops, computers)?
○ None
- One
$\circ$ Two
○ Three
- Four
- Five
- Six
- More than six 
14. We are interested in how you and your family like to spend your time together. When it comes to family time, how much does your family enjoy the following activities together? A lot, somewhat, not too much, or not at all?

$\circ$ Watching TV or movies

- Reading together

- Doing things outside together like playing, taking a walk, or going to the park

- Doing indoor activities together, like playing with toys, games, or art projects (not TV or video games)

- Playing or attending sports events together

- Participating in clubs or other groups together

- Singing songs or making music together

$\circ$ Cooking and eating meals together

15. How often do you access YouTube for young children's music videos?

- Never

- Rarely (1-2 times per month)

- Occasionally (1-2 times per week)

- Regularly (1-2 times per day)

- Frequently (3+ times per day)

16. What purpose(s) does YouTube serve in your home?

- Daytime/Nighttime Routines or Rituals

$\circ$ Learning

$\circ$ Entertainment

- Music Resource (i.e. in lieu of CDs or DVDs)

$\circ$ Other

17. To what extent do you agree or disagree with the following statements:

- In general, the less time kids spend on YouTube, the better off they are.

- My child benefits from the YouTube music education videos he/she watches.

- YouTube has the potential to be an effective children's music education resource. 
18. To what extent do you agree or disagree with the following statements:

- I have all of the skills necessary to be an effective musical parent to my child.

- I am comfortable assessing the quality of music education videos on YouTube.

- I am satisfied with the quantity of educational YouTube music videos available for my child.

- I find YouTube to be easily accessible.

- Parents should always participate actively with their child while watching YouTube.

- I feel comfortable leaving my child to watch specific YouTube music videos or channels (e.g. Little Baby Bum) alone.

19. Overall, based on what your child watches on YouTube and the amount of time he/she spends using it, do you think his/her use of media helps, hurts, or makes no difference to his/her:

○ Social Skills

$\circ$ Learning

- Ability to Focus

- Behavior

- Physical Activity

- Creativity

- Music Skills

20. When viewing a music and movement video on YouTube, does your child: (Please select all that apply)

- Sing/Chant along

- Move/Dance

$\circ$ Listen quietly

○ Other

- Not applicable- my child has never watched YouTube videos.

21. When navigating the millions of videos available on YouTube, how do you select videos for your child:

○ Type in "children's music" (or something similar) in the search bar

- Find the most popular/most viewed videos

- Select an existing playlist (i.e. Little Baby Bum)

o Other

22. Do you have any favorite YouTube children's music channels? If yes please specify. 
23. How likely are you to:

- Enroll your child in a music class for toddlers and caregivers

- Take your child to children's music concerts

- Take your child to programs that include music for children

- Attend music education workshops

- Take private music lessons

- Search/read the Internet for information about music for children

24. Is there anything else that you would like to share about the use of YouTube as a music education resource?

25. What is your highest level of education completed (or in progress)?

- High School Diploma

- Associate's Degree

- Bachelor's Degree

- Master's Degree

○ Doctorate or Professional Degree

Display logic if "Married" is selected in question 4

26. What state do you live in?

If you live outside of the United States, please select the first option.

27. What is your country of residence?

28. What is your race/ethnicity? Please check all that apply.

○ White

- Black or African American

- American Indian

- Asian

- Native Hawaiian or Pacific Islander

o Other

- Prefer not to disclose 
29. What is your family's income level?
- Less than $\$ 20,000$
- \$20,000-\$39,999
○ $\$ 40,000-\$ 59,999$
○ $\$ 60,000-\$ 89,999$
- $\$ 90,000-\$ 119,999$
- More than $\$ 120,000$
- Prefer not to disclose

Thank you very much for your participation in this survey! Please click the link for your free PDF copy of Smart Musical Parenting: YouTube Guidelines, Suggestions, and Recommendations. 


\section{APPENDIX B \\ IRB Approval Letter}

March 30, 2018

Principal Investigator: Michelle Y. (MU-Student) Ko

Department: Learn, Teach and Curric - PHD

Your Exempt Application to project entitled Parental Attitudes and Beliefs Towards and Usage of Early Childhood Music Videos on YouTube was reviewed and approved by the MU Institutional Review Board according to the terms and conditions described below:

$\begin{array}{ll}\text { IRB Project Number } & 2010951 \\ \text { IRB Review Number } & 235509 \\ \text { Initial Application Approval Date } & \text { March 30, 2018 } \\ \text { IRB Expiration Date } & \text { March 30, 2019 } \\ \text { Level of Review } & \text { Exempt } \\ \text { Project Status } & \text { Active - Open to } \\ \text { Exempt Categories } & \text { Enrollment } \\ \text { Risk Level } & \text { 45 CFR 46.101b(2) } \\ & \text { Minimal Risk }\end{array}$

The principal investigator (PI) is responsible for all aspects and conduct of this study. The PI must comply with the following conditions of the approval:

1. No subjects may be involved in any study procedure prior to the IRB approval date or after the expiration date.

2. All unanticipated problems and deviations must be reported to the IRB within 5 business days.

3. All changes must be IRB approved prior to implementation unless they are intended to reduce immediate risk.

4. All recruitment materials and methods must be approved by the IRB prior to being used.

5. The Annual Exempt Form must be submitted to the IRB for review and approval at least 30 days prior to the project expiration date. If the study is complete, the Completion/Withdrawal Form may be submitted in lieu of the Annual Exempt Form

6. Maintain all research records for a period of seven years from the project completion date.

7. Utilize all approved research documents located within the attached files section of eCompliance. These documents are highlighted green.

If you are offering subject payments and would like more information about research participant payments, please click here to view the MU Business Policy and Procedure: http://bppm.missouri.edu/chapter2/2_250.html

If you have any questions, please contact the IRB at 573-882-3181 or irb@missouri.edu. 


\section{APPENDIX C}

Informed Consent

Thank you for choosing to participate in this research project, entitled "Parental Attitudes and Beliefs Towards and Usage of Early Childhood Music Videos on YouTube." Please only complete this survey if you are a parent to a toddler - 16-to-36 months of age.

The purpose of this research study is to examine parental attitudes and beliefs about YouTube music education videos. The results are intended to assist music educators, scholars, and parents to better understand the current state of musical parenting in a digital age and/or to more effectively offer accessible resources. Upon completion of the survey, participants will be provided with some additional information and resources that they may find helpful for their own YouTube usage.

The survey that follows should take approximately 10 minutes to complete. It is unlikely you will experience any risks from participation in this study. Your participation in this research is completely voluntary. While I hope you will complete the whole survey, you will be free to decline to answer any items, as you choose. You may remove yourself from the research at any point without penalty.

Your responses to the survey questions will be completely anonymous - there will be no way for me to connect survey responses with respondents. Your answers to the survey will be downloaded only to the researchers' computers, and will be password protected.

The survey link will be active from April $10^{\text {th }}$ to April $24^{\text {th }}, 2018$. I would greatly appreciate it if you would complete this at your earliest convenience.

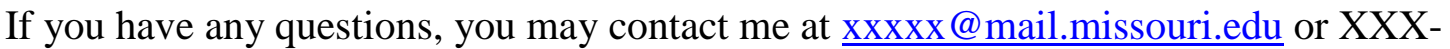
XXX-XXXX. Questions about your rights as a research participant may be addressed to the University of Missouri Institutional Review Board (IRB) at 573-882-3181.

Thank you very much,

Michelle Ko

Doctoral Candidate

University of Missouri

By clicking the $>>$ button to enter the survey, you are providing your informed consent to participate in this research project. 


\section{APPENDIX D \\ Recruitment Script}

\section{Dear Participant:}

If you are the parent of a child between the ages of 16 to 36 months, I hope you will consider participating in my survey. I am a doctoral candidate in music education at the University of Missouri, working on a research project entitled "Parental Attitudes and Beliefs towards and usage of early childhood music videos on YouTube."

The online survey comprises several rating scales, designed to examine attitudes and beliefs about and usage of music education videos available on YouTube, as well as several items to help describe the participants' digital home music environments. It will take approximately 10 minutes to complete. All survey responses will be completely anonymous, with no way for me to identify respondents.

The results are intended to assist music education researchers, to better understand parental needs in regards to musical parenting in a YouTube age. Upon completion of the survey, you will be provided with some additional guidelines and suggestions that they may find helpful for your own digital musical parenting, as well as information about how to obtain a summary of the results when completed. I also anticipate publishing the results in a refereed research journal and discussing them in conference presentations.

Please feel free to address any questions you may have about this research to me (xxxxxx@mail.missouri.edu or xxx-xxx-xxxx). If you have friends who fit into this target group and you think would like to participate as well, please feel free to send them my contact information or forward this message to them.

Thank you very much for considering this request, Michelle Y. Ko

Ph.D. Candidate

University of Missouri

Columbia, MO

$\mathrm{XXX}-\mathrm{XXX}-\mathrm{XXXX}$

xxxxxx@mail.missouri.edu

Click here to be taken to the online survey 


\section{APPENDIX E \\ Social Media Recruitment Post}

[Permitted by admin to post this to the group]

I am an early childhood music specialist and doctoral candidate at the University of Missouri, working on a research project entitled "The YouTube Generation: ParentToddler Music Experiences."

If you are the parent of a child between the ages of 16-to-36 months, I hope you will consider participating in my survey. The online survey comprises several rating scales, designed to examine attitudes and beliefs about and usage of music education videos available on YouTube, as well as several items to help describe the participants' digital home music environments. It will take approximately 8-10 minutes to complete. All survey responses will be completely anonymous, with no way for me to identify respondents.

The results of this national survey are intended to assist music education researchers, to better understand parental needs in regards to musical parenting in a YouTube age. Upon completion of the survey, you will be provided with some additional guidelines and suggestions that you may find helpful for your own digital musical parenting. I also anticipate publishing the results in a refereed research journal and discussing them in conference presentations.

Please feel free to address any questions you may have about this research to me (xxxxxxx@mail.missouri.edu). If you have friends who fit into this group and you think would like to participate as well, please feel free to send them my contact information or forward this message to them.

Thank you very much for considering this request,

Michelle Ko

Ph.D. Candidate

University of Missouri

Columbia, MO

xxxxxx@mail.missouri.edu

To participate, please click the following link:

https://missouri.qualtrics.com/jfe/form/SV_8HR7Sdz3p4atQs1 


\section{APPENDIX F}

Purposes for YouTube

Question 13: What purpose(s) does YouTube serve in your home? Please select all that apply.

Five respondents that selected "Other" provided additional information:

Distraction- plane rides, shots at doctor's office, splinter being removed from the toe

Waiting at doc appointments

Distractions- doctor office visits and brushing teeth

Distraction in public

While she eats 


\section{APPENDIX G}

YouTube Responses

Question 17: When viewing a music and movement video on YouTube, does your child:
- Sing/Chant along
- Move/Dance
- Listen quietly
○ Other

Responses Rate: 330 [multiple selections permitted]

Six respondents that selected "Other" provided additional information:

Seems mesmerized by the visuals

Goes into a zombie-like coma unless she is familiar with the characters

Asks me questions, points out things

She rarely if ever watches. She just listens.

Just now starting to sing/dance occasionally

She doesn't watch YouTube, but occasionally, I will play a song for her to hear on YouTube 


\section{APPENDIX H}

Favorite YouTube Music Channels

Little Baby Bum

Super Simple Songs

None

ABC Kid TV

Mother Goose Club

Dave \& Ava

Pink Fong

Signing Time

Blippi

Sesame Street

Little Hands

Raffi

Little Baby Bum (Espagnol)

Super Simple Songs

(Espagnol)

Badanamu

Casper Babypants

LuLu Kids

Storybots

Go Noodle

Kids Bop

Disney

The Learning Channel

Baby Signing Time

Two Little Hands

Treeschool

Streams of Praise

Kids TV 123

Wheels on the Bus

Gigglebellies

The Wiggles

Old MacDonald

ToddlerTV

PBS Kids

Kids Academy

Chu Chu TV

Bounce Patrol 
APPENDIX I

Additional YouTube Comments

Question 21: Is there anything else that you would like to share about the use of YouTube as a music education resource?

I actively discourage my children from spending time looking at screens and even my 9 year old is prohibited from using it unattended because it is too easy to end up watching highly inappropriate videos.

As a mother and a teacher (M.Ed) I work to minimize how much exposure my children have to screens and especially advertising. We do not watch regular television either. We watch only movies or Netflix. They get more than enough screen time and not enough outdoor time in school so we prioritize free play outside. They have all taken parent and me type music classes though and the older children play piano. One of my sons and one of my daughters dance and 2 more have expressed interest in starting dance as well so we do love music.

I often turn off the screen and just let them listen to the songs. I will sometimes let the three year old watch the videos, but I avoid letting $12 \mathrm{~m}$ old watching videos. We only watch little baby bum, as the animation and sound quality is more age appropriate and moves slower than other videos.

I search kid friendly and also use a children's version of YouTube to filter out inappropriate videos.

I strongly do not believe it is a replacement for Private Lessons but may assist, when guided, as an additional resource for general music concepts

I think it could be an excellent resource but it is so easy for toddlers (who are smart and industrious with tech) to navigate away from parent-approved content to weird and borderline unsavory content within the YouTube platform. We used to let our son watch LBB while preparing dinner or some activity he didn't need to be a part of then would find him watching some obscure video he'd navigated to, likely unintentionally. We have since really limited its use in our house.

I use it as a reward for good behavior, but it can become a fight to get him to turn it off. I always ask him to stop and turn it off himself. 
I use music from YouTube in my classroom as well as at home for my children (ages 13). I think it can be used as a valuable resource as long as it is used with moderation and is included with parent participation!

I'm not musical, so I don't really know where to begin to find instructional children's videos. I have just enough knowledge to understand a music scale and sight-read music enough to approximate a melody and sing reasonably well. So we just pick videos that have lovely melodies or catchy educational lyrics and roll with it.

I've used it very little for education perse, but more for exposure, in particular with dancing and ethnic music.

I've used YouTube to look up the words/tune for some children's songs but I don't allow my son to watch the videos.

In our house we think it is important to expose her to more than just children's songs.

We use YouTube mostly to play all different genres of music and have her instruments to play along with.

I've used it myself to learn guitar. That being said, I don't know if I find it appropriate for toddlers.

Love YouTube and the wide vast of options, love the fact I can make my own video playlist but I'm wary to watch my daughter watch it alone or unsupervised.

My daughter has music as part of her daycare day, goes to sleep to Enya and similar artists, and loves making noise. She does enjoy Pentatonix and instrumental music videos on YouTube. We don't have a need for anything more formal at this time, YouTube or otherwise.

My daughter is in charge of choosing what she watches. I do have some music instrument apps that she plays with as well. I am also a music education professor with an elementary focus.

My kids and I love to sing, and most of what we view on YouTube is music, but it is Disney or other catchy song about animals or the solar system. It is fun to sing along, but there is no music education involved, and I wouldn't know how to judge a good from ineffective music education video. 


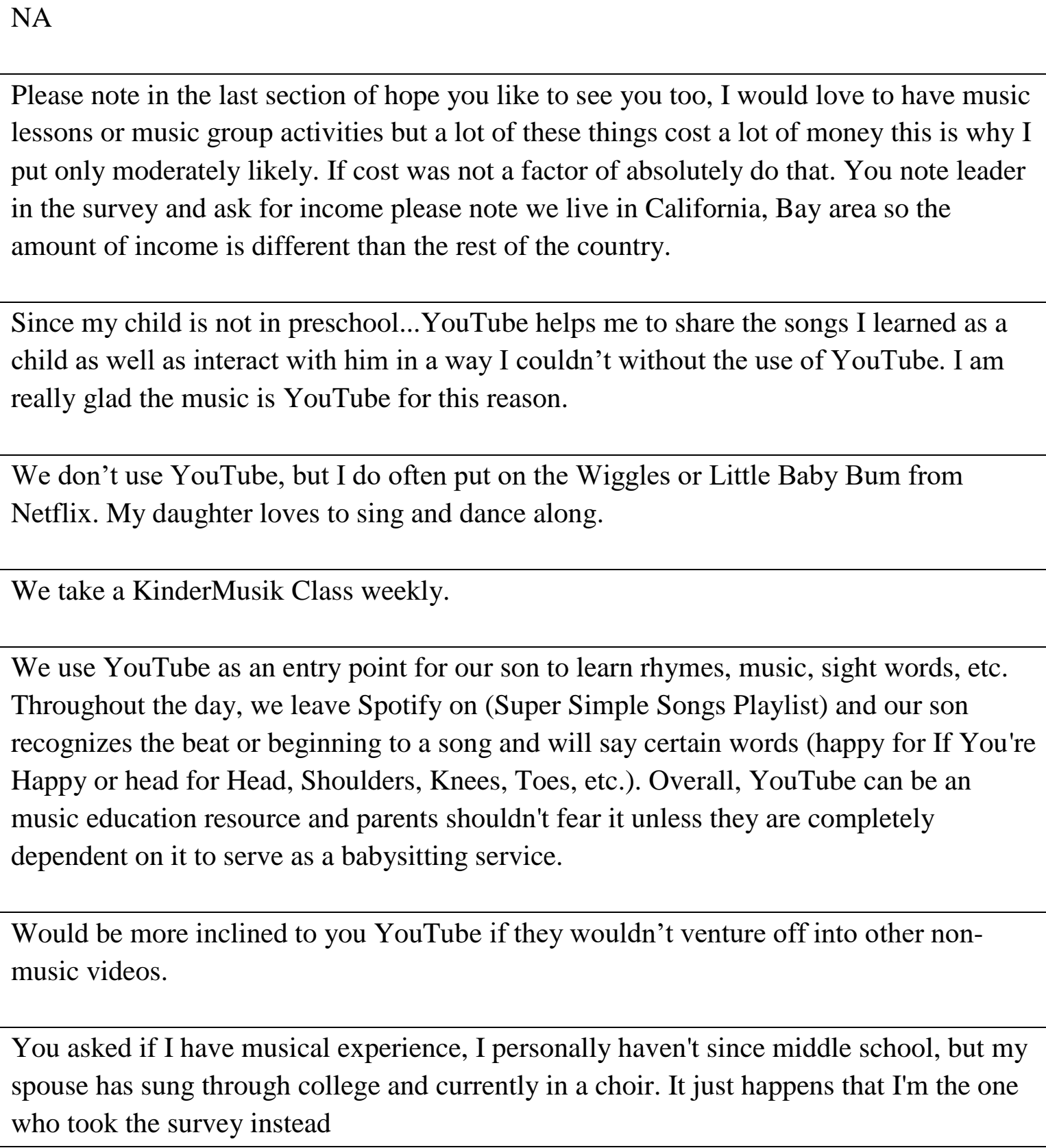




\section{APPENDIX J}

Response Percentages from a Previous National Survey and Comparison

Percent of parents who say their family enjoys doing each activity together

\begin{tabular}{lcccc}
\hline \multicolumn{1}{c}{ Activity } & \multicolumn{2}{c}{ 2014* } & \multicolumn{2}{c}{ 2018 } \\
\hline & A lot & Somewhat & A lot & Somewhat \\
Cooking and eating meals & 66 & 27 & 47 & 44 \\
Doing things outside & 52 & 40 & 68 & 28 \\
Reading & 47 & 39 & 53 & 40 \\
Watching TV or movies & 43 & 42 & 27 & 50 \\
Singing songs or music making & 30 & 36 & 35 & 47 \\
Playing or attending sports & 20 & 29 & 7 & 25 \\
Using a computer, tablet, or & 16 & 35 & 9 & 41 \\
smartphone & & & & \\
\hline
\end{tabular}

The 2014 survey refers to "Parenting in the Age of Digital Technology" written by Wartella et al. 


\section{APPENDIX K}

Facebook Post Comments

Thirteen mothers who participated in the survey commented on the Facebook posting:

Just completed the survey. Good luck!

Done!

Done!

Doctoral as a mommy, wow!

Very interesting and relevant topic! I finished the survey. Good luck! And great job on working on furthering your education while having little ones!!!

My daughter loves YouTube and is learning so much! Colors, animals, etc. I have completed the survey also! Thanks for this $\odot$ Best of luck also!

Just finished. Good luck!

Done!

Done! My guy loves watching The Wiggles on YouTube! Also the Elmo Brushy Brush song plays every night at 6:30 pm for our bedtime routine! He won't brush his teeth without it :0

Done ;)

Done. Looking forward to the results!

Done! M-I-Z Good luck!

I love that your suggestions were Super Simple Songs. That is the music that we typically have our daughter listen to. I love them! 
APPENDIX L

End of Survey Musical Parenting Resource

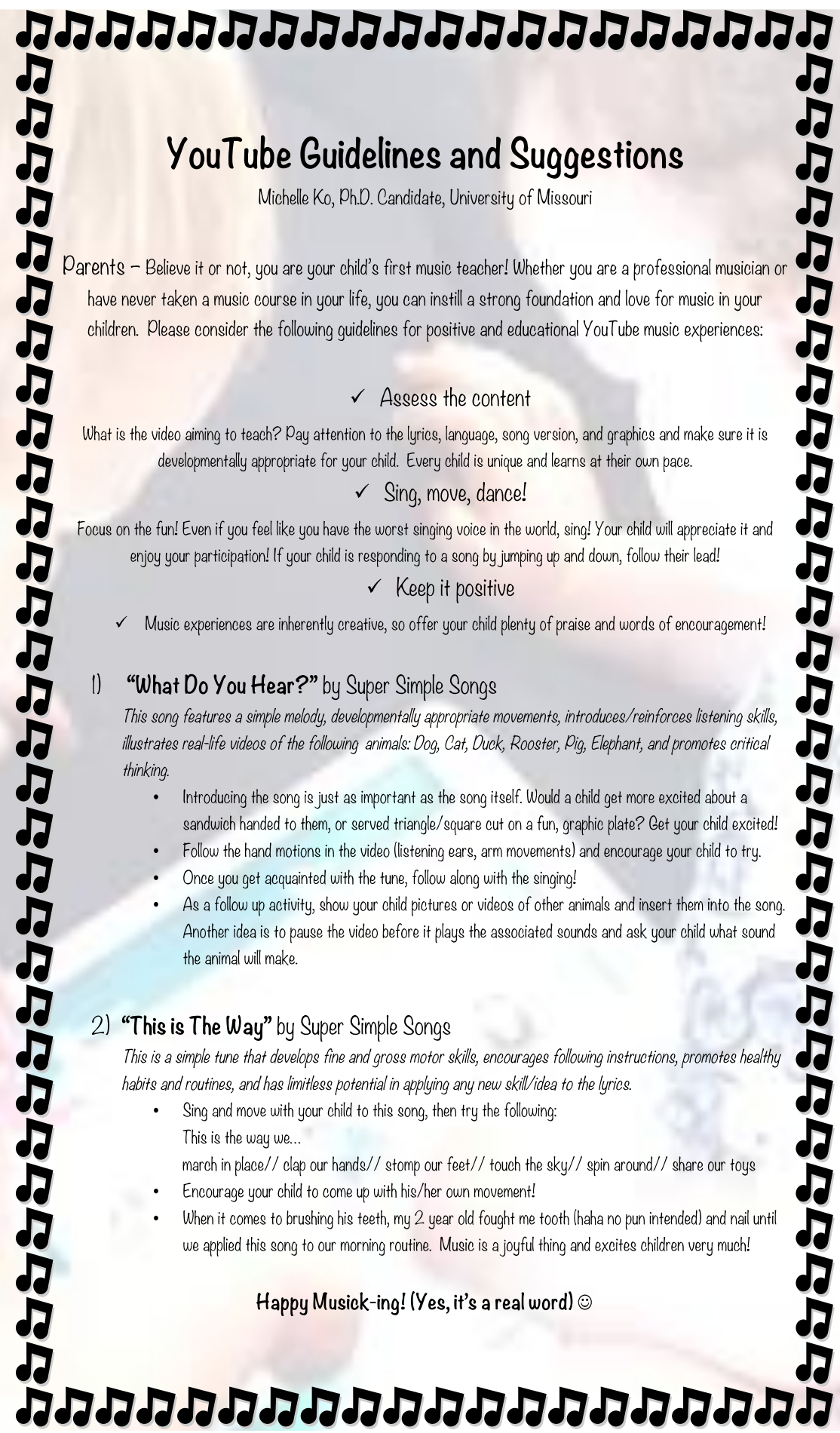




\section{VITA}

Michelle Ko attended the University of Maryland Baltimore County in Baltimore, Maryland as a Linehan Artist Scholar, and earned a Bachelor of Arts degree with an emphasis in Music Performance in 2010. Upon winning a Fulbright Scholarship and Miguel Vinciguerra Fellowship to Italy, she pursued graduate studies in flute performance and music education. She received her Master of Arts degree in Music and Music Education at Teachers College, Columbia University in New York in 2013, followed by a Doctor of Philosophy in Learning Teaching and Curriculum, with an emphasis in Music Education from the University of Missouri. Michelle taught courses in general music instruction, early childhood music education, and music teaching methods seminars while attending graduate school. She has also taught courses at the University of Maryland Baltimore County, Conservatorio di Musica di Piacenza, Teachers College Columbia University, and Ginosko University. Dr. Ko plans to continue her involvement in early childhood and university settings, focusing her research on digital music experiences, digital musical parenting, and early childhood music curriculum. 